\title{
Análise e avaliação de técnicas de pré-busca em caches para web
}

\author{
Douglas Xavier Teodoro de Oliveira
}

Orientadora: Profa. Dra. Regina Helena Carlucci Santana

Dissertação apresentada ao Instituto de Ciências Matemáticas e de Computação - ICMC-USP, como parte dos requisitos para obtenção do título de Mestre em Ciências - Área: Ciências de Computação e Matemática Computacional.

$$
\text { USP - São Carlos }
$$

Março/2004 


\section{A Comissão Julgadora:}

Profa. Dra. Regina Helena Carlucci Santana te fine the Soulewe

Prof. Dr. Eduardo Marques

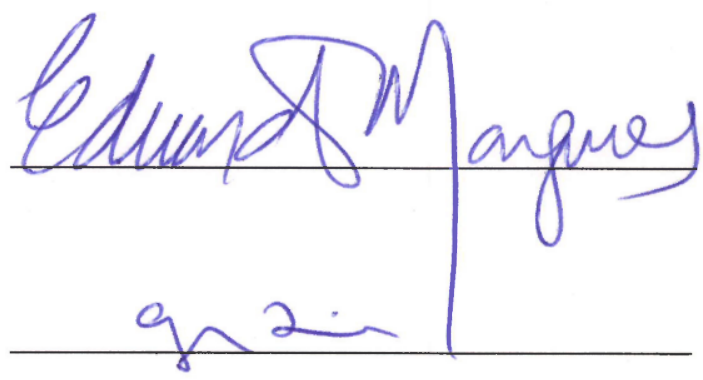

Prof. Dr. Gonzalo Travieso 


\section{DEDICATÓRIA}

Aos meus pais, Cleber e Vera.

À minha irmã, Kênia. 


\section{Agradecimentos}

À minha querida família, Cleber, Vera e Kênia, pela confiança e apoio irrestritos em todos aspectos da minha vida. Pela compreensão e postura quanto às minhas faltas, falhas e dificuldades. Amo muito vocês.

À professora. Regina Santana, pela oportunidade, paciência e orientação ao longo deste trabalho.

Aos amigos Luciano, Márcio, Mário, Renato e Vinícius pelo permanente e zeloso suporte durante a concepção deste mestrado, feito por meio de discussões, esclarecimentos c correções, tanto na implementação quanto na confecção desta dissertação.

Aos companheiros que, por questões de circunstâncias, ajudaram-me em momentos específicos, mas também decisivos deste trabalho. Álvaro, Auri, Bruno, Eliane, Hermes, Jacqueline, João Carlos, Juliano, Marcelo, Michel, Omar, Roberto, Rogério (de Pres. Prudente), Sarita, Simone, obrigado pela atenção, preocupação e apoio. Sou ciente de que vocês não mediriam esforços em me auxiliar em qualquer situação.

Por outros motivos não técnicos, mas tão relevantes quanto estes, os quais não vejo necessidade de relacioná-los aqui, gostaria de agradecer imensamente aos amigos Adriano, Bruno, Caio, Elaine (Sampa), Fábio, Jacqueline, Juliano, Laerte, Marcelo, Márcio, Mário, Michel, Nazira, Roberto e Rogério (do Paraná). Em especial, à Cintia, Lilian, Luciano, Márcio, Renato e Vinícius. Ainda irei me contentar muito ao recordar os agradáveis momentos que vivemos juntos e certamente com os que ainda virão.

A todos os colegas de trabalho, com os quais convivi diariamente (laboratórios 114 e 160). É impressionante como vocês fizeram de um ambiente de trabalho um local tão acolhedor, alegre e solidário.

A todos os professores que participaram da minha formação. Em especial aos professores Marcelo Henriques, Marcelo Siqueira e Paulo Pagliosa, pela influência direta na minha vinda para São Carlos. 
Ao professor Marcos Santana pela oportunidade e pelo intermédio quanto à obtenção do log do CISC - Centro de Informática de São Carlos.

Ao Themistoklis Palpanas, por ter cedido o seu simulador para utilização neste trabalho.

Ao Maurício Zadra Pacheco, por ter cedido gentilmente o log da W3 - Indústria Metalúrgica Ltda.

Ao Rogerio Toshiaki Kondo, por ter cedido gentilmente o log do CISC - Centro de Informática de São Carlos.

À CAPES pelo apoio financeiro.

Aos funcionários e professores do ICMC, por sempre serem prestativos e competentes.

À USP pela oportunidade.

A todos contribuíram para a realização deste trabalho. 


\section{RESUMO}

A World Wide Web tem apresentado um constante e intenso crescimento, causando um grande congestionamento. Muitas pesquisas têm sido feitas para garantir suas funcionalidades. A prática de cache na Web é uma das formas mais utilizadas para permitir escalabilidade dos serviços da WWW c melhorar seu desempenho, diminuindo os pontos de contenção e mantendo os objetos mais próximos dos clientes. Todavia, os benefícios de cache são limitados e têm diminuído por causa da grande quantidade e diversidade de características dos objetos Web. Prébusca surge nesse contexto, como uma prática complementar ao uso de caches, antecipando a busca dos objetos que serão requisitados e deixando-os disponíveis em um cache, permitindo a diminuição da latência percebida pelo usuário. O uso de pré-busca na Web dá-se de formas bastante diversas, variando seus resultados quanto à implementação de estratégias, cenários, modelos preditores e parametrização das técnicas. A estratégia de pré-busca com predição estatística mostra-se como a mais promissora das abordagens. Este trabalho de mestrado objetiva avaliar o impacto da pré-busca com predição estatística, utilizando simulação de um modelo preditor baseado no algoritmo Prediction by Partial Matching (PPM), por meio da análise das conseqüências dos ajustes de parâmetros do modelo adotado. Os resultados obtidos mostram que a pré-busca é uma técnica efetiva e valiosa na melhora do desempenho da Web e no incremento da taxa de acerto do cache. 


\begin{abstract}
The World Wide Web has experienced an intense and sustained growth which has caused traffic congestion, therefore much research has been conducted aiming at guaranteeing its availability. Web caching is one of the most used approaches for improving web services scalability and performance. It minimizes contention and brings requested objects closer to the clients. However, caching benefits are limited and have been less helpful recently due to the diversity of web objects characteristics. Prefetching arises in this scenario as a further technique to caching, anticipating the fetching of objects that will be requested in the future. Those objects become available in cache, thus minimizing the latency perceived by the user. Prefetching is employed in several ways with different parameters, strategies, scenarios and prediction models. Statistical prefetching arises as the most promising approach. This dissertation aims at evaluating the impact of statistical prefetching by simulating a prediction model based on the Prediction by Partial Matching (PPM) algorithm. The consequences of tuning the parameters of the adopted model are analyzed. The results show that prefetching is a valuable and efficient technique for improving web performance and cache hit rate.
\end{abstract}




\section{LISTA DE FIGURAS}

2.1 Número de máquinas ligadas à Internet desde 1989 a 2003 (Fonte: Internet Software Consortium

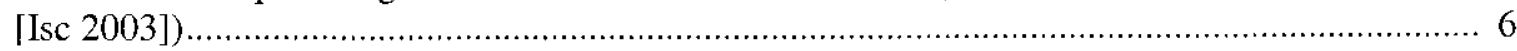

2.2 Arquitetura Cliente-Servidor da Web …….................................................................... 7

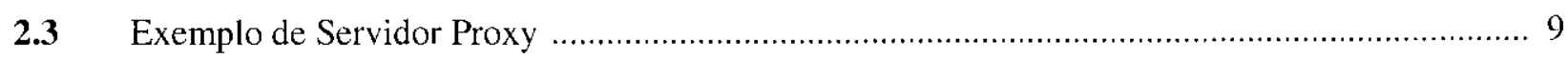

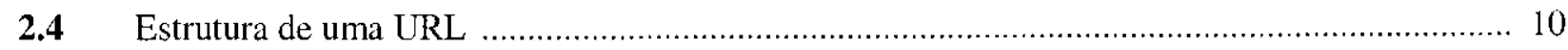

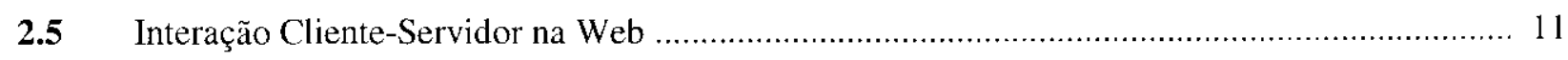

2.6 Formato genérico de mensagens [Fie 1999] ............................................................... 11

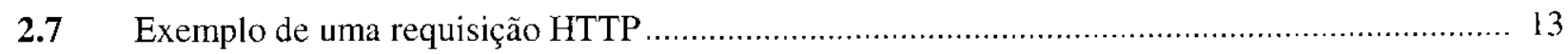

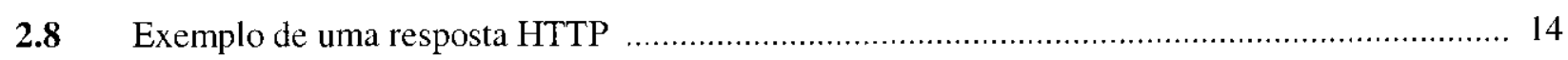

2.9 Localização de Caches na Web............................................................................... 20

3.1 Configuração típica envolvendo um proxy, separando a latência em duas componentes [Kro

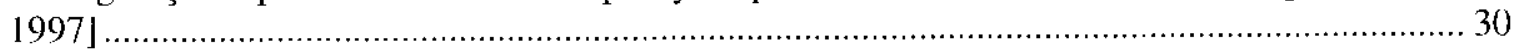

3.2 Parte de uma captura de tela que apresenta as opções de pré-busca num navegador .................. 34

3.3 Exemplo do processo de contextualização de um preditor Markov numa sequiência simples...... 36

3.4 Exemplo de processo de construção de árvore para um modelo preditor baseado em PPM, construída a partir de duas sequiências de acessos (ABCACBD e CCACBCA). Destaques em vermelho sinalizam os passos do processo de predição para a próxima página da seqüência ABCACBD e, em azul, para a seqüência CCACBCA …....................................................... 38

3.5 Algoritmo para construção/atualização do modelo de predição, utilizando uma estrutura auxiliar

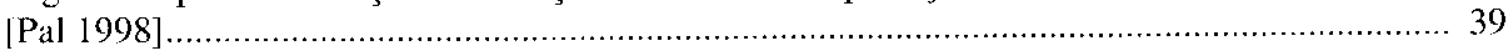

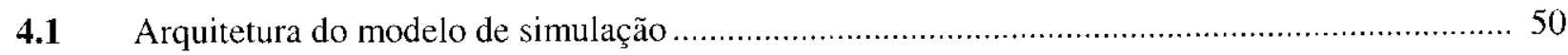

4.2 Trecho do arquivo de $\log$ do servidor Web utilizado pelo simulador .................................... 52

4.3 Trecho do arquivo de $\log$ do proxy Web......................................................................... 53

5.1 Avaliação do parâmetro ordem para o servidor Web ….................................................... 78

5.2 Avaliação do parâmetro ordem para o proxy ……............................................................. 79

5.3 Avaliação do parâmetro Contador para o servidor Web …................................................. 82

5.4 Avaliação do parâmetro Contador para o proxy .................................................................. 83

5.5 Avaliação do parâmetro Confiança para o servidor Web …................................................ 85

5.6 Avaliação do parâmetro Confiança para o proxy ................................................................. 86

5.7 Avaliação do parâmetro Número de requisições prévias para o servidor Web …...................... 90

5.8 Avaliação do parâmetro Número de requisições prévias para o proxy ...................................... 91 
5.9 Avaliação do parâmetro Tamanho de cache para o servidor Web............................................. 94

5.10 Avaliação do parâmetro Tamanho de cache para o proxy ……………….................................. 95

5.11 Avaliação do parâmetro Tempo ocioso de sessão para o servidor Web …................................. 98

$\mathbf{5 . 1 2}$ Avaliação do parâmetro Tempo ocioso de sessão para o proxy ………..................................... 99 


\section{LISTA DE TABELAS}

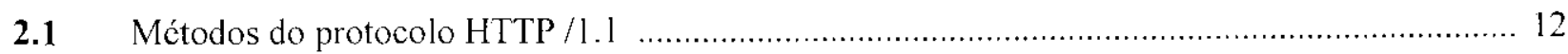

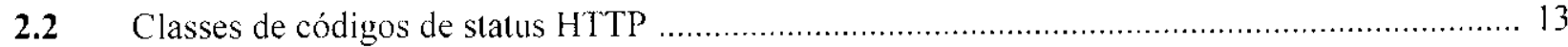

5.1 Características dos arq̨uivos de log originários das cargas de trabalho..................................... 65

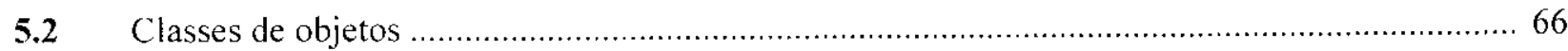

5.3 Caracterização dos logs antes e depois da filtragem de conteúdo ............................................67 67

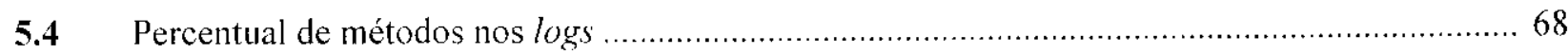

5.5 Percentual de status retornados pelos servidores, em resposta às requisições ............................ 69

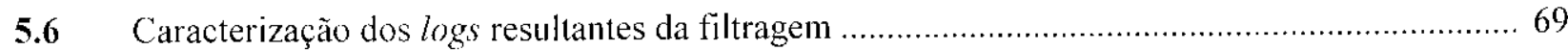

5.7 Caracterização das cargas em relação a suas subdivisões ......................................................... 70

5.8 Classificaçôes das subdivisões das cargas em relação aos tamanhos dos objetos requeridos....... 72

5.9 Valores sugeridos para os parâmetros nos cenários proxy e servidor ................................... 102

5.10 Configurações de pré-buscas do servidor Web .............................................................. 103

5.11 Configurações de pré-buscas do proxy .......................................................................... 103 


\section{Lista De ABReViaturas E Siglas}

$\begin{array}{ll}\text { CISC } & \text { Centro de Informática de São Carlos } \\ \text { CLF } & \text { Common Log Format } \\ \text { CRLF } & \text { Carriage Return Line Feed } \\ \text { DNS } & \text { Domain Names System } \\ \text { ECLF } & \text { Extended Common Log Format } \\ \text { FTP } & \text { File Transfer Protocol } \\ \text { GB } & \text { Gibabyte } \\ \text { GDB } & \text { GNU Debugger } \\ \text { GNU } & \text { "GNU is Not Unix" } \\ \text { HTML } & \text { HyperText Markup Language } \\ \text { HTTP } & \text { HyperText Transfer Protocol } \\ \text { ICP } & \text { Internet Cache Protocol } \\ \text { IETF } & \text { Internet Engineering Task Force } \\ \text { IP } & \text { Internet Protocol } \\ \text { JPEG } & \text { Joint Photographic Experts Group } \\ \text { KB } & \text { Kilobyte } \\ \text { LAN } & \text { Local Area Network } \\ \text { LFU } & \text { Least Frequently Used } \\ \text { LRU } & \text { Least Recently Used } \\ \text { MB } & \text { Megabyte } \\ \text { MIME } & \text { Multipurpose Internet Mail Extensions } \\ \text { PPM } & \text { Prediction by Partial Matching } \\ \text { RFC } & \text { Request for Comments } \\ \text { SMTP } & \text { Simple Mail Transfer Protocol } \\ \text { TCP } & \text { Transmission Control Protocol } \\ \text { TTL } & \text { Time-To-Live } \\ \text { URI } & \text { Uniform Resource Identifier } \\ \text { URL } & \text { Uniform Resource Locator } \\ \text { W3C } & \text { World Wide Web Consortium } \\ \text { WAN } & \text { Wide Area Network } \\ \text { WWW } & \text { World Wide Web } \\ & \end{array}$




\section{SUMÁRIO}

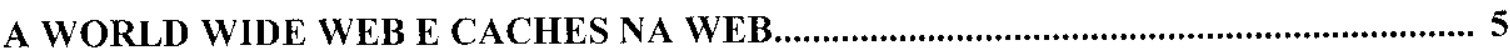

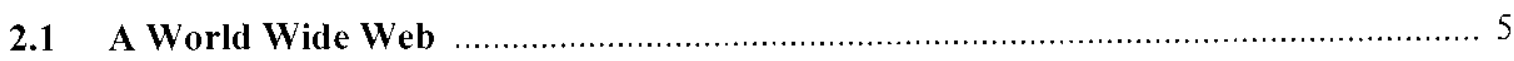

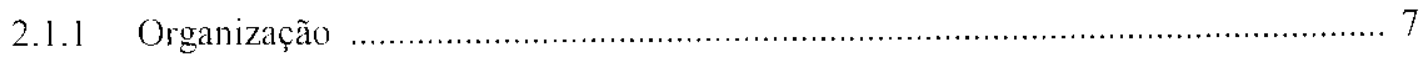

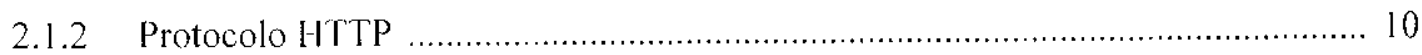

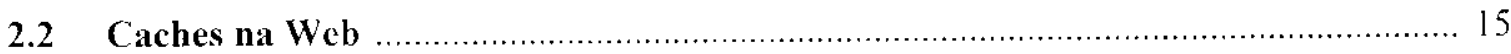

2.2.1 Características de Cache na Web ................................................................. 16

2.2.2 Localização e Topologia de caches na Web ..................................................... 19

2.2.3 Consistência de objetos em caches na Web .................................................... 21

2.2.4 Políticas de substituição de objetos em caches na Web ...................................... 22

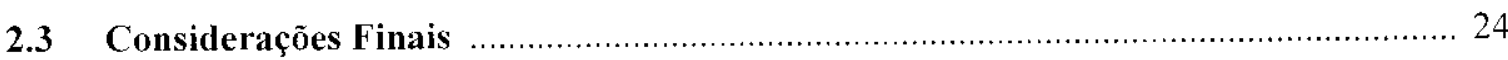

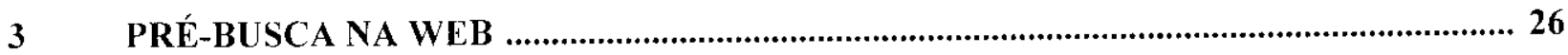

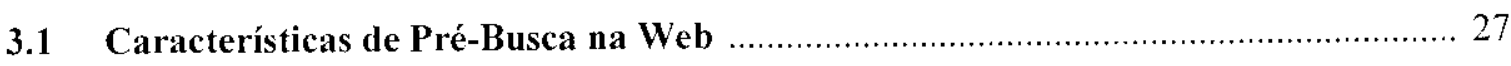

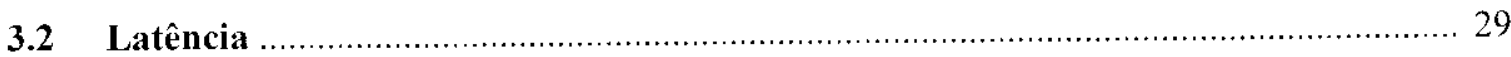

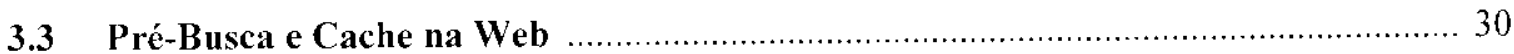

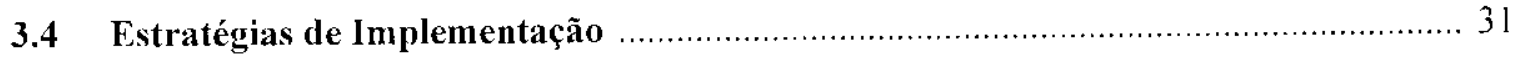

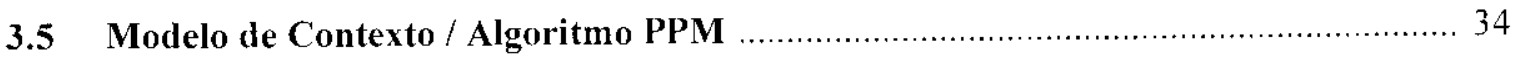

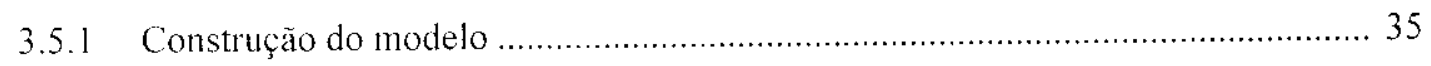

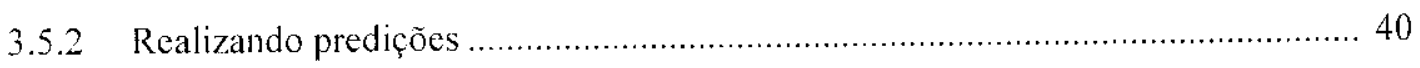

3.6 Limitações de Pré-Busca na Web ..................................................................... 41

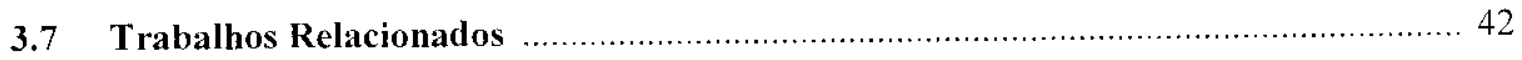

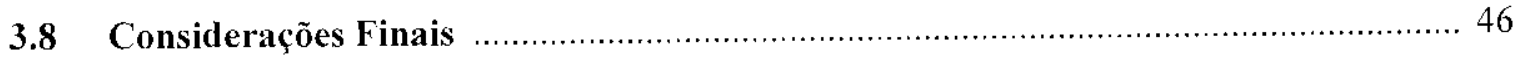

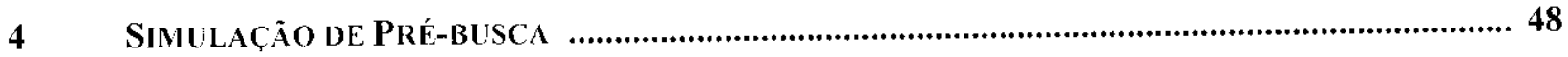

4.1 Softwares de Simulação de Pré-Busca ……….......................................................... 49

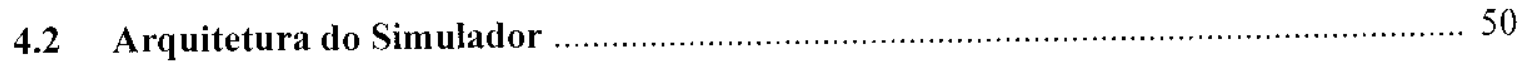

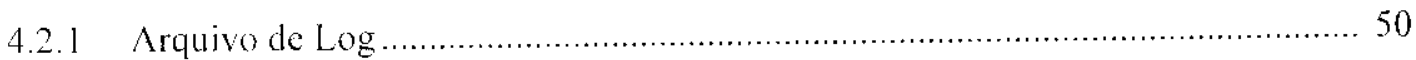

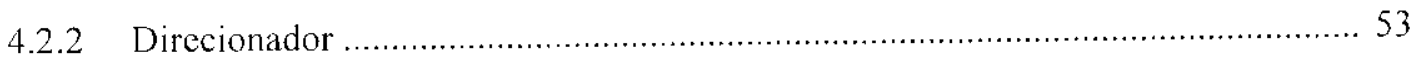

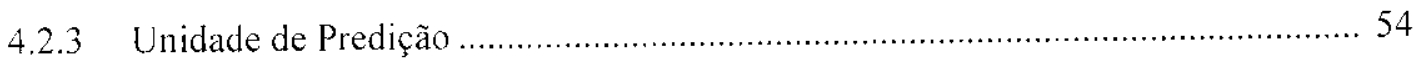

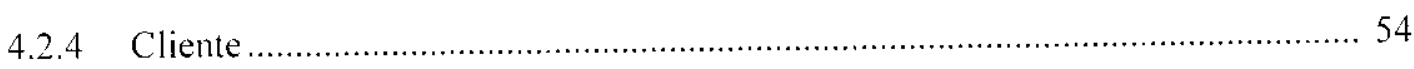

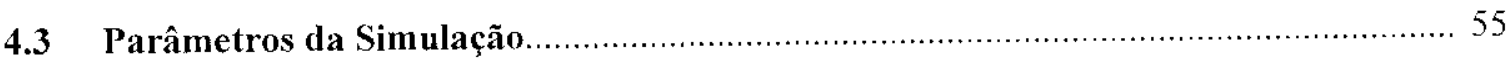




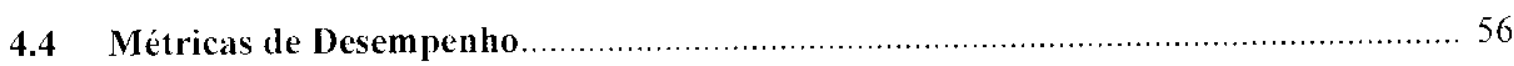

4.5 Correções e Modificações no Simulador .................................................................. 58

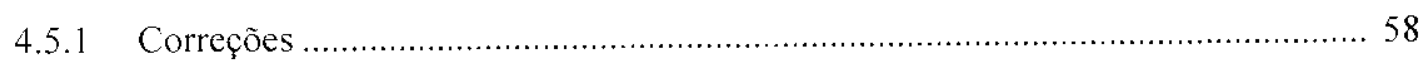

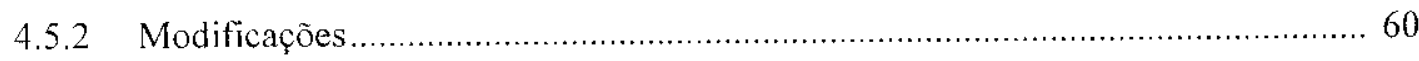

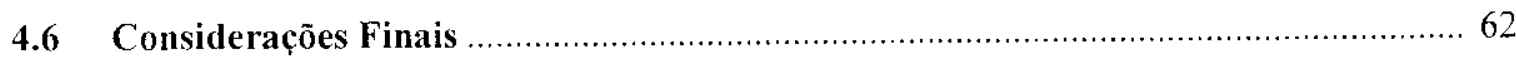

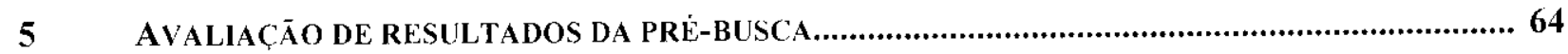

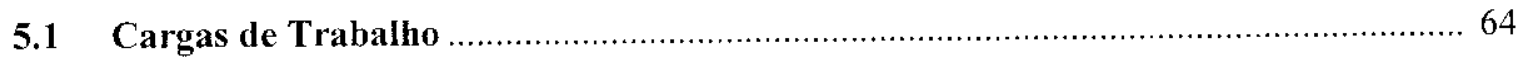

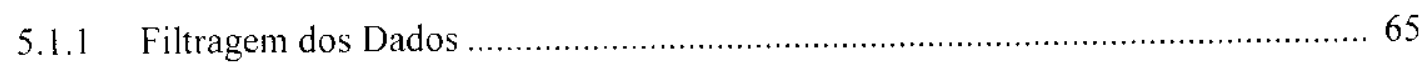

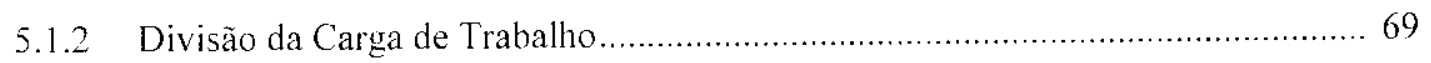

5.1.3 Comparação de Cenários: Servidor Web e Proxy Web …….............................. 73

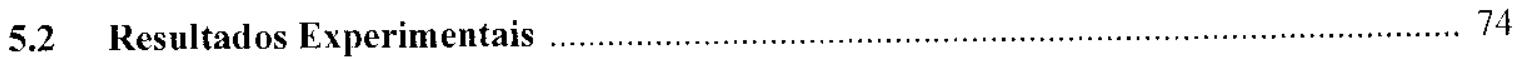

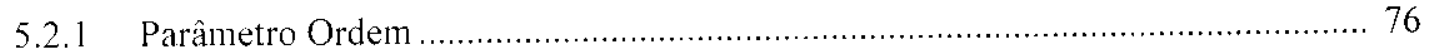

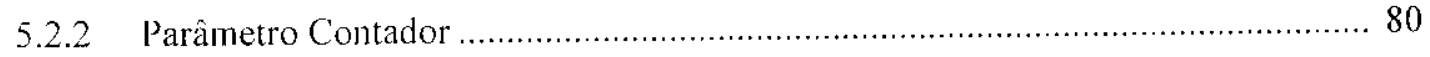

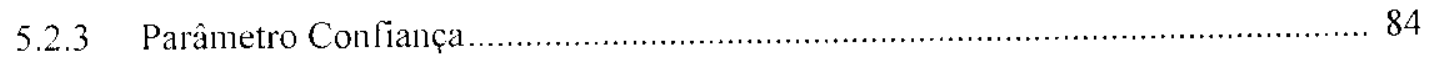

5.2.4 Parâmetro Número de Requisições Prévias ..................................................... 87

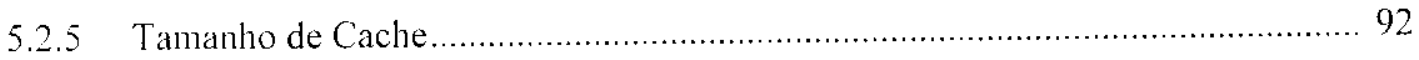

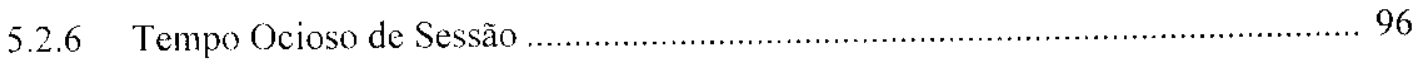

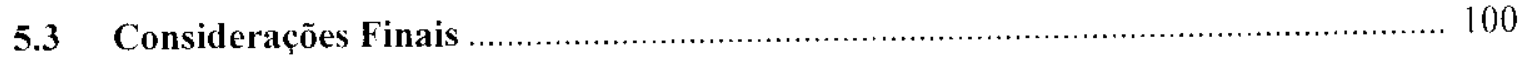

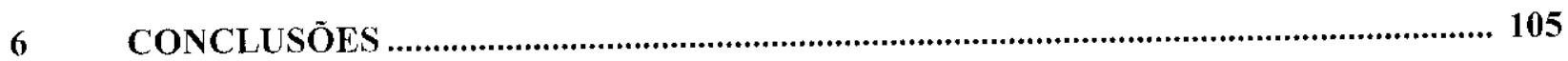

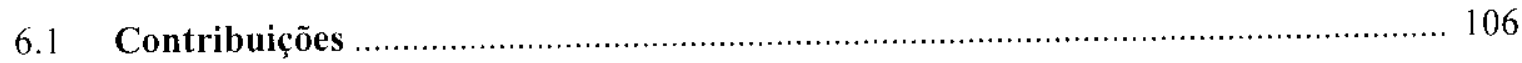

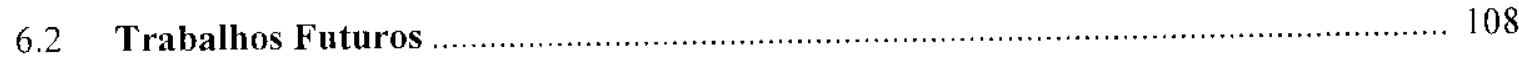

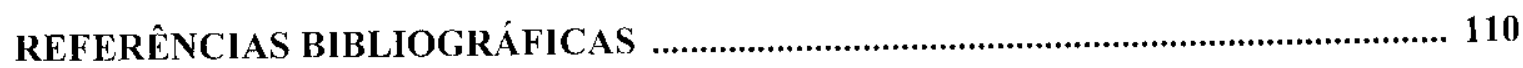




\section{CAPítulo 1}

\section{Introdução}

O contínuo crescimento da Internet nos últimos anos veio acompanhado de evidente crescimento do tráfego de dados. Atualmente, a World Wide Web (WWW) é a aplicação Internet mais popular, e o seu crescimento exponencial, por extensão, vem causando um congestionamento de dados na rede [Yan 2001; Dav 2002]. Dado o caráter multimídia dessa aplicação, os objetos que trafegam na Web (WWW) são naturalmente bastante diversos. É assim que a Web é comumente considerada como um enorme sistema de informações distribuído, provendo acesso a objetos compartilhados [Wan 1999].

O congestionamento da WWW traz consigo uma demora da recuperação dos objetos requisitados pelos usuários. Com isso, a qualidade do serviço fica prejudicada, e essa é uma das principais preocupações dos responsáveis pclo provimento das aplicações [Dod 1998; Kha 2001]. Uma solução intuitiva seria a ampliação da infra-estrutura de suporte, normalmente caracterizada pelo aumento da largura de banda da rede. Todavia, essa proposta nem sempre se mostra economicamente viável e não soluciona o problema de forma eficiente, apresentando-se como uma solução paliativa [Pal 1999]. Dessa maneira, outras formas bastante empregadas para a diminuição da latência percebida pelo usuário, ou seja, o período de inatividade entre o pedido e o início do atendimento de uma requisição, está o uso de cache e pré-busca adaptados para o contexto Web [Coh 2000; Kha 2001; Yan 2001; Dav 2002; Che 2003].

Como a Internet é uma rede mundial, a informação requisitada pode cstar fisicamente muito distante de onde foi solicitada. Cache consiste no armazenamento de uma cópia dos 
objetos requisitados pelo usuário em posições mais próximas, objetivando diminuir o tempo do próximo acesso aos objetos [Dod 1998]. Não obstante, pesquisas anteriores têm mostrado que um entre dois documentos acaba não sendo encontrado no cache (50\%) [Abr 1995; Coh 2000], e essa taxa tem diminuído não só por causa do tamanho e quantidade dos objetos Web, mas também pela diversidade de novos tipos de objetos que, em alguns casos, nem podem ser armazenados em caches Web (ex.: cookies, páginas geradas dinamicamente, etc.)[Che 2003].

Uma forma de promover um aumento da taxa de acerto (hit-rate) do cache é antecipar futuros pedidos de objetos e executar uma busca antecipada para que estejam disponíveis prontamente quando forem requisitados [Alm 1996]. A essa prática dá-se o nome de Pré-Busca. Desse modo, é intuitiva a idéia de que pré-busca está intrinsecamente ligada ao cache, não só pelo fato de necessitar desse repositório para armazenar os elementos pré-buscados, mas também pela sua propriedade complementar, que pode maximizar os benefícios e diminuir as limitações do cache.

Entende-se como servidor web o detentor do objeto original solicitado pelos clientes (browsers ou navegadores), e proxy como um ponto intermediário entre esses dois elementos. Por essa perspectiva, os cenários de pré-busca são apresentados de três formas distintas no contexto Web [Fan 1999]: entre servidor web e browser; entre servidor web e proxy; e entre proxy e browser. A observação desse aspecto permite interpretar de forma mais precisa os pontos em que os problemas se manifestam.

Para melhor caracterizar a prática de pré-busca na Web, ante a extensa lista de fontes de pesquisa considerando essa temática, pode-se, classificá-la separando suas abordagens em três estratégias distintas [El- 1998; Nam 2001]: pré-busca baseada em preferências pessoais do usuário, pré-busca com predição não estatística e pré-busca com predição estatística. Enquanto na primeira o usuário determina o que deve ser pré-buscado, nas demais há um mecanismo que antecipa o que este irá requisitar. Enquanto na predição não-estatística ocorre a pré-busca de todos os possíveis objetos a partir de um documento atual, a predição estatística mostra-se realmente especulativa, baseando-se nos padrões de acesso do(s) usuário(s).

Embora haja consenso dos benefícios do uso das técnicas de pré-busca, é comum encontrar-se na literatura observações sobre possíveis efeitos secundários quanto ao seu uso. $\mathrm{O}$ que mais recebe destaque é o tráfego adicional causado pela pré-busca [Fan 1999; Dav 2001], já que esta obtém objetos que podem nem ser utilizados pelo usuário. Contudo, também há 
consenso de que a observação quanto à utilização de abordagens cuidadosas de técnicas de prébusca adequadas às situações em que estão sendo solicitadas, normalmente tornam essa objeção inicial satisfeita quando são analisados os benefícios que pode proporcionar [Dav 2001; Nan 2001]. Dessa forma, fica patente a necessidade do domínio de tais técnicas, a fim de melhor empregá-las em seus escopos de aplicação. Especialmente, a estratégia de pré-busca baseada em predição estatística, não ao acaso, apresenta o maior número de pesquisas, justamente por promover um comportamento ponderado na execução da pré-busca, utilizando mecanismos computacionais "sofisticados" para implementá-la, aumentando as possibilidades de sucesso.

Atentando-se para essas perspectivas e para a necessidade de elucidação de questões ainda persistentes nessa temática, encontra-se a motivação para este trabalho de mestrado. Conforme discutido, a utilização de pré-busca na Web apresenta vantagens e desvantagens e vem sendo largamente considerada. Assim, o objetivo geral desta dissertação de mestrado é analisar c avaliar as propostas no que se refere às técnicas de pré-busca existentes na literatura, atentandose à análise das situações em que as estratégias de pré-busca baseada em estatística foram consideradas, para que se possa qualificá-las quanto ao seu desempenho. De posse de todo o embasamento teórico necessário para compreender como a pré-busca deve ser empregada no contexto Web, parte-se de uma ferramenta que já trata o tema em questão, para que, através de sua adaptação e adição de novas funcionalidades, se possa executar experimentos para avaliar a pré-busca na Wcb.

O capítulo 2 expõe os aspectos relevantes sobre a Web. Em seguida, descreve-se nesse mesmo capítulo a prática de cache na Web, dada a sua estreita correlação com pré-busca. $\mathrm{O}$ capitulo 3 enfoca a pré-busca na Web, apresentando suas particularidades, a principal questão a que se propõe solucionar, sua integração à implementação de cache, suas estratégias de aplicação, o modelo mais usado para a predição, suas limitações potenciais e um apanhado de trabalhos relacionados. O capítulo 4 apresenta o simulador usado para execução dos cxperimentos. Discute-se sua arquitetura e principais módulos, seus parâmetros, as mudanças feitas nele para adaptá-lo às necessidades deste trabalho e as métricas de desempenho utilizadas para avaliar os resultados obtidos a partir de experimentos com esse simulador. No capítulo 5 são feitas análises e discussões sobre os resultados alcançados neste trabalho. Antes de entrar nos resultados obtidos a partir da simulação da pré-busca, são apresentadas e caracterizadas as cargas de trabalho utilizadas na realização dos experimentos. Em seguida, são apresentados os resultados obtidos através da variação de cada um dos parâmetros do simulador e, finalizando 
esse capítulo, são ressaltadas as principais conclusões desses experimentos. Por fim, o capítulo 6 traz as conclusões alcançadas com o desenvolvimento deste trabalho de mestrado. 


\section{CAPÍtulo 2}

\section{A World Wide Web e Caches na Web}

Este capítulo aborda dois temas diretamente relacionados ao objetivo principal deste trabalho. Inicialmente, caracteriza-se o ambiente em que a pré-busca é considerada - a World Wide Web - destacando-se os aspectos que correspondem à sua estrutura, organização e tecnologia básica de comunicação (seção 2.1).

Na seção 2.2, descreve-se a prática de caches na Web, devido a sua intrínseca ligação com pré-busca. São apresentados tópicos pertinentes à sua introdução no ambiente da Web, funcionamento, benefícios, viabilidade e organização. O capítulo se encerra com algumas considerações finais na seção 2.3 .

\subsection{A World Wide Web}

A Internet é apontada como uma revolução na história da comunicação entre os seres humanos. O número de computadores conectados à Internet no ano 2000 ultrapassava os 60 milhões, distribuídos por mais de 95 mil redes, em mais de 200 países. Esta rede de caráter mundial traz a possibilidade da utilização de tudo que se pode obter quando se imagina a união do poder computacional oriundo da interligação de suas máquinas e da quantidade de informação que trafega através de scu meio. Não obstante, a mais patente das características da Internet é o seu crescimento contínuo e acelerado, o qual adquiriu natureza exponencial desde o início dos anos 80, chegando a dobrar de tamanho em alguns anos [Hun 1997; Com 2000; Bar 2002; Isc 
2003]. A figura 2.1 apresenta o crescimento do número de máquinas ligadas à Internet ao longo dos últimos 15 anos.

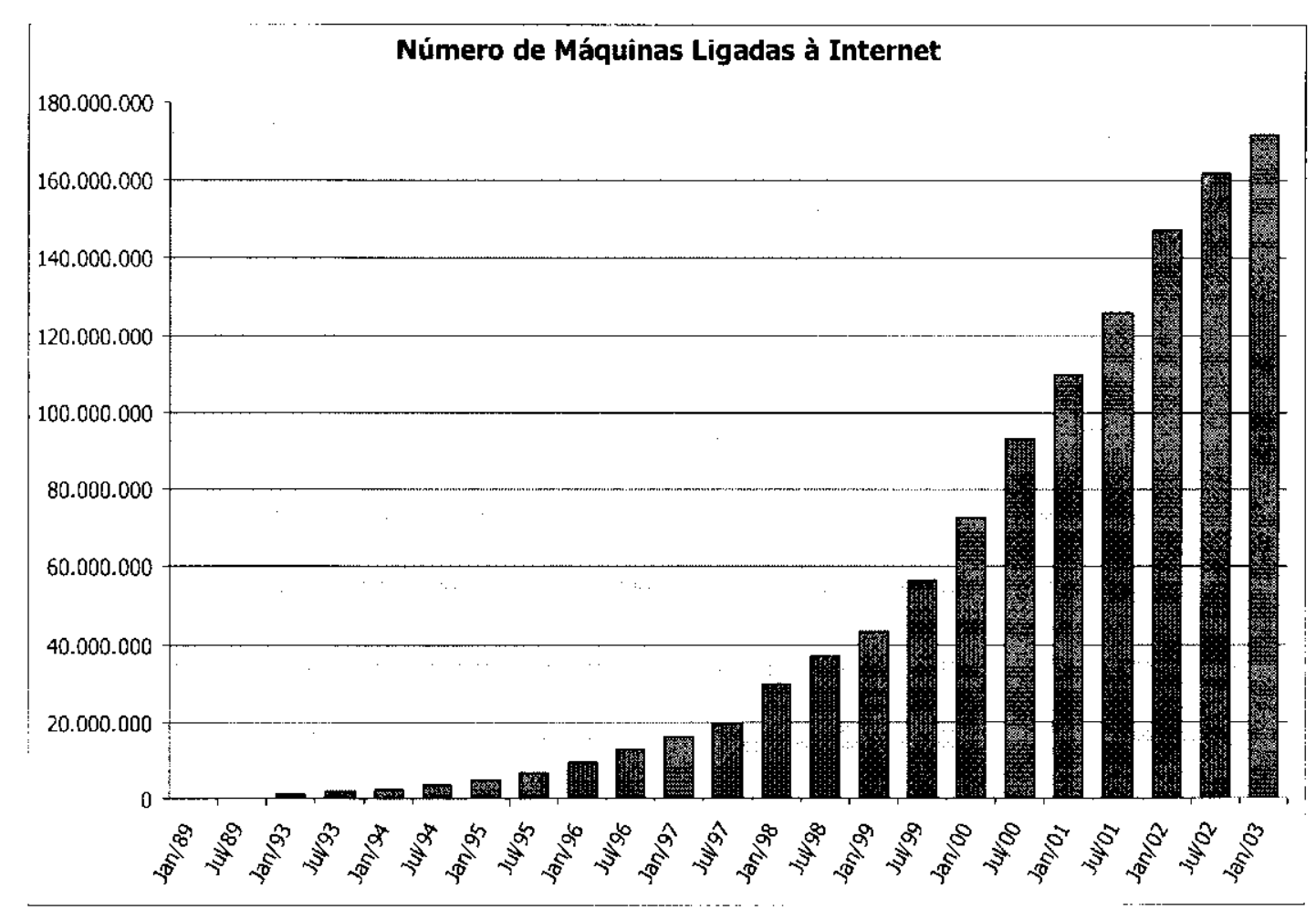

Figura 2.1 - Número de máquinas ligadas à Internet desde 1989 a 2003

(Fonte: Internet Software Consortium [Isc 2003])

Os protocolos padrões para a comunicação via Internet são o Transfer Control Protocol (TCP) e o Internet Protocol (IP), criados como solução para a interligação entre os computadores. Tais protocolos apresentam um conjunto de características que lhes renderam a consolidação de seu uso em grande escala, viabilizada tanto pela facilidade de implementação, quanto pela portabilidade. $O$ uso de padrões abertos, a independência da tecnologia de rede, protocolos padronizados, interconexão total e confïmações fim-a-fim são as principais características do TCP/IP que o distingue de outros conjuntos de protocolos [Com 2000]. As especificações dos protocolos TCP/IP estão livremente disponíveis na Internet, através das RFCs (Request for Comments), promulgadas pela IETF (Internet Engineering Task Force).

No topo da chamada arquitetura TCP/IP encontram-se serviços e aplicações, tais como a transferência de arquivos (FTP), correio eletrônico (SMTP), terminal virtual (TELNET), dentre outros. Mas é na aplicação World Wide Web, WWW ou simplesmente Web, que a Internet tem o seu maior uso. Em meados da década passada, a Web veio a se tornar a responsável pela maior 
parte do tráfego na Internet. Atribui-se a isso, uma série de fatores, dentre eles o aspecto democrático que permeou seu início e que permanece até hoje, e a facilidade de acesso e de utilização por parte dos usuários.

\subsubsection{Organização}

A Web compreende a área hipermídia da Internet. Conciliando textos, imagens, sons, animações, a Web é considerada como um sistema hipertexto gigantesco, cuja base é composta de documentos, denominados "páginas Web". A principal linguagem de escrita destas páginas é a HyperText Markup Language (HTML) [W3c 1999], que proporciona um padrão que garante sua portabilidade, descreve a estrutura e formatação da página e estabelece as ligações (links) entres os documentos e recursos da Web.

Com conteúdo disperso em diversas máquinas, mesmo que estas tenham diferentes arquiteturas, portes, softwares básicos e aplicativos, a Web deve permitir que as informações sejam acessadas diretamente, motivando assim, que possa ser imaginada como um único repositório. É desta forma que a Web pode ser considerada como uma aplicação distribuída, cuja rede de comunicação é a Internet (figura 2.2) [Tan 1997].

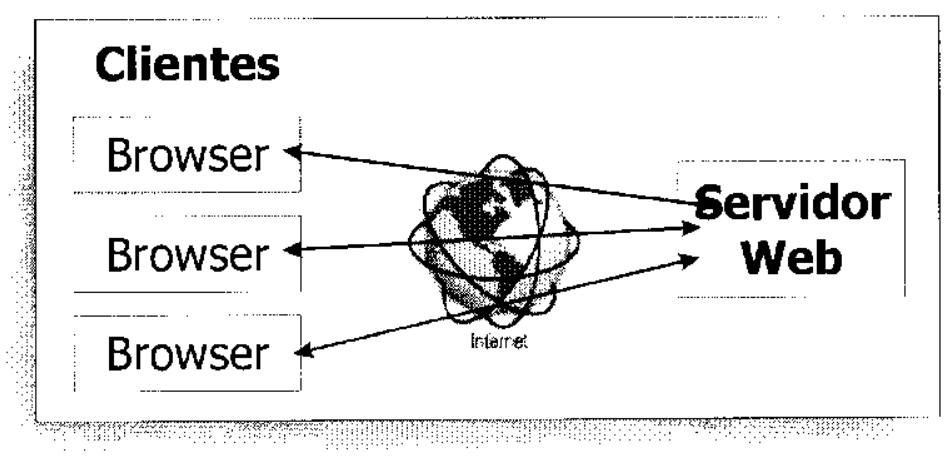

Figura 2.2 - Arquitetura Cliente-Servidor da Web

Inicialmente a Web oferecia suporte apenas a páginas estáticas, que são criadas como um documento comum e são armazenadas no servidor para que possam ser acessadas, mostrando-se disponíveis para a leitura do usuário. Com o desenvolvimento da Web e maior exigência por parte das aplicações, surgiram as páginas dinâmicas. Enquanto a solicitação por uma página 
estática apresenta sempre o mesmo resultado (uma página previamente criada), as páginas dinâmicas são construídas após sua solicitação, já que, normalmente, depende de parâmetros fornecidos na requisição. Um exemplo característico desse tipo de página é o resultado de consultas $\mathrm{em}$ sites de busca, nos quais as informações solicitadas pelo usuário são recebidas, tratadas por um programa no servidor e só então é gerada a página como resposta à solicitação.

Os documentos e objetos que circulam na Wcb são fornecidos por Servidores Web e são acessados pelo usuário através de programas denominados browsers ou navegadores [Orf 1999]. Nesse contexto, dá-se a estas aplicações o nome de Clientes Web. Caracteriza-se, dessa forma, o paradigma cliente-servidor como forma de interação empregada pela Web, no qual os programas específicos para fornecer as páginas são claramente distintos dos que são utilizados para visualizá-las. Como exemplo de servidores Web, tem-se os programas Apache, Netscape Enterprise Server e Microsoft Internet Information Server; e de Clientes Web, tem-se os mais conhecidos: Netscape Communicator e Internet Explorer.

$\mathrm{Na}$ arquitetura cliente-servidor, encontra-se um terceiro elemento denominado Proxy Web. Objetivando efetuar requisições que beneficiem vários clientes, o proxy é um programa intermediário que age tanto como servidor quanto como cliente Web [Fon 1998]. Quando recebe requisições do cliente, ele age como servidor e, de forma análoga, quando encaminha rcquisições ao servidor Web, age como cliente. Por centralizar vários pedidos de conexão, o proxy torna-se relevante ponto de armazenamento da informação que trafega entre cliente/servidor na Internet (figura 2.3). A partir desse ponto de vista, proxy pode ser considerado como um ponto intermediário nas transações típicas da Web, podendo exercer o papel de servidor para um conjunto de usuários, centralizando suas solicitações.

Originalmente, proxies foram projetados como aplicações firewalls, para que administradores de rede pudessem controlar o acesso de usuários de uma rede privada à Internet, separando-as logicamente, evitando também que possíveis invasores tivessem acesso à rede interna [Orf 1999]. Todavia, a popularidade dos proxies deveu-se à observação de que eles poderiam servir como repositório de objetos acessados freqüentemente, o que normalmente acontece quando estão instalados em comunidades de interesses semelhantes, como por exemplo, em uma universidade [Fon 1998]. São justamente nesses locais que os proxies são mais encontrados. 


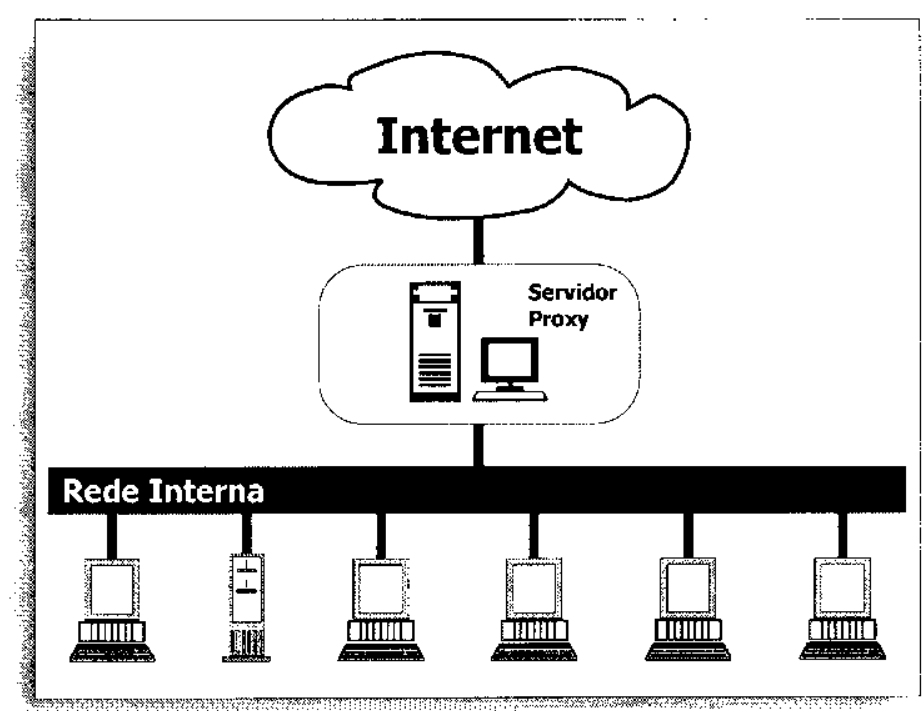

Figura 2.3 - Exemplo de Servidor Proxy

\section{- Nomenclatura}

Abstraindo-se uma simplificação de como a Web está organizada, pode-se dizer que trata-se de um servidor de arquivos universal baseado em URLs (Uniform Resource Locators) [Orf 1999]. URLs fornecem a base do sistema de nomenclatura da Web, identificando qualquer recurso ou objeto da Internet de forma não ambígua.

A observação da estrutura de um URL, permite um entendimento de como a própria Internet está estruturada e de como os recursos podem ser acessados. Uma URL encerra um protocolo, um servidor, uma porta e um recurso, conforme ilustra a figura 2.4 .

- Protocolo. Também chamado de esquema [Tan 1997], especifica o protocolo no qual os dados serão transportados (HTTP, FTP, FILE, NEWS, etc.). Dentre eles, o HTTP é o "idioma nativo" da Web utilizado pelos servidores HTTP (seção 2.1.2). A interpretação das outras partes do URL é determinada a partir do protocolo escolhido;

- Nome do servidor. É o nome Domain Name System (DNS) do host, ou seu próprio endereço IP;

- Número da porta. Especifica a porta em que um processo no servidor está aguardando por mensagens. Geralmente não é informado e, nesse caso, é utilizado o valor padrão de cada protocolo; 
- Localização do recurso. Nome local que indica um recurso (normalmente é um nome de arquivo na máquina onde está armazenado).

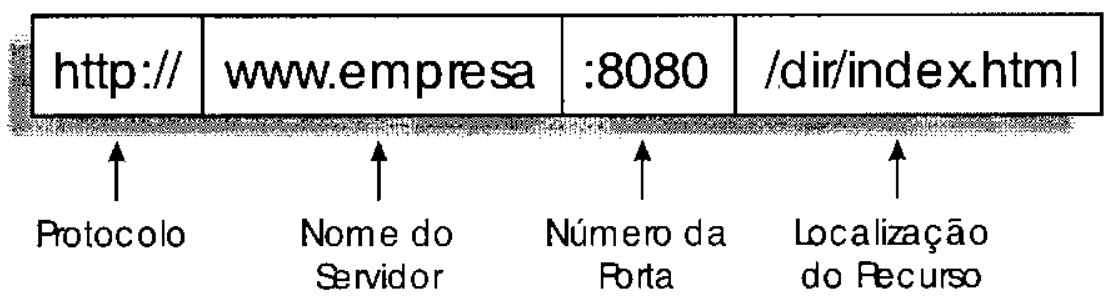

Figura 2.4-Estrutura de uma URL

\subsubsection{Protocolo HTTP}

O HTTP (Hypertext Transfer Protocol) é o protocolo de comunicação na Web. Através dele, browsers e servidores trocam informações entre si por meio de mensagens. É um protocolo cm nível de aplicação que, na arquitetura TCP/IP, trabalha sobre o protocolo TCP (formalmente, não é requerido como padrão [Tan 1997]). Tem-se, assim, um canal de comunicação bidirecional, orientado à conexão e confiável, entre as partes envolvidas.

Uma transação HTTP ocorre segundo um mecanismo do tipo requisição/resposta (request/reply). A figura 2.5 ilustra uma interação ou transação HTTP típica. Inicialmente, o browser contata um servidor Web partindo de uma URL a ser alcançada, especificada implícita ou cxplicitamente (digitada ou embutida em um link) pelo usuário. Em seguida, o browser faz uma requisição ao servidor. Este estabelece uma conexão com o cliente ao receber o pedido escutado na porta pré-definida. Por fim, envia-lhe uma resposta, encerrando a conexão. O browser, ao receber a resposta, apresenta o documento ao usuário que o solicitou. Caso haja alguma falha durante o mecanismo, é responsabilidade do cliente repetir a transação, porque o servidor não guarda nenhuma informação em relação ao estado do cliente (stateless). 


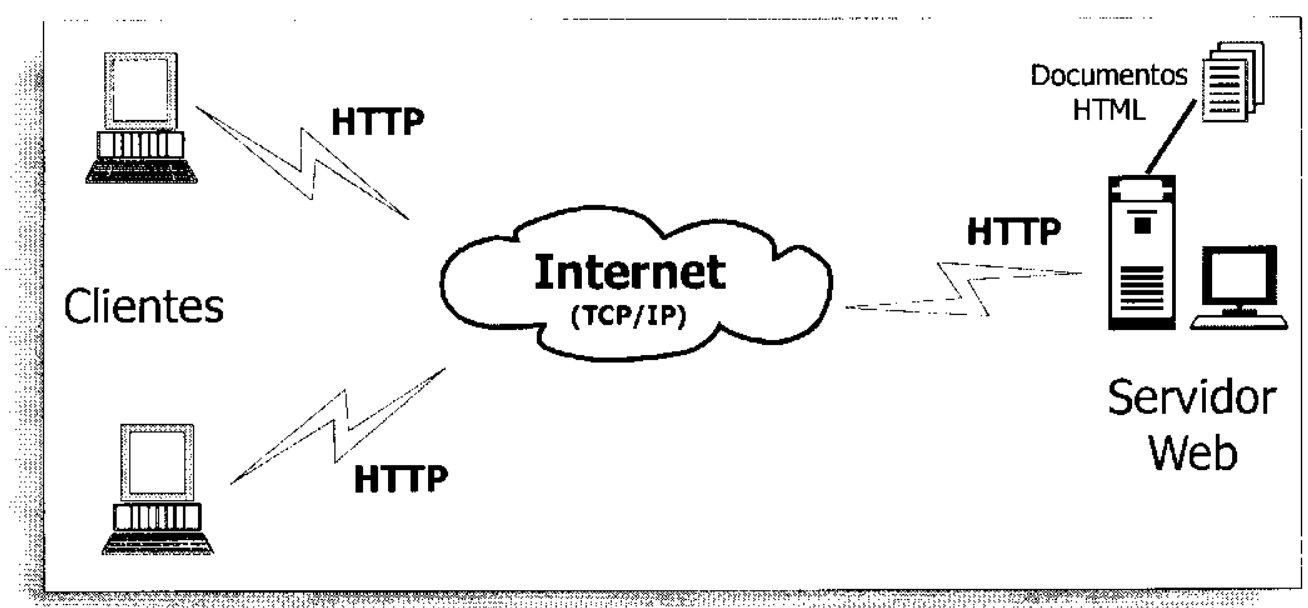

Figura 2.5 - Interaçāo Cliente-Servidor na Web

\section{- Mensagens de Requisição e Resposta}

As mensagens trocadas entre o cliente e o servidor, requisição e resposta, seguem o formato genérico de mensagens da RFC 822 (Request for Comments 822 - padroniza o formato de mensagem de texto usado pelo protocolo HTTP), conforme mostra a figura 2.6. Estas mensagens consistem de uma start-line, headers (opcionais), uma linha em branco (uma linha com nada precedendo um CRLF - Carriage Return Line Feed) indicando o fim dos headers, e o corpo da mensagem (figura 2.6).

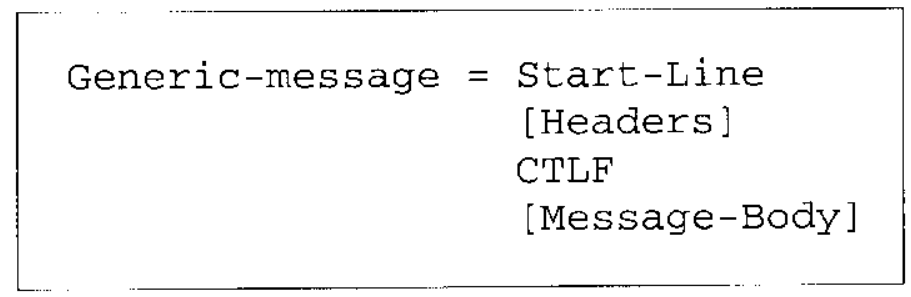

Figura 2.6 - Formato genérico de mensagens [Fie 1999]

O Cabeçalho de uma mensagem HTTP (headers), quando existe, pode conter um ou mais campos no formato nome_do_campo:valor_do_campo. Os campos dos cabeçalhos são classificados nos seguintes grupos:

- General Header. Trata da mensagem sendo transmitida, e não a entidade (objeto) sendo transferida; 
- Request ou Response Header. Fornece informações adicionais sobre si mesma (requisição ou resposta) e de quem a está enviando (cliente ou servidor);

- Entity Header. Define metainformações a respeito do corpo da mensagem ou do recurso identificado pela mensagem.

O protocolo define o conjunto de métodos que o cliente pode invocar, funcionando como comandos enviados ao servidor Web. O protocolo define também códigos de status que descrevem o resultado das requisições feitas pelo cliente. Compostos por 3 dígitos, esses códigos indicam ao cliente o grau de sucesso obtido com a solicitação de um objeto - Ex.: 200 - $O K, 302$ - Moved Temporarily, 304 - Not Modified, 404 - Not Found, 500 - Internat Server Error, dentre outros. A tabela 2.1 apresenta um resumo dos métodos suportados pelo HTTP 1.1 para uma requisição, e a tabela 2.2 apresenta as cinco classes de respostas, indicadas pelo primeiro dígito do código.

Tabela 2.1 - Métodos do protocolo HTTP /I.I

\begin{tabular}{|l|l|}
\hline \multicolumn{1}{|c|}{ Método } & \multicolumn{1}{|c|}{ Funcionalidade } \\
\hline GET & Solicita que seja retornado o recurso identificado pela URL. \\
\hline HEAD & $\begin{array}{l}\text { Obtém informações sobre o recurso sem que o mesmo seja retornado } \\
\text { ao cliente. Testa validade de links, acessibilidade e a data da última } \\
\text { modificação. }\end{array}$ \\
\hline OPTIONS & $\begin{array}{l}\text { Envia informações adicionais do cliente para o servidor no corpo da } \\
\text { mensagem como, por exemplo, dados digitados em formulários } \\
\text { HTML. }\end{array}$ \\
\hline PUT & $\begin{array}{l}\text { Obtém as opções de comunicação disponíveis ou os requisitos } \\
\text { associados ao recurso solicitado, sem necessariamente iniciar sua } \\
\text { recuperação. }\end{array}$ \\
\hline DELETE & $\begin{array}{l}\text { Sermite criar ou modificar um recurso no servidor Web. } \\
\text { Web. }\end{array}$ \\
\hline TRACE & $\begin{array}{l}\text { É usado para enviar uma mensagem de teste, do tipo loop-back, ao } \\
\text { servidor. }\end{array}$ \\
\hline CONNECT & \begin{tabular}{l} 
Reservado para comunicação com servidores proxy. \\
\hline
\end{tabular}
\end{tabular}


Tabela 2.2 - Classes de códigos de status HTTP

\begin{tabular}{|l|l|}
\hline Categoria & Descrição \\
\hline $1 \times x$ & $\begin{array}{l}\text { É uma resposta temporal; indica que a requisição foi recebida e está } \\
\text { atualmente sendo processada. }\end{array}$ \\
\hline $2 \times x$ & $\begin{array}{l}\text { Significa que a requisição foi recebida com sucesso, entendida e } \\
\text { processada pelo servidor. }\end{array}$ \\
\hline $3 \times x$ & $\begin{array}{l}\text { Redireciona o cliente a outra URL. O Cliente deve executar outras } \\
\text { ações para que a requisição seja completada (por exemplo, requisitar } \\
\text { uma outra URL). }\end{array}$ \\
\hline $5 \times x$ & $\begin{array}{l}\text { Indica que uma requisição inválida foi feita pelo cliente. A requisição } \\
\text { contém erro de sintaxe ou não pode ser atendida. }\end{array}$ \\
\hline $5 x x$ & $\begin{array}{l}\text { Indica que, embora a requisição do cliente tenha sido válida, o } \\
\text { servidor foi incapaz de processá-la. Esse erro ocorre enquanto a } \\
\text { requisição está sendo processada. }\end{array}$ \\
\hline
\end{tabular}

A start-line de uma requisição é uma Request-Line composta pelo método HTTP (a operação requisitada), pela identificação do recurso em que o método deve ser aplicado c a pela versão utilizada do protocolo HTTP. O corpo da mensagem é utilizado quando o cliente precisa passar dados adicionais ao servidor [Orf 1999], como no caso do método POST. A figura 2.7 apresenta o formato de uma requisição típica. Nesse exemplo, o cliente solicita (GET) o arquivo /docs/arq.html, usando o protocolo HTTP/1.1. Os itens seguintes fazem parte do cabeçalho (são do grupo Request Header) e indicam que o arquivo desejado está no servidor (Host) www.empresa.com, que o lado cliente reconhece (Accept) texto em formato HTML (text/html) e imagens em formato JPEG (image/jpeg), e qual o browser (User-Agent) utilizado (Netscape/4.7).

GET /docs/arq.html HTTP/1.1

Host: www.empresa.com

Accept: text/htm1, image/jpeg

User-Agent: Netscape/4.7

Figura 2.7 - Exemplo de uma requisição HTTP

Para uma resposta, a start-line é uma Status-Line que contém a versão do protocolo e um código de status. O corpo da mensagem tipicamente contém o documento HTML que o cliente solicitou [Orf 1999]. No exemplo da figura 2.8, a Status-Line indica que o servidor usa o 
HTTP/1.1 e que a solicitação foi completada com sucesso (código de status 200). O campo Date (General Header) especifica a data e horário da resposta e o campo Server (Response Header) informa o tipo de servidor Web (NCSA/1.4). Os campos seguintes, pertencentes ao Entity Header, denotam o tipo do documento (text/html), o seu tamanho em bytes (1194) e quando foi atualizado pela última vez. Finalmente, tem-se uma linha $\mathrm{em}$ branco e o documento propriamente dito.

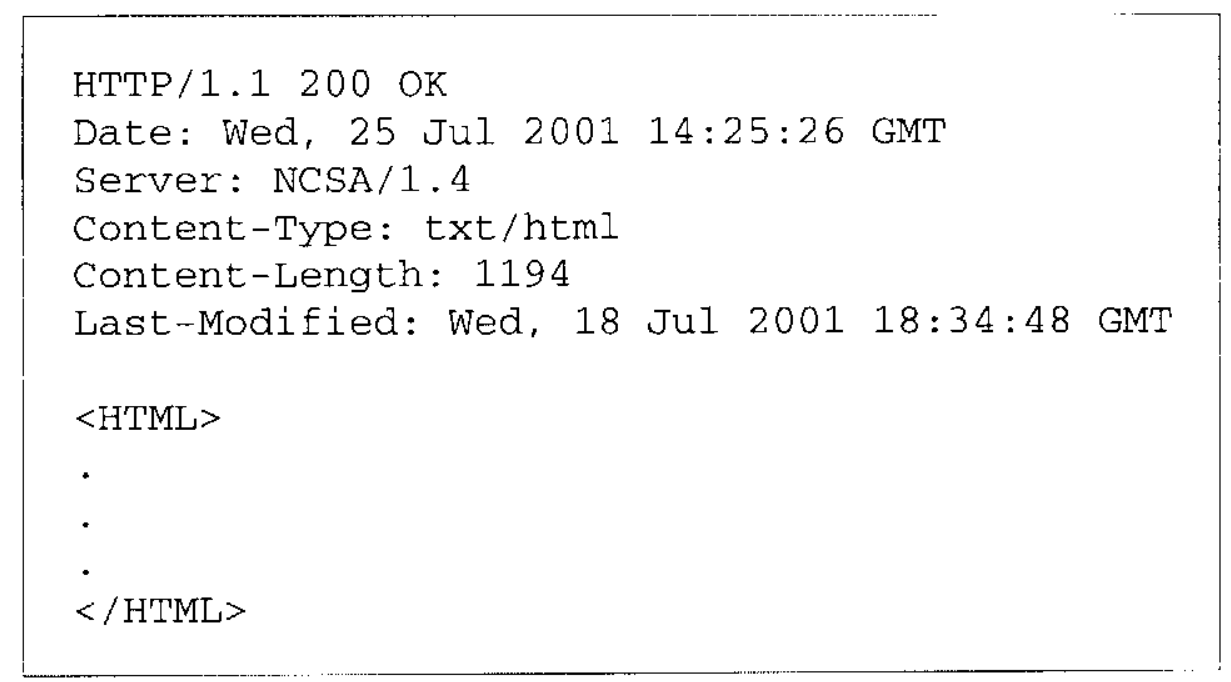

Figura 2.8 - Exemplo de uma resposta HTTP

\section{- HTTP 1.0 e 1.1}

O protocolo HTTP 1.0 foi projetado para lidar com documentos Web simples. Com o crescimento da Web, novas necessidades surgiram e esta versão do protocolo começou a apresentar limitações. Esta versão do protocolo cria uma nova conexão TCP para cada URL IOrf 1999], ou seja, o cliente estabelece uma conexão antes de enviar uma requisição e o servidor a fecha após enviar a resposta. Quando se trabalha com documentos simples, isso não implica em problema. No entanto, quando ocorrem diversas requisições, geradas em cadeia a partir de uma requisição original, pode-se ter problemas de desempenho. Por exemplo, quando uma página contém várias imagens, como a grande maioria das páginas na Web, uma conexão é realizada para cada um dos objetos, ocasionando sobrecarga no servidor e na rede.

O HTTP 1.1, padronizado em 1999 pelo W3C (World Wide Web Consortium), introduziu alguns mecanismos que tornaram o download dos documentos mais eficiente, melhorando 
significativamente a performance do tráfego na Web [W.3c 1999]. Uma mudança importante dessa versão refere-se à adoção de conexões persistentes como esquema padrão, no qual uma mesma conexão TCP pode ser usada por várias transações http. Outras características essenciais são o pipelining de requisições, que permite a um usuário enviar múltiplas requisições sem ter que esperar pela resposta (o servidor deve responder às requisições na mesma ordem que as recebeu) e os comandos específicos para que os clientes ou servidores proxy possam manter caches locais consistentes. Essa estratégia de manter cópias locais com a finalidade de diminuir o tempo de acesso à informação é denominado cache.

\subsection{Caches na Web}

O crescimento da popularidade da Web torna cada vez mais importante a existência de projetos relativos à escalabilidade de seu sistema de redes, a fim de garantir sua funcionalidade. Várias pesquisas vêm sendo conduzidas na área de Web Caching, por esta ter se mostrado uma solução efetiva na redução do tráfego de rede, latência e carga no servidor [Bar 2000; Kri 2001; Pin 2001; Wes 2001; Rab 2002; Pod 2003].

Ditos "tradicionais", os sistemas de caches de memória presentes nos computadores modernos aumentam a velocidade de acesso à memória principal, melhorando o descmpenho dos processadores. Cache também é conhecido como uma técnica que melhora a escalabilidade e desempenho de sistemas cliente-servidor, já que minimiza os pontos de contenção na rede ou no servidor, aumentando o número de clientes que podem ser atendidos.

Por se tratar também de um sistema cliente-servidor, a Web pode fazer uso de cache estendendo para csse ambiente a noção de se armazenar os objetos localmente ou quão perto possível do cliente. A utilização de caches na Web permite a redução da latência nas requisições, a qual trata-se de um fator determinante na qualidade dos serviços fornecidos aos usuários. Além disso, Arlitt \& Williamson [Arl 1996] demonstraram que uma pequena fração dos objetos corresponde à maioria dos acessos ao servidor Web. Já Pinto et al. [Pin 1997] constataram que mais de $50 \%$ dos objetos requisitados ou das transferências de FTP já foram realizados por algum usuário anteriormente. Dessa forma, a sobrecarga percebida nas redes atuais pode também 
ser reduzida com a identificação dos objetos comuns solicitados por vários usuários, colocandoos em caches próximos a estes, evitando que ocorram repetidas transferências do servidor.

\subsubsection{Características de Cache na Web}

O uso de caches tradicionais tornou-se viável devido a dois princípios de acesso à memória: localidade temporal e localidade espacial [Tan 1995]. Nesse contexto, estas "localidades" indicam que, se um processador acessa uma determinada posição de memória, é muito provável que ele a acesse novamente em um curto espaço de tempo — temporal — e que é muito provável que ele acesse posições adjacentes também $\mathrm{cm}$ um curto espaço de tempo espacial.

Com a observação de $\operatorname{logs}$ de servidores Web e de proxies, verifica-se que caches na Web também podem fazer uso desses princípios. Por esse prisma, localidade espacial implica que documentos requeridos recentemente irão afetar a sequiência das próximas requisições. Assim como outros pesquisadores, Almeida et al. [Alm 1996] constataram que as referências entre as requisições são realmente correlacionadas, quando compararam o número total de sequiências únicas em traces reais da Web com traces aleatórios permutativos, c observaram um menor númcro de sequêencias distintas entre os traces reais da Web.

Almeida et al. [Alm 1996] também apontaram a localidade temporal revelada em logs da Web, observando que os documentos acessados recentemente são mais provávcis de serem requeridos num futuro próximo. Esta observação também foi apresentada por diversos outros autores em diferentes situações [Arl 1996; Cao 1997; Riz 1998].

Embora haja princípios, conceitos c características semelhantes entre caches tradicionais e caches na Web, o que viabiliza o aproveitamento de pesquisas de um para outro, há quatro diferenças básicas entre eles:

- Tamanho dos objetos. A memória cache tradicional é dividida em pequenas unidades de mesmo tamanho denominadas "linhas de cache" ou blocos, sendo também a unidade de transferência entre esta memória e a memória principal. Nos caches na Web, os objetos têm diversos tamanhos e são transferidos e armazenados integralmente; 
- Latência. A latência é definida como o tempo necessário para completar uma requisição ou serviço [Jai 1991]. Em caches tradicionais, o tempo de espera por uma requisição é, na prática, fixo. Em caches na Web, mesmo para objetos de mesmo tamanho, o tempo de resposta geral pode variar muito devido a fatores como: largura de banda, sobrecarga na rede, no servidor, no cliente, e localização em relação ao cliente;

- Carga de trabalho. Os dois sistemas de cache trabalham com cargas bastante diferentes. Composta por milhões de objetos, servidores e usuários espalhados pelo mundo, a Web possui muito mais usuários que um sistema distribuído de larga escala. Inclusive, estas características da Web (variabilidade e larga escala) desafiam a sua avaliação de descmpenho e propostas de soluções para seus problemas [Mur 2000];

- Operação de escrita. Caches tradicionais cxecutam a operação de escrita no cache e esses dados são repassados imediatamente ou não à memória principal [Sta 2003] - a escrita em cache é feita nas duas direções. Nos sistema de cache da Web, os clientes não gravam informações no cache para serem repassadas para um proxy ou scrvidor - a escrita em cache é feita em apenas uma direção.

As diferenças apresentadas influenciam nos parâmetros para a avaliação e funcionamento de caches na Web. Aspectos de gerenciamento comuns a ambos os sistemas (tradicional e na Web), tais como a atualização do cache, determinação do tamanho total do cache e dos objetos armazenados, acabam por ter tratamentos diferentes. Ainda nesta questão, outro fator que recebe bastante enfoque são as políticas de substituição, as quais determinam quais objetos devem ser retirados do cache para dar lugar a novos objetos. Alguns desses aspectos de gerenciamento de cache na Web são discutidos na seção 2.2.3.

Vale ressaltar que, como objetos dinâmicos normalmente são dependentes de parâmetros presentes nas requisições atendendo a solicitações específicas, a utilização de caches na Web é limitada aos objetos estáticos, já que esses são atualizados apenas ocasionalmente [Pin 2001].

Murta \& Almeida [Mur 2000] destacam alguns benefícios alcançados com o uso de sistemas cache na Web:

- Redução de tráfego. Menos requisições e respostas trafegam na Web. Com caches, pode-se aumentar a escalabilidade, reduzir a possibilidade de congestionamento e maximizar a utilização da infra-estrutura da Internet, minimizando a quantidade de tráfego 
redundante na Web. Para os provedores de acesso e administradores de rede, a redução de tráfego é especialmente interessante, já que pagam por largura de banda. Pelo lado do usuário, a redução do tempo de acesso implica em recebimento dos objetos mais rapidamente;

- Redução na carga de servidores. Menos requisições para os servidores Web atenderem. Além desse benefício comum aos servidores Web em geral, um sistema de caches pode ser projetado para auxiliar os servidores Web, por exemplo, em situações de grande congestionamento;

- Redução de latência. A requisição e a resposta percorrem apenas o caminho entre o cliente e o cache. A latência é inversamente proporcional à proximidade do cache em relação ao cliente, pois quanto mais próximo o cache está do cliente, podendo assim fornecer o objeto requisitado mais prontamente ao cliente, menor é a latência de acesso;

- Possibilidade de acesso off-line. Quando um servidor Web especificado numa URL está inacessível, o objeto pode ser acessado caso esteja armazenado no cache, embora possa não estar atualizado.

Wang [Wan 1999] aponta possíveis problemas que podem ocorrer com o uso de cache:

- Manter a consistência. Os objetos podem não estar atualizados no cache, porque não é fácil prever o tempo que um objeto permanecerá válido. Esse é um fator crítico de sucesso de caches na Web;

- Objeto requisitado não se encontra no cache (miss). O tempo adicional para verificar se um objeto encontra-se no cache, pode constituir uma sobrecarga caso ocorra muitas falhas na tentativa de obtenção do objeto. Consequientemente, o projeto de sistemas de cache deve procurar minimizar o número de falhas e o custo de cada falha;

- Gargalo no sistema. Caso o cache esteja localizado em um proxy e não seja controlado o número de usuários que esse proxy possa atender, o cache pode se tornar um gargalo no sistema. Logicamente, o acesso ao cache deve ser, no mínimo, tão eficiente quanto o acesso ao servidor de origem;

- Ponto de falha. Caso seja implantado em um único servidor proxy, um cache torna-se um potencial ponto de falha; 
- Menos acesso ao servidor de origem. Sendo usado cachês em servidores proxy, há redução de acesso aos servidores de origem, implicando em uma estimativa irreal de número de acessos nesses servidores.

\subsubsection{Localização e Topologia de caches na Web}

Quando um objeto requisitado se encontra atualizado no cache $\mathfrak{c}$ pode ser, dessa forma, utilizado pelo cliente, dá-se o nome de accrto no cache (cache hit). Quanto mais o cache puder atender às solicitações, maior será a taxa de acertos (hit rate). Falta no cache (cache miss) é o termo encontrado na literatura para contrapor acerto no cache.

A fim de maximizar a taxa de acertos e atender o tipo de tráfego gerenciado, assim como atender a sua função primária, caches podem ser implantados em diferentes locais da Web (figura 2.9), classificando-os como:

- Cache de cliente. Como é bastante provável que um usuário acesse as mesmas páginas freqüentemente, a grande maioria dos navegadores Web implementam um cache próprio. Esse tipo de cache tem como vantagens evitar o acesso à rede c proporcionar velocidade na recuperação do objeto (apenas o tempo de acessar o objeto na memória principal ou no disco da própria máquina do usuário). Porém, não permite o compartilhamento entre os usuários, ocasionando, por exemplo, que um mesmo objeto tenha réplicas em vários clientes;

- Cache de servidor. Scu objetivo é manter acessos rápidos a objetos mais acessados, colocando-os na memória principal do servidor Wcb. Por conseguinte, esse cache está restrito ao conjunto de objetos presentes no servidor;

- Cache de proxy. Configura a implementação $\mathrm{cm}$ pontos estratégicos da rede, como descrito na seção 2.1.1, tendo como objetivo atender um grupo de clientes que utilizam a mesma saída para a Internet [Mur 2000]. Além da vantagem intrínseca de disponibilizar os objetos com maior proximidades dos clientes, permite também que se mantenha apenas uma cópia do objeto para vários usuários. Um proxy trabalha recebendo ou interceptando requisições HTTP dos clientes e, caso encontre o objeto requerido em seu cache, retorna-o ao usuário. Se o objcto não é encontrado, o proxy o requisita ao scrvidor de interesse do usuário (servidor original), possivelmente o deposita em seu cache, e finalmente retorna o objeto ao cliente [Bar 
2000). Para que funcionem assim, muitos proxies requerem que os usuários finais configurem suas aplicações para apontar para eles.

- Cache de proxy transparente. É usado principalmente por provedores Internet, por não requerer configurações do lado cliente. Os usuários finais não percebem que estão usando um proxy [Orf 1999]. Ele intercepta as requisições HTTP de forma transparente e as redireciona para o cache [Bar 2000].

- Cache de proxy reverso. Ao contrário do cache de proxy, está mais próximo do servidor original, interceptando requisições destinadas a um ou mais servidores Web [Bar 2000]. São independentes dos caches implantados próximos dos clientes, mas podem coexistir para melhorar o desempenho da Web. Esta solução é atrativa para servidores ou domínios populares, objetivando assegurar a qualidade de serviço prestado.

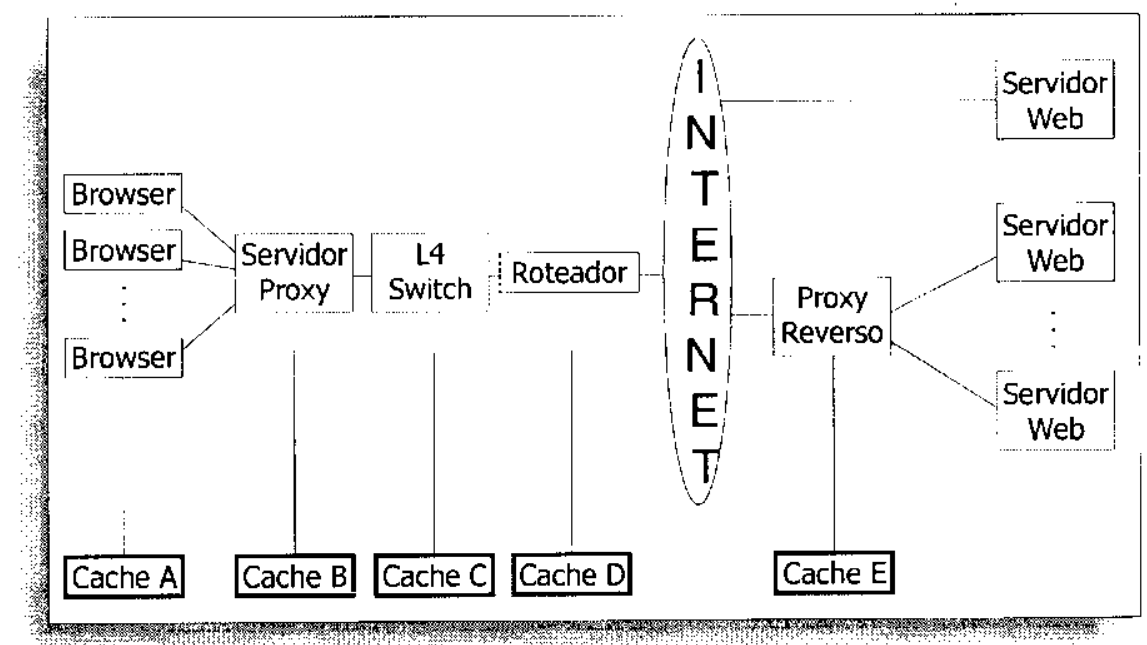

Figura 2.9-Localizaçāo de Caches na Web

Quanto à topologia, ou seja, a forma como os caches estão organizados, a literatura destaca duas formas principais: caches hierárquicos e cooperativos. Em caches hierárquicos, as falhas são resolvidas por servidores em níveis mais altos na hierarquia [Cha 1996], porém, caches em um mesmo nível não podem se comunicar para atender requisições. Nesta abordagem, os caches de níveis mais altos podem ser sobrecarregados e tornarem-se gargalos no sistema. Outras possíveis desvantagens são o armazenamento dos objetos em todos os caches utilizados 
para transportá-los ao usuário, e a sobrecarga adicional ocasionada pela necessidade de uma nova conexão TCP cada vez que se queira carregar um objeto.

Em caches cooperativos, um conjunto de caches se comunica para atender diferentes usuários. Se ao receber uma requisição, um cache cooperativo constata que o objeto não está em seu cache, ele verifica se algum de seus irmãos tem o objeto armazenado. Em caso positivo, o objeto é requisitado, podendo fazer uso de diferentes protocolos para esta tarefa - o Internet Cache Protocol (ICP) é um exemplo desses protocolos [Wes 1997]. Caso a cópia do objeto tenha sido obtida de outro cache, ela não fica armazenada em quem o requisitou. É assim que se observa que caches cooperativos podem ser projetados para balanceamento de carga, visto que um único cache pode não ter recursos para atender a uma grande comunidade de usuários.

Uma solução híbrida, combinando as vantagens das duas abordagens, pode reduzir os tempos de conexão e transmissão [Rod 1999]. São caractcrizados alguns ajustes no grau de cooperação em caches do mesmo nível para minimizar o tempo de recuperação de objetos, bem como o uso de largura de banda dependendo do congestionamento na rede, da carga no cache em níveis superiores ou nos servidores de origem.

\subsubsection{Consistência de objetos em caches na Web}

A inconsistência de cache ocorre quando há modificações num objeto original e as cópias de caches se mantêm desatualizadas. Para que o armazcnamento em cache seja efetivo, não pode haver inconsistências. Uma solução intuitiva, porém impraticável por questão de desempenho, scria checar todas as requisições para verificar se o objeto está desatualizado. Assim, encontramse na literatura diversos mecanismos de consistência de cache. Gwertzman \& Seltzer [Gwe 1996] apontam algumas soluções, como: Time-To-Live (TTL), polling de cliente e o protocolo de invalidação pelo servidor.

TTL é uma estimativa do tempo de vida de um objeto e determina por quanto tempo um objeto armazenado no cache permanece válido. Se o tempo de vida de um objeto requisitado ainda não expirou, o cache o fornece sem contatar o servidor. Caso o objeto esteja expirado, fazse uma requisição condicional ao servidor (If-Modified-Since) para verificar se o objeto foi alterado. O servidor retorna um código de status informando se o objeto foi ou não modificado e, 
no primeiro caso, retorna o novo objeto. TTLs são de simples implementação no protocolo HTTP, bastando usar o cabeçalho expires (Entity Header) [Fie 1999].

A técnica de polling de cliente baseia-se na verificação periódica da validade de um objeto, partindo da suposição de que os objetos novos são modificados com maior frequiência dos que os objetos antigos. Esta técnica utiliza um campo TTL expresso em porcentagem, conhecido como threshold ou limiar, usado para ser comparado com o tempo desde a última atualização. Esta abordagem possui a desvantagem de gerar muitas requisições condicionais ao servidor.

O protocolo de invalidação pelo servidor garante uma consistência mais precisa, pois o servidor notifica os caches quando suas cópias se tornam inválidas. Todavia, esse protocolo é computacionalmente caro, porque o servidor deve manter um registro dos caches que armazenam seus objetos. Além disso, tem que lidar com clientes indisponíveis, devendo continuar tentando notificá-los, uma vez que os caches só poderão invalidar os objetos se forem notificados pelo servidor.

\subsubsection{Políticas de substituição de objetos em caches na Web}

Enquanto a consistência cuida da atualização dos objetos em cache, as políticas de substituição tratam da definição de quais objetos devem ser retirados para ceder lugar a novos objetos quando o cache estiver cheio, visto que, em qualquer sistema de cache real, o espaço de armazenamento é finito. A importância das políticas de substituição está na influência direta à eficácia do uso de caches na Web.

Para a seleção adequada de quais objetos devem ser substituídos, os fatores mais considerados são: o tempo do objeto no cache, a freqüência de acesso, o tamanho dos objetos, o período de validade do objeto no cache e os tcmpos de transferência. Os parâmetros para a avaliação também são diretamente influenciados por esses fatores. Por exemplo, quando as políticas de substituição favorecem objetos menores, a taxa de acerto é maximizada, pois uma maior quantidade de objetos poderá ser armazenada. Já quando favorecem objetos maiores, há maior probabilidade de se ter uma economia do tempo de transferência e maior taxa de acertos por bytes. 
Estudos recentes propõem um considerável número de algoritmos de substituição de objetos na Web para, além de aumentar as taxas de acertos, viabilizar o controle de uma latência média e diminuição do custo total [Pin 2001; Pod 2003]. As políticas de substituição podem ser classificadas em [Agg 1999]: tradicionais, baseadas em chaves (parâmetros prioritários) e baseadas em funções. Elas agrupam, respectivamente, (1) políticas tradicionais de cache e suas variações, (2) políticas que hierarquizam a prioridade dos parâmetros de substituição, e (3) políticas que se baseiam em funções para calcular o custo da substituição dos objetos. As políticas Least Recently Used (LRU) e Least Frequently Used (LFU) são, de longe, as políticas mais freqüentes na literatura de caches na Web, mesmo porque são tidas como básicas também na literatura de caches convencionais.

LRU substitui os objetos que há mais tempo não foram requisitados, garantindo que objetos com acessos mais recentes estejam no cache assim que forem solicitados. Por esta razão, ela favorece cargas em que haja uma elevada localidade temporal (seção 2.2.l). Normalmente, a implementação desta política é feita por meio de uma lista ordenada pelo último tempo de acesso de cada objeto, permitindo que um elemento da lista seja adicionado e removido em tempo constante $O(1)$, dado que precisa apenas acessar a cabeça (ou cauda) da lista. As atualizações na lista, quando um objeto é referenciado, são também de tempo constante, dado que ela está associada à estrutura de metadados que dá suporte ao armazenamento dos objetos [Dil 1999]. A desvantagem está em não levar em consideração o tamanho do objeto e o tempo necessário para recuperá-lo na origem.

LFU substitui os objetos que foram acessados menos vezes. Para isso, a implementação desta política utiliza um contador de acessos para cada objeto no cache, e substitui o objeto com o menor contador. Caso mais de um objeto tenha o mesmo valor de contador, pode-se utilizar uma segunda política de substituição. Diferentemente da política LRU, csta implementação não pode ser feita por uma lista encadeada simples, e as operações realizadas sobre a estrutura escolhida são de pelo menos $O(\log N)$, quando é utilizado um heap, por exemplo [Dil 1999]. Um problema da política LFU é que não há garantias de que um objeto com contador alto seja um objeto não obsoleto, já que esse objeto pode ter sido bastante referenciado no passado e não ser mais referenciado no futuro. Isso quer dizer que, embora o objeto seja um bom candidato a ser substituído, permanecerá em cache e desfavorecerá o aproveitamento efetivo do espaço. 
As duas políticas descritas acima são, de forma geral, a base de muitas outras políticas de substituição, ora pela variação de seus comportamentos básicos, ora pela complementação desses comportamentos por meio de adição de parâmetros que não a recentidade e freqüência de acesso. Em uma outra forma de classificar as políticas de substituição, baseando-se na quantidade de parâmetros considerados para a substituição, a diferença no uso destas políticas tradicionais fica mais bem definida. Alguns exemplos das políticas seguindo esta classificação são [Pin 2001]: LRU, LFU, LFU-Aging, LFU*, LFU*-Aging, Size Policy [Wil 1996], Least Dynamic Frequency Rule (LDRF) [Agg 1997] - Políticas que consideram apenas um parâmetro na substituição; Segmented LRU (SLRU), LRU-K, Frequency-Based Replacement (FBR), Greedy Dual-Size (GD-Size) [Cao 1997], Pyramidal Selection Scheme (PSS) [Agg 1997b], Lowest Relative Value (LRV) [Riz 1998] - Políticas que consideram dois parâmetros na substituição; Baseada no tempo de recuperação dos objetos [Bol 1996], Hybrid [Woo 1997], Dinâmica [Bra 2001] - Políticas que consideram múltiplos parâmetros na substituição.

Resta salientar que, em se tratando de políticas de substituição, embora haja grande esforço para maximizar a taxa de acerto, não se conhece uma política melhor que todas as demais para todos os tipos de padrões de acesso na Web, visto que elas dependem altamente das características próprias de tráfego na Web [Wan 1999].

\subsection{Considerações Finais}

A Web é caracterizada na bibliografia como um sistema distribuído de grande abrangência, que permancce em constante crescimento. No entanto, adaptar conceitos de sistemas distribuídos convencionais à Web não é uma tarefa trivial. Sendo um sistema de alcance mundial e possuindo aspectos únicos de infra-estrutura, o entendimento da natureza do tráfego da Web é essencial. Por isso esse capítulo foi dedicado inicialmente à descrição da Web, seus componentes, características de seus objetos e como se dá o acesso a eles, organização, e como o protocolo HTTP consegue fornecer o suporte necessário para seu funcionamento.

A prática de cache na Web é uma proposta muito difundida para melhorar a escalabilidade da Web, aumentando o número máximo de usuários que podem ser atendidos, promovendo também uma diminuição de pontos de contenção na rede ou no servidor. Porém, na 
bibliografia de pré-busca, é recorrente a afirmação de que esta prática, quando aplicada isoladamente, apresenta limitações que poderiam ser minimizadas com a adoção conjugada de pré-busca. Foi assim que esse capítulo se dedicou também às particularidades concernentes ao uso de cache na Web, tais como suas diferenças em relação a caches tradicionais, seus benefícios, os locais onde podem ser implementados, a organização que podem assumir, e as diversas estratégias e técnicas de tratamento de possíveis problemas encontrados na sua implantação. 


\section{CAPÍTULO 3}

\section{Pré-Busca na Web}

O crescimento da Web vem impulsionando cada vez mais estudos para que seja possível oferecer serviços mais eficientes. Sistemas de cache para a Web são alvo de um grande número de pesquisas e têm sido bastante utilizados, por permitirem maior desempenho e melhor escalabilidade. Todavia, se apenas objetos que já foram acessados anteriormente forem armazenados no cache, a cficiência do cache fica limitada. Outro fator limitante está relacionado com o fato dos dados no cache estarem sempre atualizados [Zha 2001]. Com o intuito de ampliar a eficiência dos caches na Web, a Pré-Busca (prefetching) vem scndo bastante estudada [Yan 2001; Dav 2002; Che 2003; Ség 2003].

Este capítulo visa expor os aspectos que caracterizam a prática de pré-busca no ambiente Web. Os pontos referentes às justificativas e particularidades serão apresentados na seção 3.1. Em seguida, na seção 3.2, define-se os diversos tipos de latência encontrados na literatura, a fim de promover o entendimento necessário quanto à distinção do uso dos diversos termos. Na seção 3.3, faz-se comentários sobre os benefícios da união de pré-busca à prática de cache, sendo logo seguida pelas diferentes estratégias de implementação de pré-busca na Web (seção 3.4). As características do modelo de predição em que a pré-busca se baseia e o principal algoritmo utilizado na predição dos elementos que scrão pré-buscados são explicados na seção 3.5. Nesta seção também estão descritos a construção da estrutura de dados que implementa o modelo, e o processo de predição a partir do modelo construído. A seção 3.6 expõe as limitações impostas à prática de pré-busca na WWW. Por último, na seção 3.7, faz-se um levantamento de algumas 
pesquisas rclevantes sobre a temática deste trabalho, tendo-se preocupação em enfocá-las de acordo com seus cenários específicos, e a seção 3.8 encerra o capítulo com considerações finais.

\subsection{Características de Pré-Busca na Web}

Pré-busca é uma importante técnica utilizada para reduzir latência $\mathrm{cm}$ sistemas distribuídos. Em sistemas de informação como a Web, sua idéia central consiste em antecipar a busca das próximas páginas que serão requisitadas pelo usuário, bem como os demais objetos agregados, c colocá-las em um cache [Bes 1995; Pad 1995]. Esse processo ocorre em segundo plano c não é percebido pelo usuário [Nan 2001]. Assim, quando um usuário faz uma requisição por páginas que já foram pré-buscadas, elas podem ser retornadas imediatamente, salvando o esforço de buscá-la do servidor original [Kri 2001; Zha 2001].

A proposta de pré-busca é mais ampla do que a proposta básica das técnicas de cache, dado que antecipa uma futura requisição do usuário, ao invés de aproveitar algo que já foi requisitado outrora [Tua 2000]. Observa-se que pré-busca está diretamente associada à prática de cache, já que os objetos pré-buscados são armazenados neste. O estudo das técnicas desses dois conceitos, cache e pré-busca, ora se dá de forma integrada, ora de forma separada. Vale notar que, enquanto a preocupação principal das técnicas de cache na Web diz respeito às políticas de substituição, a maior prcocupação das análises de pré-busca no que se refere à integração com caches está em determinar onde este deve estar localizado [Zha 2001].

No contexto Web, pré-busca é uma estratégia para csconder do usuário a latência de recuperação dos objetos Web requisitados, ao invés de reduzi-la [Pad 1996; Pal 1998; Nan 2001]. Isso quer dizer que, o tempo decorrido desde que foi lançada a requisição até que o objeto requisitado tenha chegado ao usuário permanece o mesmo, mas o usuário não percebe e não precisa ficar aguardando esse processamento. Esse tempo, somado ao tempo que a máquina cliente precisará para processar a resposta, caracteriza a expressão denominada "Latência percebida pclo usuário", ou seja, o atraso que o usuário percebe desdc o momento que requisitou uma página ou qualquer outro objeto da Web, até que ele esteja disponível no seu navegador. Esse é apontado como o principal problema de desempenho da Web [Coh 2000]. Assim, a idéia de pré-busca baseia-se no aproveitamento do tempo ocioso da conexão do usuário (enquanto este 
não está, explicitamente, buscando algo) para buscar os objetos que serão possivelmente requeridos no futuro.

Os mecanismos de pré-busca variam de acordo com a estratégia de predição implementada (baseada em histórico de acesso ou não) e, caso seja baseado em histórico, de um ou de vários usuários, qual o modelo/algoritmo preditor utilizado [Bes 1995; Pad 1995]. Além desses fatores, um aspecto que direciona as abordagens de pesquisas em pré-busca é o cenário em que será empregada [Kro 1997; Fan 1999]: cntre cliente e proxy, entre proxy e servidor e entre cliente e servidor. Dada a correlação entre cache e pré-busca, esses cenários são estudados conjuntamente com as localizações e topologias de caches na Web (seção 2.2.2).

Fora do contexto da Web, pré-busca tem sido cstudada extensivamente em Sistemas Operacionais (ex.: sistemas de arquivos) e em hardware (ex.: hierarquias de memórias de processador), de onde se extrai grande parte do conhecimento aplicado no contexto da Web [Pal 1999]. As características particulares da Web, tais como as que diferem cache tradicionais e cache na Web (seção 2.2.2), provocam a necessidade de adequação a essa temática [Kro 1997]. Embora pré-busca possa exercer função mais relevante na Web do que, por exemplo, em hardware [Kha 2001], a Web adiciona complexidade à sistemática. Um exemplo disso é que, em hardware, há pontos de decisão que são meramente bifurcáveis (if-then), e na Web o grau de ramificação é muito alto. Outro exemplo também relacionado a hardware, é que, muitas vezes, todas as ramificações podem ser pré-buscadas em paralelo. Na Web isso é impraticável.

Como visto anteriormente, o protocolo HTTP fornece o suporte de comunicação à Web. A motivação para a atual versão (HTTP 1.1), como proposta de mclhoria da versão 1.0, foi a alta latência na Web, sendo que a nova versão realmente representou um passo importante em direção à amenidade desse problema [Coh 2000, Kri 2001]. Na seção 2.1.2, foram relacionadas as relevantes melhorias incorporadas à última versão, inclusive o suporte ao uso de cache. Porém, em termos de pré-busca, o HTTP mostra-se ainda deficiente. Alguns estudos como os de Padmanabhan \& Mogul [Pad 1996], Lee [Lee 1996], Duchamp [Duc 1999] e Davison [Dav 2001], sugerem inclusões e/ou modificações para viabilizar o suporte para implementação das diversas estratégias de pré-busca na Web. Por exemplo, Duchamp sugere a inclusão de um novo cabeçalho, denominado Prefetch, que funcionaria de forma análoga a técnica de piggyback. $\mathrm{O}$ novo cabeçalho é incluído nas requisições e respostas para passar informação de uso de recurso pelo cliente e recursos sugeridos para pré-busca pelo scrvidor. Já Davison sugere a inclusão de 
uma nova versão para o método GET, denominado GET2 no qual é inserido um cabeçalho denominado GET2-Constraint. As novas propostas tentam endereçar problemas de segurança na utilização de pré-busca como, por exemplo, evitar que se faça a pré-busca de um documento excessivo (supera um parâmetro chamado max-size) ou prevenir a pré-busca de um documento que é atualizado rapidamente (não atende ao parâmetro denominado min-fresh).

Como ver-se-á adiante, mesmo com a identificação das necessidades de melhoria no protocolo de comunicação, as pesquisas indicam formas de implementar pré-busca de maneira satisfatória.

\subsection{Latência}

Os fatores característicos determinados pelo congestionamento causado pelo crescimento da Web são os atrasos de recuperação de seus objetos. Os elementos que influenciam no tempo de recuperação dos documentos Web são: a largura de banda de rede, atraso de propagação, perda de dados, e a carga nos clientes e nos servidores [El-1998].

Latência é um termo genérico que define um "periodo de inatividade entre um estímulo $e$ a resposta por ele provocada". Na literatura de pré-busca, encontram-se definidos diversos tipos de latência. Como visto na seção 3.1, a latência percebida pelo usuário inclui o período em que o usuário fez uma requisição, recebeu a resposta correspondente e a processou para que pudesse ser visualizada [Coh 2000]. Ela é, genericamente, chamada de latência de recuperação.

A latência de operações de recuperação corresponde ao período de transmissão da requisição, do processamento no servidor e da transmissão da resposta. Assim, essa latência depende do desempenho dos servidores e da latência da rede. Os servidores precisam de algum tempo para processar uma requisição, ou talvez recuse aceitá-la devido à sobrecarga. A latência da rede também é chamada de latência de comunicação, e depende do congestionamento da rede e do atraso de propagação. Enquanto o atraso de propagação é um componente constante, o qual não pode ser reduzido, o congestionamento pode ser minimizado com o aumento da largura de banda, que é constantemente aumentada com a ampliação das capacidades das redes e com a instalação de novas redes [Wan 1996; El- 1998]. 
Se o modelo de rede de computadores de uma organização possui um servidor proxy, pode-se dividir a latência da Web em duas componentes (figura 3.1): latência externa, causada pela latência de rede e pelos servidores externos à organização, c latência interna, causada pcla rede e computadores internos às fronteiras da organização. Essa perspectiva facilita a identificação das características de latência. A mais significativa delas, apontada em estudos que promovem a separação da latência nas duas componentes, está no fato de que o percentual de latência externa, em relação ao total de latência de acesso, é dominantemente maior [Kro 1997; Che 2001].

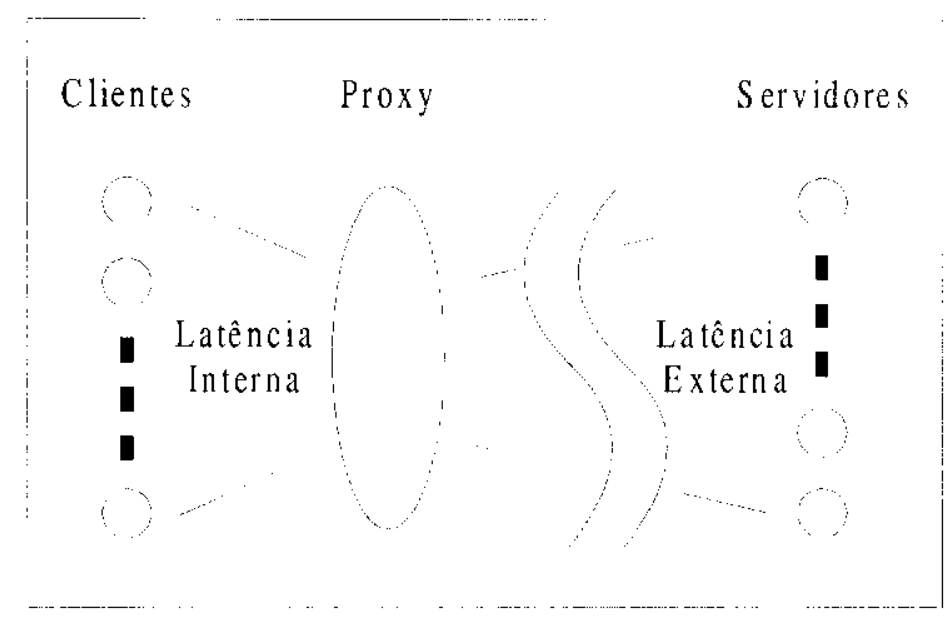

Figura 3.1 - Configuração típica envolvendo um proxy, separando a latência em duas componentes [Kro 1997]

\subsection{Pré-Busca e Cache na Web}

Desde o surgimento da Web, seus perfis de acesso, scus objetos e sistemas de provimento de informações têm se diversificado e vêm mudando com o passar dos anos, e isso tem causado impacto nos sistemas que provêem sua infra-cstrutura [Pal 1999, Kri 2001]. Embora cache venha sendo amplamente utilizado para reduzir efetivamente a latência, estudos apontam que as taxas de acerto vêm diminuindo significativamente [El- 1998; Bar 1999; Che 2001], atribuindo-se a isso: (a) o fato do surgimento $\mathrm{c}$ aumento do número de objetos Web, principalmente dos que não são geralmente armazenados no cache, tais como cookies, páginas dinâmicas, etc.; (b) aumento do tamanho dos objetos Web, cm que o tamanho do cache acaba limitando o número de objetos 
que podem ser armazenados; e (c) a diversidade dos tipos de site, implicando em variações de acesso.

Essa diminuição da taxa de acerto agrava os limitados benefícios do uso de cache na Web. Diz-se que são limitados, porque as taxas de acerto atcndem, tipicamente, entre 30 a $50 \%$ das requisições [El- 1998; Coh 2000; Dav 2001], enquanto caches tradicionais atendem 90\% [Wil 1996]. Pré-busca mostra-se complementar ao mecanismo de cache, podendo melhorar significantemente seu desempenho, já que aumentará a taxa de acerto de acordo com a eficiência de sua predição. Isso é claramente observado quando um usuário requisita um objeto que já foi pré-buscado, e este está prontamente disponível no cache [Pal 1999].

\subsection{Estratégias de Implementação}

A principal questão de pré-busca está em decidir/predizer o quê e quando pré-buscar. Há um grande número de situações de pré-busca implementadas no contexto Web, e as diversas propostas de métodos e mecanismos encontrados nessas pesquisas podem ser, em geral, agrupadas da seguinte forma [Wan 1996; El- 1998]:

- Pré-busca baseada em preferências pessoais do usuário. Trata-se dos mecanismos que implementam formas dos clientes escolherem quais informações querem receber. Existem dois segmentos de implementação. No primeiro, conhecido como tecnologia Push (de "Push Delivery of Information"), os usuários inscrevem-se em "canais" de interesse, estabelecendo um perfil de opções. Quando o programa é executado, o mecanismo de pré-busca contata o servidor especificado pelo(s) canal(is) de informações e adquire todos os objetos necessários para que o usuário possa navegar desconectado (off-line). O usuário não tem que requisitar ou buscar manualmente as informações, e sua real utilização fica prejudicada, já que o que normalmente ocorre é que o usuário seleciona apenas parte das informações dentro do conteúdo total que foi pré-buscado. Um aspecto comum a esses tipos de mecanismos é que há rápida atualização do conteúdo desses canais, provocando um dos seus principais fatores apontados como efeito colateral. Quando esse mecanismo se tornou popular, chegou a congestionar redes corporativas com muitos usuários dessa tecnologia, porque, além de pré-buscar as informações, verifica constantemente se há atualizações no conteúdo. 
No segundo segmento, normalmente chamado de pré-busca determinística ou informativa, a pré-busca também é configurada de forma estática pelos usuários, contudo, é mais específica que a do segmento anterior. Fazendo-se uma analogia, no primciro segmento o usuário especifica quais os canais assiste em uma TV e, no segundo, quais os programas de TV. Na prébusca determinística, o usuário configura quais os documentos quer receber dentre os que poderiam ser acessados manualmente através de um navegador (por exemplo, pode determinar o recebimento diário das páginas das seções de esporte e política de um jornal on-line, deixando-as disponíveis no cache para que se possa acessá-las desconectado). Ela representa o tipo mais "conservativo" de pré-busca, já que, freqüentemente, ocasionam pouca ou nenhuma sobrecarga na largura de banda, embora tenha um escopo de uso limitado, já que o usuário precisa saber e determinar o que será pré-buscado.

- Pré-busca com predição não-estatística. Corresponde às formas de implementação com menor sofisticação. Normalmente, pré-buscam todas as páginas referenciadas em um documento HTML requisitado pelo cliente, executando uma pré-busca dita "agressiva". Principalmente nos primórdios da Web, em que se tinha documentos simples sem muitos objetos agregados, esse tipo de pré-busca tinha uma maior eficácia, mais ainda assim era insuficiente por não executar uma predição especulativa. Ela resultava em melhora na latência percebida pelo usuário, mas tornar-se-ia inviável se fosse genericamente implementada, dada à sobrecarga na infra-estrutura total da Web.

Atualmente, alguns produtos comerciais (os próprios navegadores ou acessórios acoplados a estes) implementam essa opção, todavia com alguma mancira de se controlar determinadas op̧̧ões, tais como escolher quais os tipo de objetos que se quer pré-buscar, a partir da página corrente, como é exemplificado na figura 3.2. Outros já começam a implementar algum fator especulativo, contudo, ainda simples e ineficientes (ex.: PeakJet2000 ${ }^{1}$ ). Vale notar que estas implementações são normalmente úteis em conexões clientes feitas por modems, em que se aproveita o seu tempo ocioso.

- Pré-busca com predição estatística. Baseia-se nos acessos passados do(s) usuário(s) para prever os acessos futuros, observando a probabilidade de uma mesma sequiência de passos executada anteriormente, volte a ser novamente seguida. As técnicas dessa estratégia exploram o fato de que os usuários não acessam os documentos de forma aleatória c, embora o padrão de

\footnotetext{
${ }^{1}$ http://www.peaksoft.com/techpeakjet3.html
} 
acesso dos usuários não pode ser determinado exatamente, pode se ter uma noção dos próximos documentos que provavelmente seguirão o documento atual. Normalmente, essa classe de prébusca é chamada de especulativa porque realmente investiga o que deve ser pré-buscado, ao contrário das outras estratégias. Estas técnicas abrangem o maior número de pesquisas, porque visa uma forma eficiente de pré-busca, na qual não há intervenção direta do usuário.

O agente que realmente realiza a pré-busca é um cliente (browser ou proxy). Contudo, de acordo com qual parte está mais envolvida para fornecer as informações necessárias para a estatística, os diferentes gêneros de pré-busca especulativa podem ser classificados nas seguintes categorias [Kro 1997; Pal 1998; Che 2001]:

- Baseada no Cliente/Proxy. Bascia-se no comportamento de navegação de usuário(s) específico(s) em diversos servidores Web, sendo a informação relevante reunida no lado do cliente. Pode tanto ser feita tendo por base um usuário (um modelo para cada usuário), ou para uma comunidade de usuários (modelo baseado $\mathrm{cm}$ um servidor proxy). Nesse modelo, a precisão da predição fica limitada, porque ainda não se tem os dados do servidor global.

- Baseada no Servidor. Baseia-se no comportamento de todos os usuários acessando um servidor Web específico. O processo central de pré-busca é realizado no servidor, em que esse é quem fornece as informações de acesso dos usuários. A grande vantagem de basear-se no servidor é que o mecanismo de prébusca aproveita a fusão das seqüências de referências (concernente às mesmas páginas) de um grande número de clientes. Todavia, a desvantagem está na necessidade de frequientes comunicações entre cliente/proxy c os scrvidores (adiciona comunicações extras ao processo de predição).

Embora a união desses dois fatores juntasse as vantagens de ambas abordagens, a implementação seria complicada, porque requer modificações nos dois lados e possivelmente implicaria em problemas relacionados à perda de privacidade [Fan 1999].

Resta salientar que, dependendo de vários parâmetros e ajustes baseados $\mathrm{cm}$ probabilidade, pode-se optar por uma configuração agressiva ou conservadora [Fan 1999], permitindo avaliar o equilíbrio entre custo e benefício da pré-busca. 


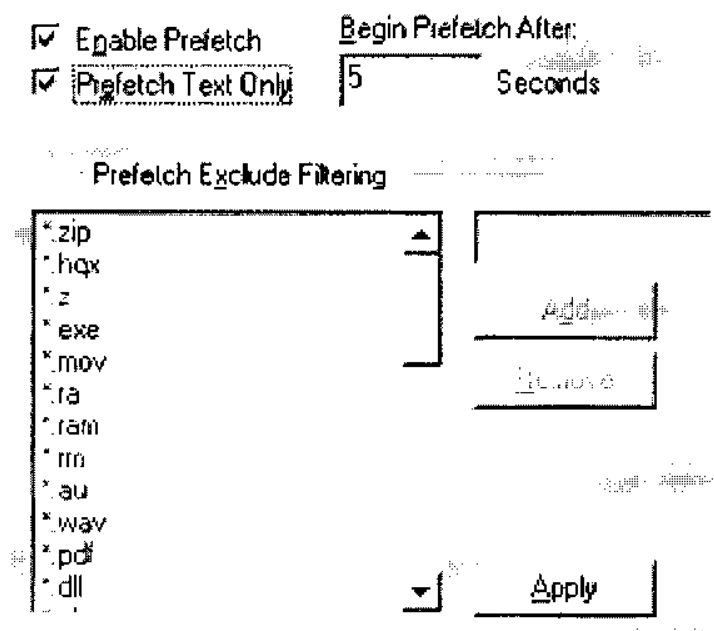

Figura 3.2 - Parte de uma captura de tela que apresenta as opções de pré-busca em um navegador

\subsection{Modelo de Contexto / Algoritmo PPM}

A maneira adequada de se realizar a predição irá implicar diretamente na eficcácia da prébusca, resultando em redução da latência percebida pelo usuário. Os algoritmos de predição fornecem a base da implementação, especialmente nas abordagens estatísticas de pré-busca. A precisão do modelo de implementação escolhido é o fator determinante para o sucesso da prébusca [Pal 1999; Nan 2001].

Alguns modelos utilizados para conduzir um sistema de pré-busca também são encontrados na literatura de compressão de dados, visto que a idéia principal utilizada nos algoritmos de compressão é proveitosa para a predição [Cur 1993; Pal 1999]. Os trabalhos de ambos, compressão e predição, dirigem-se a um mesmo objetivo, que é a predição do próximo clemento cm uma sequiência particular [Pal 1999]. A compressão busca estabelecer modelos para gerar uma probabilidade de distribuição de elementos nos dados (por exemplo, elemento = string, $\mathrm{c}$ dados $=$ texto), para que os elementos com maior probabilidade de ocorrência sejam codificados com poucos bits, e aqueles com menor probabilidade com mais bits. A predição pode, da mesma forma, estabelecer tais modelos para pré-buscar as páginas com maior probabilidade de screm acessadas (elemento $=$ acesso, e dados $=$ seqüiências de acessos).

Um algoritmo universal de compressão/predição que tem apresentado melhor desempenho em ambos os casos [Vit 1991; Kri 1994], é o Prediction by Partial Matching (PPM) 
[Cle 1984]. Originalmente, o algoritmo PPM data compressor consiste de um preditor para estimar a probabilidade dos elementos e um codificador aritmético para efetuar a compressão [Mud 1996]. Porém, no contexto de pré-busca, é de interesse apenas o componente preditor.

PPM concentra a maior parte da implementação de pesquisa de predição. Em termos práticos, ele normalmente supera a performance de outro algoritmo de compressão bastante difundido, o Lempel-Ziv (LZ) [Cur 1993]. A principal característica, que distingue e favorece o algoritmo PPM em rclação ao LZ, está na construção do modelo de predição, fazendo com que o LZ convirja lentamente para um bom desempenho, enquanto o PPM oferece melhor performance mais prontamente.

\subsubsection{Construção do modelo}

Em um sistema dinâmico isolado, por exemplo, com $N$ partículas em movimento, se em um instante $t$ qualquer tem-se informação suficiente de algumas propricdades destas partículas, tais como posições e velocidades, pode-se antever a evolução do sistema sem que scja necessário saber todos os estados anteriores, nem quando e em que circunstâncias cada uma delas entrou em movimento. Nesse exemplo, pode-se determinar o próximo estado do sistema a partir de seu cstado atual, que contém toda a informação relevante. Analogamente, em probabilidade esse estado é chamado de markoviano ou que tem a propriedade de Markov [Thi 2001].

As bases de um algoritmo PPM dito de ordem $m$ são um conjunto de até $(m+1)$ preditores Markov para determinar o próximo passo de uma seqüência em particular, a qual, no contexto Web, é a seqüência de acesso de um cliente. Um preditor Markov de ordem $j$, em uma seqüência $x$ de elementos, usa estatística de contexto de comprimento $j$ na sequiência $x$, para realizar suas predições para o próximo elemento. Ele baseia-se nos $j$ elementos imediatamente anteriores à posição atual, e verifica quais elementos e quantas vezes eles ocorrem após essa mesma cadeia dentro de $x$. Um PPM de ordem $m$ mantém preditores Markov de ordem $j$ para todos $0 \leq j \leq m$. Dessa forma, o PPM pré-busca os elementos com maior probabilidade, dando prioridade aos preditores de mais alta ordem.

A figura 3.3 apresenta um exemplo para ilustrar a idéia básica do funcionamento de um preditor Markov em uma seqüência simples. Supondo a seqüência da figura 3.3 e $j=2$, o 
próximo elemento é predito baseado no contexto atual, ou seja, nos últimos $j=2$ elementos da sequiência: $B A$. Na sequiência inteira, $B A$ precede o elemento $A$ apenas uma vez, e precede o clemento $B$ duas vezes. Assim, $A$ é predito com a probabilidade $1 / 3$, e $B$ é predito com a probabilidade $2 / 3$.

\section{$A \subset$ B $A(A)$ B $A(B) A(B) \subset$ \\ j últimos elementos}

Figura 3.3 - Exemplo do processo de contextualização de um preditor Markov em uma seqüencia simples

Quando não há um padrão anterior (um "padrão" significa que a cadeia aparece pelo menos uma vez na seqüência) referente aos $m$ últimos elementos, PPM usa os $(m-1)$ clementos imediatamente anteriores para encontrar o mais próximo preditor Markov de ordem $(m-1)$. Ele permanece nessa tentativa, decrementando o número de elementos imediatamente anteriores, até achar um preditor que possa ser utilizado. Quando $j$ chega a ser igual a 0 , o próximo elemento é predito baseado no número de vezes que cada elemento aparece na seqüência. Retomando o exemplo da figura 3.3 , caso não existisse a cadeia $B A(j=2)$, ele se basearia no elemento $A(j=$ 1) e, caso não ocorresse esse elemento anteriormente na seqüência $(j=0)$, prediria o elemento de maior freqüência.

A implementação de PPM é executada $\mathrm{em}$ um servidor que atende as requisições de vários clientes, centralizando em si as informações desses acessos. Assim, se $A, B$ e $C$, são três páginas $W e b$, e há o contexto $\{A B C\}$, essa sequiência de páginas foi acessada por pelo menos um dos clientes. Para os modelos de contexto baseados em PPM, a estrutura de dados utilizada é uma variação da estrutura conhecida como "árvore digital". Em um processo markoviano tal qual o modelo PPM, o sistema não "memoriza" as informações que permitiriam reconstituir os estados anteriores ao cstado alcançado. Dessa forma, a árvore que implementa o modelo markoviano não guarda a seqüiencia de acesso dos usuários propriamente dita, mas sim a estrutura necessária para determinar a probabilidade de se acessar determinada(s) página(s), visto que armazena a freqüência de ocorrência das seqüências de requisições.

A figura 3.4f apresenta um exemplo de árvore para um modelo preditor baseado $\mathrm{cm}$ PPM, construída a partir de duas seqüências de acessos: $A B C A C B D$ e $C C A C B C A$. Uma possível 
situação que poderia originar esse exemplo scria a colcta das sequiências de dois usuários em um proxy, a fim de predizer seus futuros acessos, a partir da análise da conjunção de seus perfís de acessos. Na maioria das implementações, a raiz apenas agrupa as subárvores cujas raízes realmente representam um acesso (na figura 3.4, tal raiz é $R$, e o nível seguinte representa acessos reais). A profundidade da árvore, considerando-se apenas os nós efetivos (excluindo $R$ ), é igual a $m+1$, sendo $m$ a ordem do PPM (na figura, o PPM é de ordem 2 e tem $m+1=3$ níveis efetivos). Cada percurso da árvore, saindo da raiz até um nó específico, reconstitui uma cadeia de acesso que, na verdade, é um contexto de comprimento igual à profundidade do nó. À medida que tal percurso é realizado, pode-se saber quantas vezes essa cadeia de accssos ocorreu na sequiência de acessos de um ou de vários usuários (seção 3.5.2). A estrutura em árvore favorece a combinação de contextos de diferentes comprimentos, já que qualquer contexto de comprimento $j$ contém todas as informações requeridas pelo seu contexto de comprimento $j-1$ correspondente.

Como é sabido, um contexto atual de comprimento $j$ expressa os $j$ últimos eventos da seqüência de acessos. Então, um novo evento, i.e., a próxima página acessada na sequiência, é adicionado ao modelo seguindo dois passos básicos:

1) Para cada contexto atual de comprimento $j$ verifica-se se algum dos nós filhos representa o novo evento (nova página);

2) Sc tal nó existe, ou seja, a mesma sequiência já fora realizada em outro momento, incrementa-se o número de ocorrências para esse contexto. Em caso contrário, cria-se um novo nó filho, e prossegue-se com a mesma operação até que todos os contextos sejam atualizados.

Retomando os passos ilustrados na figura 3.4, pode-se acompanhar um exemplo de como o procedimento acima constrói o modelo. Supondo que o modelo de ordem 2 está vazio inicialmente, e dois usuários realizam seus accssos simultaneamente (usuário 1 : $\triangle B C A C B D$ e usuário 2: $C C A C B C A$ ). Num momento inicial, o único contexto disponível é o de ordem 0 , o qual é representado pelo quadrado pontilhado que envolve a raiz $\mathrm{R}$ (figura 3.4a). Assim, o clemento $\underline{\mathrm{A}}$, o primeiro acesso na sequiência do usuário 1 , se torna o filho de $\mathrm{R}$ e, ao mesmo tempo, o contexto de ordem 1 (figura 3.4 b). Nota-se que o novo contexto de ordem 0 é (e sempre será) o nó raiz. Quando o usuário 2 começa seu acesso, o elemento $\underline{C}$ é introduzido no modelo de forma semelhante ao elemento $\underline{\mathrm{A}}$ do usuário 1 (figura 3.4c). No segundo acesso do usuário 1 , o clemento $\underline{B}$ é introduzido e todos os contextos são atualizados um após o outro (figura 3.4d). Visto que não há filho rotulado $\operatorname{com} \underline{B}$ em qualquer dos contextos visto até aqui, dois nós filhos 


\section{R}

(a)

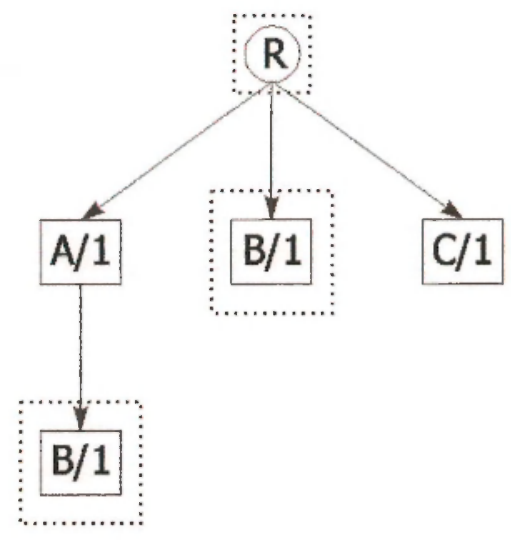

(d)

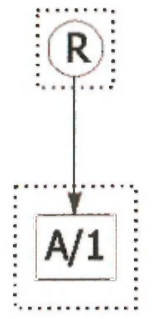

(b)

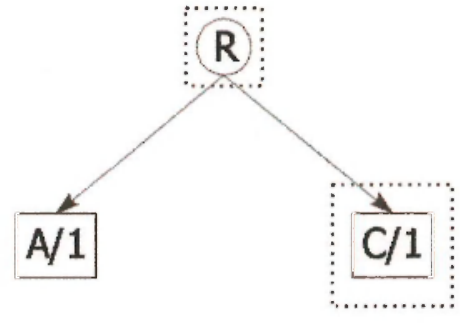

(c)

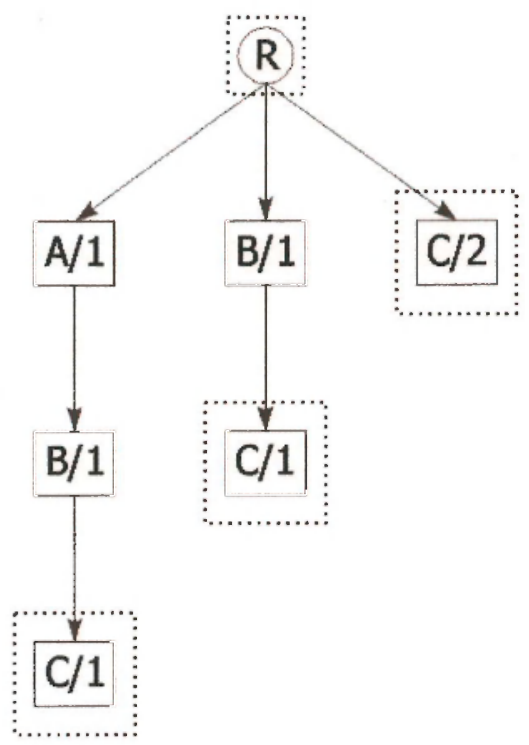

(e)

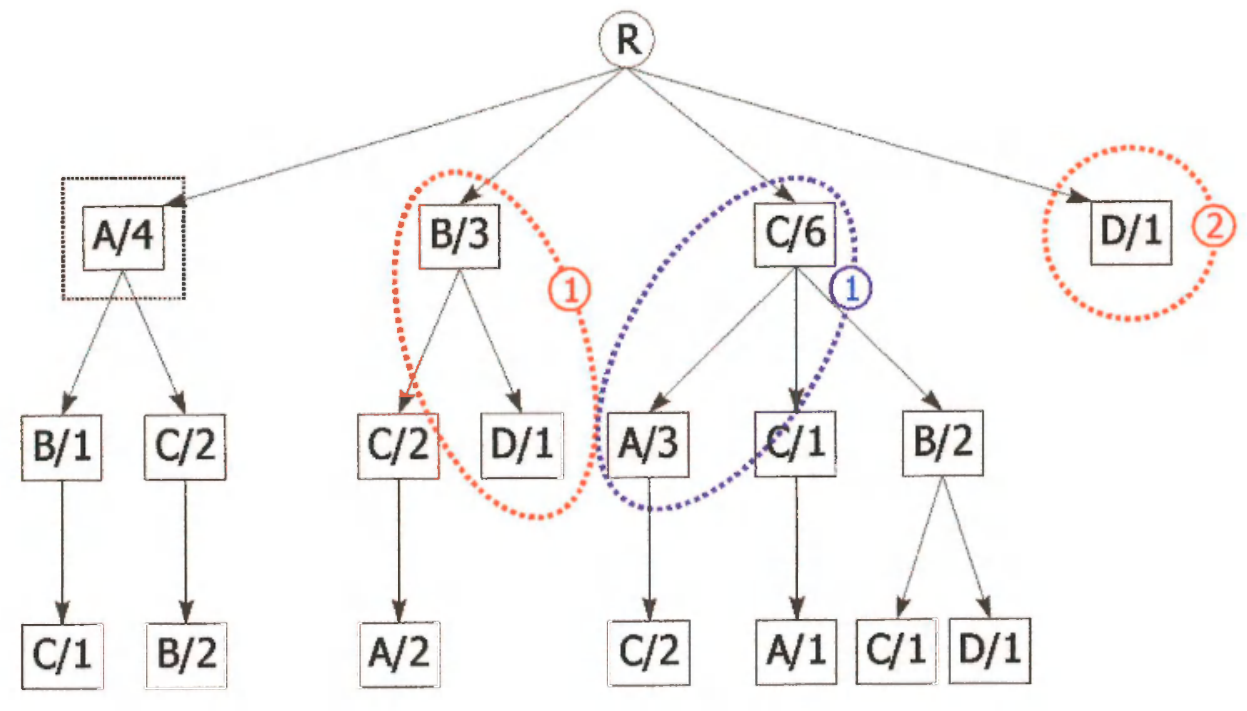

(f)

Figura 3.4 - Exemplo de processo de contrução de árvore para um modelo preditor baseado em PPM, construida a partir de duas sequências de acessos $(A B C A C B D$ e CCACBCA). Destaques em vermelho sinalizam os passos do processo de predição para a próxima página da sequência $A B C A C B D$ e, em azul, para a seqüência CCACBCA 
são criados, um para cada um dos contextos existentes. Quando o usuário I faz o seu terceiro (clemento $\underline{\mathrm{C}}$ ), são criados dois novos nós para os contextos novos, e o contador de um nó é incrementado, já que esse contexto já estava presente na estrutura (figura 3.4e). Esse processo continua até que todas as seqüências sejam processadas e armazenadas na estrutura (figura 3.4f).

$\mathrm{Na}$ estrutura completa, nota-se que as folhas não podem corresponder a um contcxto já que não há outro evento que as siga. Nota-se também que nem todos os ramos da árvore têm a mesma altura.

Na implementação apresentada acima, o processo de construção/atualização na árvore é feito imediatamente, processando a atualização à medida que os usuários realizam seus acessos, ao passo que pode também prover predições a acessos futuros de forma simultânea. Contudo, há várias formas de se implementar a construção/atualização na estrutura. Uma delas, que facilita esse processo, utiliza uma cstrutura auxiliar que guarda a trilha de contexto atual de comprimento $j$, para $0 \leq j \leq m$, de cada usuário, e depois repassa esses dados para a estrutura. $\mathrm{O}$ algoritmo apresentado na figura 3.5 esboça essa variação na construção do modelo.

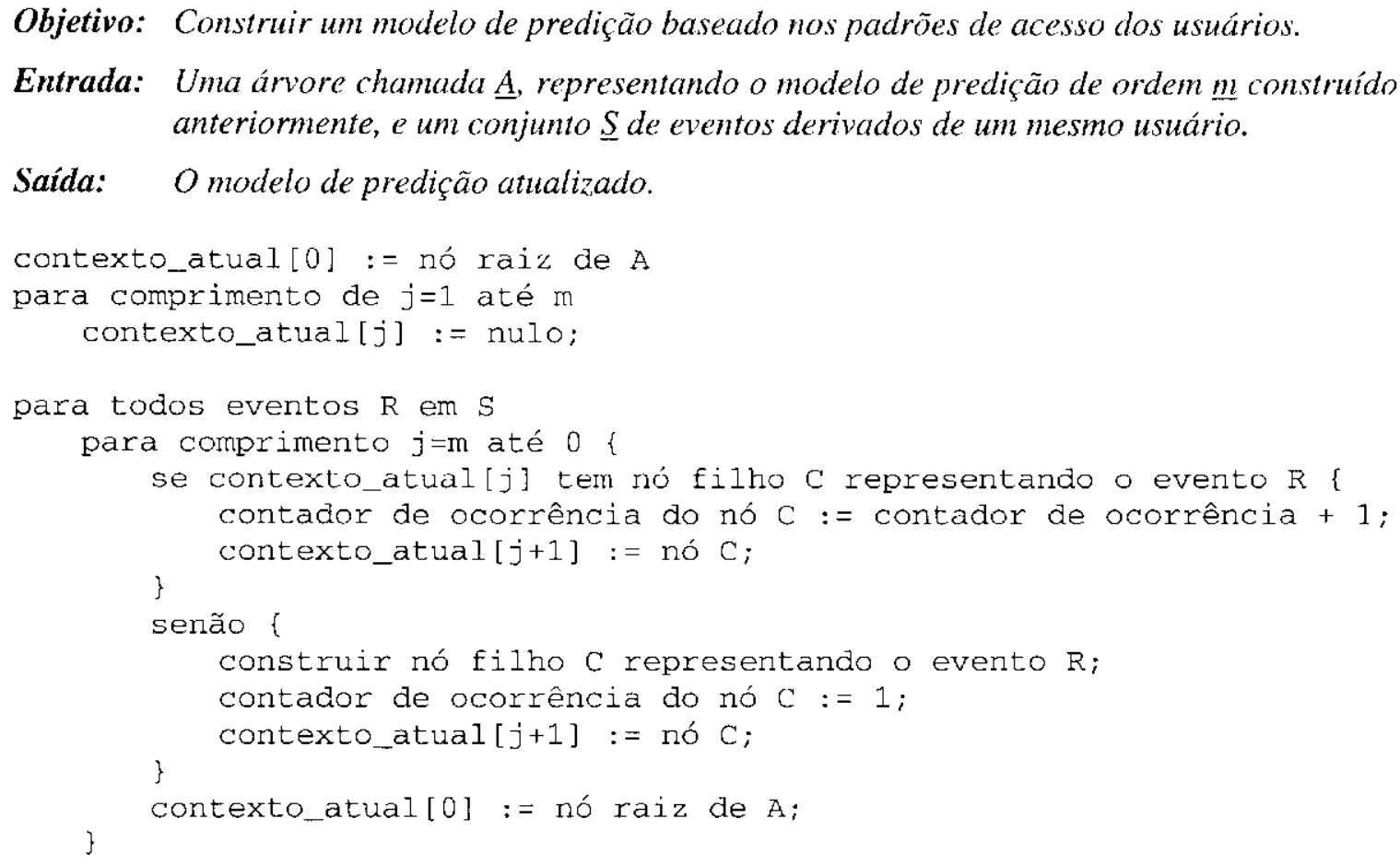

Figura 3.5 - Algoritmo para construção/atualização do modelo de predição, utilizando uma estrutura anxiliar [Pal 1998] 
Outras formas de implementar a atualização dizem respeito à política adotada no processo de atualização. De maneira mais genérica, cada novo accsso gera atualizações $\mathrm{cm}$ cada nível da árvore, um para cada preditor Markov, scja pela atualização de contador, seja pela adição de novo nó. Em um exemplo de abordagem mais específica, a update exclusion atualiza somente o preditor (nível) que realizou a predição e o preditor com a maior ordem $(m)$ - os preditores intermediários não são atualizados.

\subsubsection{Realizando Predições}

A pré-busca baseada em modelos que descrevem os padrões de acesso dos usuários, pode realizar predições para requisições futuras utilizando algoritmos de predição que adotam diferentes procedimentos para isso. Mesmo assim, todas as variações dependem do cálculo e comparação da probabilidade de um certo evento ocorrer da próxima vez. Estas probabilidades são derivadas do númcro de vezes que cada evento já fora observado anteriormente. Algumas alternativas que csboçam variações dos algoritmos são:

- Selecionar eventos somente de contextos de ordens mais altas, quando possível;

- Combinar predições a partir de muitas ordens;

- Atribuir diferentes níveis de confiança para várias ordens de contexto;

- Escolher acima de $k$ eventos para pré-buscas, onde $1 \leq k \leq k_{\max }$.

Quanto mais limitações o algoritmo impõe, mais predições precisas cle irá produzir. Em um caso extremo, ele pré-buscaria todos os eventos possíveis indicados pelo modelo. Entretanto, essa abordagem não é realista desde que o aumento considerável do tráfego da rede seria um fator restritivo. Então, evidencia-se a necessidade de equilibrar entre as pré-buscas corretas esperadas e a largura de banda disponível.

Efetivamente, quando um contexto de ordem $j$ é usado, o pré-buscador está realmente realizando predições baseadas nos $j$ acessos anteriores daquele cliente. Então, o modelo está limitando implicitamente os eventos possíveis que scguirão. Como visto, quando o contexto de ordem $j$ não é suficiente para permitir uma predição, bascia-sc então no contexto de ordem $j$-1. Caso seja necessário, segue-se decrementando até que seja utilizado o contexto de ordem 0 . No exemplo da figura 3.4f, o qual é de ordem 2, a predição do próximo acesso da sequiência "CCACBCA" se basearia no contexto CA (passo azul(1) e, visto que o elemento $\mathrm{C}$ (e somente 
ele) sucede duas vezes esse contexto, esse seria o elemento sugerido como próximo acesso. A sequiência " $A B C A C B D$ " iria se basear nos elementos BD (ordem 2 - passo vermelho(1)), mas essa sequiência não ocorre outra vez a não ser no justo momento da predição. Assim, a predição passa a ser feita no elemento D (ordem 1 - passo vermelho(2)). Já que esse elemento também só aparece nesse momento, a predição seria realizada no contexto de ordem 0 e sugeriria, como já explicado, o elemento de maior freqüência (C).

\subsection{Limitações de Pré-Busca na Web}

O uso de pré-busca tem se mostrado bastante promissor para amenizar o impacto sofrido pelo usuário, originado do crescimento da Web. Porém, possui desvantagens causadas com o aumento da quantidade de objetos que são transferidos, já que, geralmente, é maior que a exigida pelas reais requisições do usuário [Coh 2000; Dav 2001a; Zha 2001]. Pode-se observar que esse aumento de tráfego acaba resultando em excesso de uso de recursos, principalmente quando comparado com à prática de cache apenas [Pal 1998]. Outro efeito colateral bastante mencionado ć o aumento de carga no servidor [Dav 2001a; Zha 2001].

Um consenso entre diversos autores que abordam o tema, é que há a necessidade de se maximizar a precisão do modelo preditor, dado que o tráfego adicional mostra-se inútil justamente quando a predição foi executada de forma incorreta. Esse aspecto é enfatizado mesmo dentre o estudo de pré-busca em sistemas distribuídos e paralelos. A Web, com toda sua diversidade de infra-estrutura e sistemas, possui características especiais que podem limitar ainda mais os benefícios de pré-busca, caso não se atente para uma implementação adequada [Bes 1995; Pad 1995; Pal 1998, Kri 20011. Uma característica desse ambiente é que pré-busca pode ser vantajosa quando clientes navegam em um site com um propósito, isso é, não salta desinteressadamente de uma página para outra, e quando o padrão geral de acesso no servidor não varia radicalmente [Cun 1997; Pal 1998].

Alguns outros problemas atribuídos à pré-busca são os que podem causar erros de execução em serviços ou erros de estatística da Web. No primeiro caso, as requisições efetuadas pela pré-busca podem causar ações indesejáveis, a exemplo de adicionar um item a um carrinho de compras sem que o usuário realmente tenha requisitado (clicado) no link (ferramentas que 
implementam pré-busca aconselham que seja desativada em site de e-comércio) [Dav 2001; Dav 2001a]. No segundo caso, índices utilizados para mensurar popularidade de páginas podem apresentar imprecisão, dado que uma página pode ter sido requisitada na pré-busca, mas não foi realmente utilizada [Dav 2001].

Outras características que devem ser observadas no uso de pré-busca variam de acordo com a adequação da cstratégia implementada. Exemplo disso é que, em uma predição nãoestatística ou em uma predição estatística agressiva, a pré-busca feita a partir de uma página inicial (com muitas opções de caminhos), torna-se inviável, já que aponta para muitos outros documentos que denotem interesses de acessos para perfis de usuários muito distintos [Wan 1996; Pal 1998].

Embora os casos supracitados possam limitar os benefícios esperados, pré-busca pode, comprovadamente, dar substancial melhora de desempenho quando empregada apropriadamente, como scrá visto na seção 3.7. Essa perspectiva reforça a necessidade de pesquisa na busca de manciras que promovam o equilíbrio entre os efeitos colaterais e a redução da latência percebida [Pal 1998; Dav 2001; Dav 2001a; Zha 2001].

\subsection{Trabalhos Relacionados}

O trabalho de Padmanabhan \& Mogul [Pad 1996] foi um dos primeiros relatos em prébusca na Web e é bastante referenciado na literatura. Eles analisaram o custo/benefício entre as limitações de pré-busca, especialmente a sobrecarga na rede, e a diminuição de latência percebida pelo usuário. Eles utilizaram trace de servidores Web e simulação trace-driven, e o algoritmo utilizado é baseado em PPM de ordem 1. A proposta relatada descreve um modelo preditor baseado no servidor (agente preditor), o qual fornece dicas (hints) de futuros acessos ao agente que realiza a pré-busca (cliente). As dicas são enviadas em piggybacking para os clientes.

Piggyback é um conceito habitualmente encontrado na literatura de pré-busca, na qual é definido como um processo de transmissão de informações, não sendo necessário uma conexão explícita para que a informação chegue ao seu destinatário. Por exemplo: o cliente solicita um documento através de uma requisição; em uma pré-busca baseada no servidor, este pode, na resposta à solicitação do cliente, enviar informações adicionais referentes a uma possível pré- 
busca, utilizando uma parte da mensagem de resposta; por sua vez, quando for fazer uma nova requisição, além dos dados relativos ao pedido, o cliente pode mandar adicionalmente a sua mensagem um aviso que um determinado documento pré-buscado obteve êxito [Pad 1996, Kri 2001].

O cliente pode decidir se deve pré-buscar ou não os objetos, ponderando, por excmplo, se a rede conseguirá suportar o tráfego, se o objeto já está no cache, quais os tipos de objeto quer receber, etc. Uma vez que tenha decidido por realizar a pré-busca de um documento, ele envia uma requisição para o servidor, indicando também que ela é uma pré-busca e não uma busca. $O$ servidor pode utilizar essa informação para atualizar o modelo preditor, ou dar pouca prioridade a cssa requisição, para que possa atender as requisições reais mais prontamente.

A acurácia das predições não é reportada, mas eles mostraram que há um razoável equilíbrio entre a redução da latência c o aumento no tráfego da rede. Enquanto dobrando-se a largura de banda reduziria a latência $\mathrm{cm} 20 \%$, a pré-busca pôde reduzir a latência média em $30 \%$, com um aumento de $25 \%$ no tráfego da rede. O estudo mostrou também, que a pré-busca feita de servidores Web para clientes (individuais) pode reduzir a latência $\mathrm{cm}$ até $45 \%$, ao custo de dobrar o tráfego da rede.

Bestavros [Bes 1995] também propôs uma abordagem similar a de Padmanabhan \& Mogul, em que a probabilidade entre o acesso de pares de documentos está associada a uma janela de tempo. Essa abordagem diz-se iniciada no servidor, porque ele envia outros documentos especulados (também usando modelo preditor baseado em PPM) como sendo requisitados em um futuro próximo, em adição ao documento requisitado. Porém, o faz de forma cooperativa, na qual o servidor sabe, trocando informações em piggybacking, o que o cliente tem em seu cache, e só envia o necessário. Ele apresentou resultados encorajadores, em que, causando um aumento de $10 \%$ no tráfego da rede, pôde aumentar em $23 \%$ a taxa de acerto do cache. Além disso, concluiu que, para um melhor ajuste da estatística, pode-se usá-la de forma associada com períodos de tempo, e que a predição é mais efetiva quando feita conservadoramente.

Em 1998, Markatos \& Chronaki [Mar 1998] propuseram uma abordagem mais simples que as duas supracitadas, dado que não implementa algoritmos "sofisticados" para realizar a predição e, sim, uma métrica que os servidores realizam rotineiramente: a de seus documentos mais populares. Dessa forma, não se tem trabalho extra para calcular quais documentos devem 
ser pré-buscados, tirando-se proveito do fato que "documentos populares são muito populares". Os servidores Wcb ou proxies (agindo como scrvidores) enviam seus $n$ documentos mais populares regularmente aos clientes ou proxies (agindo como clientes) mais freqüentes, estabelecendo parâmetros para evitar clientes ocasionais. Os resultados apontaram, para a maioria dos casos, uma efetiva antecipação de $40 \%$ das requisições dos usuários, ao custo do aumento de $10 \%$ do consumo de largura de banda da rede.

O estudo de Kroeger ct al. [Kro 1997] se concentrou cm pré-busca entre proxies e servidores Web, apontando também as diferenças entre latência interna e externa. Eles identificaram limites de alcance da prática de cache e pré-busca em condições idealizadas. Sua conclusão mais notória é que, utilizando um cache ilimitado e um algoritmo ideal de predição, o limite alcançável de redução de latência é de $60 \%$ para clientes que possuem uma banda relativamente alta (acessam a Web em uma LAN $\mathrm{c}$ não $\mathrm{cm}$ um modem). Eles também identificaram uma concentração maior na latência cxterna, cujo percentual chega a $77 \%$ da latência total.

Pré-busca entre cliente c proxy foi estudada por Fan et al. [Fan 1999], observando que grande parte dos usuários da Internet acessam a Web por modems. A abordagem utilizada enfoca pré-busca nesse tipo de conexão, associando-a à técnica Delta-Compression, na qual se transfere somente a diferença entre a página que já está presente no cache e a que está sendo pré-buscada, evitando transferência de dados redundantes. Os autores estabelecem alguns parâmetros ao modelo preditor baseado em PPM, tais como search depth, que define a quantidade de passos que o algoritmo tenta predizer no futuro, e um limiar (igualmente a muitos autores) para estabelecer qual o mínimo de probabilidade que os objetos devem atender para que scjam considerados na pré-busca.

O modelo preditor usa os padrões de referências observados em todos os usuários, para predizer o comportamento de um usuário em particular. Embora isso possa diminuir a exatidão da predição para um usuário individual, pode aumentar o domínio da predição por meio do aumento da amostragem. Fan et al. observaram que, no contexto de sua abordagem, o segundo aspecto (uma maior amostragem) era mais importante, visto que um cache de cliente com tamanho adequado poderia absorver a maioria dos acessos repetidos. Um dos mais relevantes resultados de suas simulações mostrou que a pré-busca, combinada a um grande cache de browser e delta-compression, pode reduzir a latência percebida pelo usuário em $23,4 \%$. 
O trabalho de Chen \& Zhang [4] propõe uma técnica de pré-busca baseada em predição estatística implementando PPM, a qual utiliza como principal fonte de informação os dados contidos em um proxy. Como visto na seção 3.4, utilizar os dados de acesso contidos no servidor Web fornece uma melhor precisão para a predição. Viu-se também que, basear-se somente no servidor, traria a desvantagem da comunicação extra entre o servidor e proxy para que este possa realizar a predição para seus clientes. Diante disso, eles identificaram o limite de eficácia da prébusca baseada somente no proxy e, ao mesmo tempo, aproveitaram também as informações contidas no servidor (de forma coordenada com o proxy). Assim, eles combinam essas duas categorias de fonte de informação e propõem uma técnica denominada coordinated proxy-server.

Foi desenvolvido um simulador para montar múltiplos servidores Web indiretamente conectados aos clientes, já que utilizaram proxies como intermediários entre eles. Para isso, foi construída uma LAN entre cliente e proxy e uma WAN entre proxies e servidores Web. A LAN é uma rede banda larga e baixa latência de rede, com o RTT (Round Trip Time) $<\mathrm{lms,} \mathrm{cnquanto}$ a WAN, embora seja também uma rede de banda larga, possui alta latência, com o RTT $=90 \mathrm{~ms}$.

O algoritmo PPM é implementado em ambos, proxy e servidor. Os modelos PPM são mantidos dinamicamente e são atualizados bascados nos dados de histórico de um intervalo de tempo de 1 dia. Como ambos, servidor e proxy, são elementos ativos na predição, cles realizam as decisões de pré-busca baseados nos modelos PPM e enviam, respectivamente, para proxy ou clicntes, as páginas requisitadas juntamente às páginas geradas na pré-busca.

Para realizar seus experimentos foram utilizados 6 logs de servidores proxy e 6 logs de servidores Web. Na avaliação dos autores, foi comparada a eficiência entre três categorias: a proposta deles (coordinated proxy-server), a pré-busca baseada em proxy c a pré-busca baseada em servidor. Os resultados mostram que, em média, a proposta dos autores obteve um ganho de $85 \%$ na taxa de acerto (hit rate) em relação à pré-busca baseada em cache, e $5 \%$ de perda em relação à pré-busca baseada em servidor. Eles acrescentam que, embora haja essa perda, a taxa de redução da sobrecarga obtida com a diminuição da comunicação entre o proxy e o servidor, foi de $48,6 \%$ para os 6 servidores Web. O desempenho para taxa de acerto baseadas em bytes (byte hit rate) os números se mantiveram consistentes com os da taxa de acerto.

Davison [Dav 2002], em seu trabalho de doutorado, estudou o projeto e a avaliação de pré-busca na Web em conjunto com a Caches Web. Para tanto, destaca-se a construção de um 
simulador baseado em traces, que cstima o tempo de resposta percebido pelo usuário, simulando funcionalidades simplistas de cache e pré-busca em várias localidades de uma rede que compreende clientes, proxies (opcionais) e vários servidores Web. Esse simulador, denominado Network and Cache Simulator (NCS), foi usado para avaliar várias abordagens de pré-busca.

Enquanto a maioria dos simuladores de cache avalia taxa de accrto c largura de banda utilizada, poucos consideram detalhes necessários para estimar tempos de resposta confiáveis (ex.: custo de novas concxões, atrasos próprios do TCP, etc). NCS foi projetado para estimar explicitamentc a latência percebida pelo cliente, por simular latências da rede c os efeitos da presença de caches na rede. Além disso, ele incorpora técnicas de pré-busca que podem ser testadas e avaliadas, principalmente aquelas com preditores de muitos contextos (como, por exemplo, PPM).

Os estudos supracitados são bastante recorrentes na bibliografia de pré-busca. Muitos outros estudos apresentam análises das diversas estratégias, abordagens e contextos de aplicabilidades de pré-busca dentro da Web, ou propõem variações das formas que se pode realizá-la, a exemplo dos trabalhos de Palpanas \& Mendelzon [Pal 1999], de Duchamp [Duc 1999] c Yu \& Kobayashi [Yu 2000].

\subsection{Considerações Finais}

Existe uma vasta bibliografia sobre pré-busca na Web. Como os cenários determinam as localidades $\mathrm{cm}$ que a latência se apresenta, cada estudo inicialmente considera em qual cenário o tema se concentra, a fim de precisar as soluções de acordo com as características do problema. Embora nem sempre o façam de forma explícita, os autores determinam as estratégias de implementação c, caso seja preditora, qual o modelo de predição adotado. Se o modelo de predição for estatístico e for baseado cm PPM (caso da maioria), realizam a apuração da precisão do modelo.

Observando-se a litcratura, pode-se constatar que diversos estudos mostraram características específicas da implementação de pré-busca com predição estatística na Web, tais como: 
- As implementações normalmente não generalizam em propostas que sirvam para LAN e WAN, dada a catcgórica distinção entre as propricdades de cada uma delas, da qual sobressai-se a própria descrição entre as latências da rede (interna e externa);

- A precisão do modelo preditor claramente determina a eficiência da pré-busca, porém a implementação completa do mecanismo de predição envolve não só este fator, mas também a fontc da informação (cliente c/ou servidor) e a amostragem (número, periodicidade, descarte de amostras, etc.);

- Ajustes na agressividade do modelo preditor (controle do limiar da probabilidade) influem diretamente nas características de tráfego da rede $\mathrm{c}$, de forma inversa, na latência percebida pelo usuário.

Resta salientar que as pesquisas relacionadas à pré-busca com predição estatística, basicamente adotam duas abordagens: estudo dos limites quanto aos benefícios que a pré-busca pode proporcionar em condições ditas ideais, e, para simulações em ambientes reais, as relações custo/benefício das implementações em diferentes cenários. 


\section{CAPÍTULO 4}

\section{Simulação de Pré-Busca}

Com o intuito de avaliar os efeitos que a utilização de pré-busca com predição estatística ocasiona na cficácia da prática de cache na Web, este trabalho faz um estudo da pré-busca em diversas situações, com os seguintes objetivos:

- Estudar o desempenho da técnica de pré-busca variando-se diversos parâmetros sua de conliguraçào:

- Estudar a influència da técnica de pré-busca aplicada em diferentes cenários.

Para alcançar esses objetivos, utilizou-se um programa computacional que simula o luncionamento da lécnica de pré-busca, permitindo estimar o descmpenho do modelo de predição através desse simulador. Dentro dos objetivos propostos por este trabalho, fazer uma avaliação $\mathrm{cm}$ ambiente real scria inviável, devido à complexidade da implementação da prébusca estatística na infra-estrutura atual da Web, tanto no lado servidor como no lado cliente. Além disso, todos os trabalhos correlatos estudados utilizam programas de simulação ao invés de experimentação prática.

Este capítulo tem o intuito de apresentar o simulador utilizado como base para o desenvolvimento deste trabalho. A seção 4.1 apresenta os principais softwares de simulação de pré-busca encontrados na literatura, sendo que um deles foi utilizado (com correções e modificações) neste trabalho. Em seguida, na seção 4.2, apresenta-se a arquitetura geral do simulador, discutindo-se cada um dos seus módulos, bem como a interação entre eles. Na seção 4.3 discute-sc os parâmetros de configuração do simulador. Cada parâmetro é definido c 
excmplificado. Na seçio 4.4 são discutidos os principais problemas encontrados no simulador adotado neste trabalho, c quais medidas foram tomadas para sanar esses problemas. Nessa seção também são descritas as modificaçõcs c inclusõcs feitas no simulador, para adaptá-lo ao trabalho descrito nesta dissertação. Na seçăo 4.5, apresentam-sc as métricas utilizadas para avaliar os resultados obtidos neste trabalho de mestrado. as quais são definidas e exemplificadas. Por fim, a seçīo 4.6 traz algumas consideraçòes finais.

\subsection{Softwares de Simulação de Pré-Busca}

Durante a revisào bibliográlica, foram encontrados alguns simuladores para o modelo de predição estudado neste trabalho. os quais poderiam ser utilizados como ponto de partida para o desenvolvimento do simulador usado neste trabalho.

Alguns dos pesquisadores citados na seçâo 3.7 foram consultados sobre 0 desenvolvimento $\mathrm{c}$ a disponibilidade dos programas utilizados em seus trabalhos. Os pesquisadores contatados $\mathrm{e}$ as respostas obtidas foram:

- Fan et al.[Fan 1999]: O simulador é de propriedade da "Universidade de Wisconsin-Madison" e seu código não é disponibilizado;

- Chen \& Zhang |Che 2001]: O simulador não foi disponibilizado pelos autores por ainda estar em desenvolvimento;

- Davison [Dav 2002]: não respondeu ao contato;

- Palpanas [Pal 1999]: disponibilizou o simulador.

O simulador de Palpanas [Pal 1999] foi então utilizado como base, sendo estendido em alguns aspectos de seu funcionamento para a utilização neste trabalho. Várias alterações foram necessárias, incluindo adaptações e correções de erros, conforme explicado na seção 4.4. A arquitetura do simulador utilizado e as modificações que foram necessárias para adaptá-lo a cste trabalho são discutidas nas próximas seções. 


\subsection{Arquitetura do Simulador}

A figura 4.1 fornece uma visào geral da arquitetura do simulador utilizado neste trabalho. O simulador é composto por 4 módulos principais: log, direcionador cliente c unidade de predição. Dentre tais módulos, destaca-se o direcionador como módulo central, responsável pela interação dos demais módulos.

\section{$\log$}

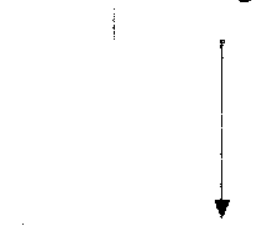

Direcionador

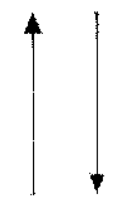

Cliente
Unidade

de

Predição

Fisura 4.1 Arquitetura do modelo de simulaçùo

A seguir, são detalhados cada um desses módulos, discutindo as suas funções dentro do esquema de simulação, assim como a interação entre eles.

\subsubsection{Arquivo de Log}

Um servidor de páginas da Web, seja ele um servidor Web ou proxy Web, normalmente gera um $\log$ como parte do processamento dos pedidos do cliente. Cada entrada do log corresponde a um pedido H'T'P tratado pelo servidor, incluindo informações sobre o cliente solicitante, o horário do pedido c as mensagens de pedido e resposta. O logging (registro em $\log$ ) tem sido freqüentemente empregado na pesquisa envolvida na avaliação de desempenho da

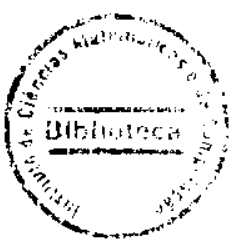


Wcb. Tais logs fornecem informações valiosas sobre os padrões de acesso dos clicntes a um determinado domínio servidor ou proxy [Kri 2001].

Atualmente, nenhum padrăo formal define o formato dos campos de um arquivo de log [Kri 2001]. Todavia, a maioria dos esquemas de proxy e servidor empregados na Web seguem normas não padronizadas para selecionar os dados a serem registrados. Nesse sentido, a definição de log mais usada e accita pela comunidade Web é o Common Log Format (CI.F).

No simulador, os acessos são baseados em logs coletados de um servidor Web ou de um proxy Web. O arquivo de log do servidor Web usado pelo simulador segue o padrão CLF, o qual apresenta os seguintes campos:

- Host: Idenlifica o cliente que enviou a requisição para o servidor. Esse cliente pode ser uma máquina pertencente a um usuário especifico ou um servidor proxy representando o interesse de uma comunidade de usuários;

- Ident: A informação de identidade relatada pelo cliente;

- Authuser: A identificação de usuário (userid) usada quando ć requerido um documento protegido por senha;

- Time: A data e a hora da requisição;

- Request: Requisição enviada pelo clicnte. Ela inclui o método (direcionando o servidor para realizar uma ação específica), a URI da página Web que o usuário está interessado e a versão do protocolo HTTP;

- Status: Código de status de três dígitos que é retornado para o cliente. Contém informaçào sobre o resultado da operação requisitada;

- Bytes: O número de bytes enviados para o usuário, sen incluir os cabeçalhos de mensagem.

A figura 4.2, apresenta um exemplo para ilustrar o trecho de arquivo de log de servidor Web do tipo CLF, que foi utilizado como entrada de dados para o simulador. No exemplo, são mostrados alguns registros, ondc os campos Ident e Authuser são "- -", pois o servidor não registra a identidade remota ou o usuário autorizado. O campo Time contém o dia, mês, ano e a hora local. O "--0200" indica que a hora local está duas horas atrás do (ireenwich Mean Time. 
200.174.145.64 - [08/(0ct/2002:18:36:14 -0200] "GET/centro.css HTTP/1.1" 2002241

200.174.145.64 - - [08/Oct 2002:18:36:15 -0200] "GET/programacao.html HTTP/1 .1" 2007640

200.174.145.64 - - [08/Oct/2002:18:36:20 -0200] "(jET/centrop.css HTTP/1.1" 200838

212.86.241.74 - [08/()c1/20(12:18:36:31 -0200] "GET/outubro.html HTTP/1.1" 2007535

192.112.251.48 - [08/Oct/2002:18:37:01 -0200] "GET/comandos/doswrite.html HTTP/1 .1" 2006492

192.112.251.48 - - [08/()ct/2002:18:37:03 -0200] "GET/tutorial.css HTTP/1 1" 2001921

200.213.70.34 - [08/(Oet/200)2:18:37:08 -0200] "GET/lista.html HTTP/1.0" 2004946

200.213.70.34 - [08/Oct 2002:18:37:08 -0200] "GET/centrol.css HTTP/1.0" 200143

143.I07.239.61 - - [08/0ct/2002:18:37:13 -0200] "GET/cisc.css HTTP/1.1" 2002841

Figura 4.2 Thede do arquire de log do servidor Web utilizado pelo simulador

Em alguns casos, como o de um proxy Web, que atua tanto como cliente quanto servidor, é desejável que algumas outras informaçooes sejam registradas. Como resultado, um proxy pode registrar campos adicionais que não estão disponíveis em um log gerado por um servidor. Para a inclusão de novos campos, além dos campos definidos pelo CLF é usado o Extended Common Log Format (ECLF), cue como o próprio nome diz, é uma extensão do CLF e tem como objetivo adicionar informações àquelas contidas em um arquivo de log de servidor Web do tipo CLF.

O arquivo de log do proxy. Web usado neste trabalho foi obtido a partir do acesso a um scrvidor Squid ${ }^{1}$. Esse servidor define, cm sua concepção, seu próprio formato de log [Squ 2003], o qual não se distingue muito do esquema CLF. Esse formato apresenta os seguintes campos:

- Timestamp: Tempo que o pedido foi completado, em segundos desde $01 / 01 / 1970$;

- Elapsed: Tempo gasto em milissegundos para completar a requisição;

- Client: Identifica o cliente que lançou a requisição para o servidor;

- Action: Descreve como a requisição foi tratada localmente (hit, miss, etc.);

- Code: Código de resposta HTTP retornado pelo servidor Web;

- Bytes: Bytes transferidos do servidor proxy para o cliente;

- Method: Método HTTP (GET, POST, etc.), ou ICP_QUERY para requisições ICP:

- URI: Localização do objeto requisitado;

- Hierarchy: Descrição de como c onde o objeto requisitado foi obtido;

- From: Nome da máquina em que o objeto foi obtido;

\footnotetext{
' O Squid (http:/www.squid-cache.org/) é um programa para criar/manter um servidor proxy, con código fonte disponivel, utilizado na maioria das implementações de proxy na Web
} 
- Content: Tipo de objeto especificado no formato MIME.

A figura 4.3. apresenta um exemplo para ilustrar o trecho de arquivo de log do proxy Web Squid, que após adaptado (capitulo 5), também foi utilizado como cntrada de dados para o simulador deste trabalho. No exemplo, são mostrados alguns registros, onde o campo Iierarchy é “-“, pois esta não é uma implementação de scrvidor Squid hierárquico. Para visualizar melhor, substituiu-se aqui no exemplo o valor real do campo URI pela marca " $<$ URI $>$ ".

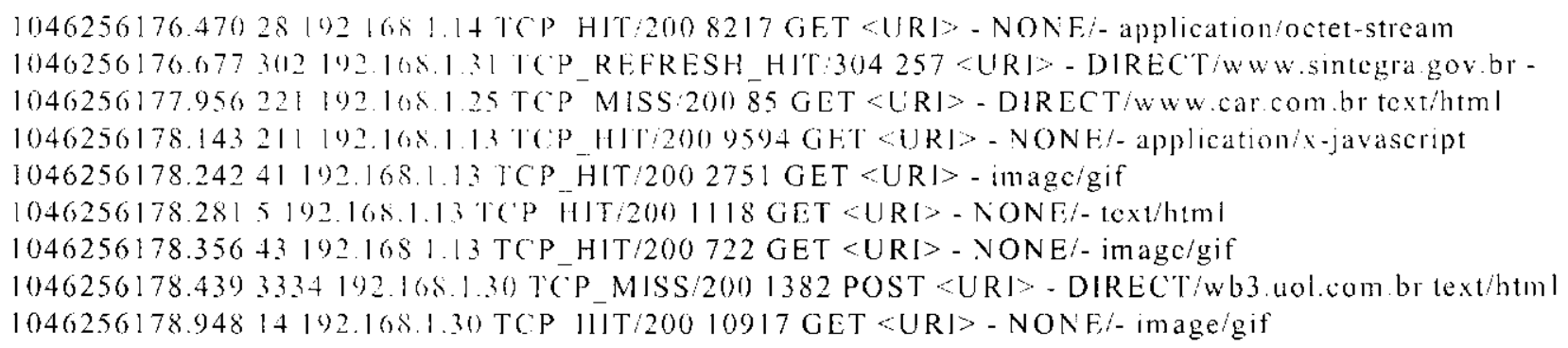

Figura 4.3 Trecho do arquivo de log do proxy web

Os arquivos de log utilizados pelo simulador são divididos $\mathrm{em}$ duas partes. A primeira é usada para iniciar a árvore de predição c gerar dados suficientes para que o modelo de predição tenha condição de gerar pré-buscas. Nessa fase, não se considera a existência de clientes e, logo, não é gerada nenhuma pré-busca. Na segunda parte, com a árvore cheia e a possibilidade de predição de acessos. as requisições do log simulam um ambiente real de pré-busca na Wcb, com clientes lançando suas requisições e obtendo retomo do serviço requisitado - páginas Web, e em adição, as pré-buscas.

Dentro da arquitetura do simulador, as entradas do $\log$ são extraídas através do módulo direcionador.

\subsubsection{Direcionador}

O Direcionador é o módulo responsável pela coordenação dos demais módulos do sistema. Ele interage com os demais e atua como um mediador na comunicação entre eles. Mais especificamente, a operação desse módulo pode ser resumida dentro das seguintes tarefas: 
1. Ler e analisar a próxima requisição registrada no $\log$ até o final do arquivo. Nesse momento, o módulo deve decidir se essa é uma requisição válida para a simulaçào:

2. Rcpassar a requisição, caso ela seja válida, para o mccanismo de predição;

3. Receber a resposta vinda do mecanismo de predição, que consiste da predição propriamente dita:

4. Retornar para o clicnte correspondente o resultado da requisição. A resposta consiste da página requisitada e da predição sugerida pela unidade de predição;

5. Quando a simulaçào termina, reunir e armazenar dados cstatísticos.

Como mencionado na subscção anterior, uma requisição vinda do arquivo de $\log$ pode ter objetivos distintos: ora treinar o modelo, ora simular de fato. Para as requisições que se destinam a treinar o modelo de prediçào, o módulo direcionador segue os passos 1 e 2, pois clas só são usadas para construir a arvore c podem ser ditas como requisições sem pré-busca. Para as demais, as ditas com pré-busca, todos os passos são seguidos, pois nesse caso existe de fato um cliente para o qual será enviada a resposta e possivelmente uma página em pré-busca.

\subsubsection{Unidade de Predição}

A Unidade de Predição implementa o mecanismo de pré-busca. Ela constrói c atualiza o modelo de prediçào de acordo com as requisições fcitas pelos usuários, e oferece as predições de forma independente para cada usuário. O mecanismo de predição em si é, baseado em PPM e segue a descrição feita na seção 3.5 desta dissertação.

\subsubsection{Cliente}

O módulo cliente simula o lado cliente do sistema. Para cada usuário do log (campos host c client) é criada uma instância do módulo. Ele armazcna a página realmente requisitada, bem como qualquer página adicional enviada por pré-busca. Além de funcionar como um cache de browser, cle pode avisar o módulo direcionador caso a página que está sendo cnviada em 
antecipação já esteja armazenada no cache. Dessa forma, uma página que já está armazenada no cache não scrá enviada novamente pela ação da pré-busca.

\subsection{Parâmetros da Simulação}

O simulador, cujos módulos foram descritos nesta seção, necessita da configuração de alguns parâmetros para o scu funcionamento.

Os experimentos mostrados nesta dissertação avaliam o efeito da variação de diversos parâmetros sobre o algoritmo que implementa o mecanismo de pré-busca, os quais são descritos a seguir. A fim de pcrmitir uma melhor compreensão de cada um dos parâmetros, são apresentados excmplos da utilizaçào de cada un deles.

- Ordem do modelo de predição: Especifica o tamanho máximo do contexto que o algoritmo de predição pode assumir (seção 3.5). Por exemplo, para um valor de Orlem igual a 2 , busca-se na árvore de predição a sequiência dos últimos 2 acessos do usuário para sugerir a pré-busca, independente do número de acessos realizados pelo usuário:

- Contudor: Especifica o número necessário de ocorrências do nó atual. Isto é, dada uma página sugerida pelo mecanismo de predição, a pré-busca só ocorre se o número de acessos dessa página for maior ou igual ao valor delinido $\mathrm{cm}$ contador. Por exemplo, a página sugerida pelo modelo foi acessada 3 vezes. A pré-busca ocorre se o valor definido para o parâmetro contador for menor ou igual a 3 ;

- Confiança: Define a razão entre o número de ocorrências do nó atual pelo número de ocorrèncias do nó pai. Tal parâmetro caracteriza um limiar para auxiliar na precisão do mecanismo de predição. Por exemplo, para uma dada seqüência na árvore, tem-se que o nó folha dessa seqüência teve 3 acessos, logo, essa sequiencia teve 3 acessos. Contudo, se o nó pai dessa folha teve 6 accssos, o caminho até a folha foi feito 3 vèes das 6 possíveis $\cdots 3 / 6$ ou $50 \%$. Essa pré-buscá é sugcrida se o valor definido para o parâmetro confiança for $50 \%$ (0.5) ou menor. Caso contrário, essa página não é sugerida pelo mecanismo de pré-buscal; 
- Número de requisiçoes prévias: Refere-se ao número de requisições feitas até o momento por um cliente específico. Com isso, pode-se determinar a partir de quantas requisições começa-se a fazer pré-busca para este usuário. Por exemplo, para um usuário que efetuou 2 acessos, a pré-busca ocorre se o valor definido no parâmetro Nimero de requisições prévias for menor ou igual a 2;

- Tamanho de cache: Determina o tamanho de cache do cliente. Seu valor ć dado en números de páginas em vez de número de bytes. Por excmplo, se o valor definido para o parâmetro Tamanho de cache for 10 , o cache tem capacidade de armazenar 10 acessos de um mesmo usuário sem que seja necessária a ação da politica de substituiçăo;

- Tempo arioso de sessão: Define o tamanho do intervalo de tempo ocioso que determina a quebra de uma sessão. O modelo considera sessões de navegação distintas para um mesmo cliente, ou seja, um mesmo usuário rcaliza seus acessos de tempos em tempos e assim eles são registrados no arquivo de log. Porém, nem todos os accssos são feitos em seqüência, pois alguns acessos podem não ter mais relação com o acesso que o antecedeu. Por exemplo, um usuário acessa um determinado scrvidor de páginas todos os dias pela manhã. Esses acessos estão no log, porém o primeiro acesso de um determinado dia não deve ser considerado como parte de uma seqüencia do último acesso feito no dia anterior, a menos que o valor definido para o parâmetro Tempo ocioso de sessão tenha tamanho suficiente para abranger 1 dia, o que não ć descjado;

\subsection{Métricas de Desempenho}

Para avaliar os resultados obtidos através dos experimentos apresentados nesta dissertação, foram utilizadas métricas de desempenho que quantificam aspectos relacionados ao mecanismo de pré-busca. Fssas métricas são usadas para avaliar o desempenho do mecanismo de pré-busca e são calculadas a partir dos dados retornados pelo simulador. Elas foram escolhidas através de uma pesquisa feita em trabalhos relacionados à avaliaçăo de pré-busca. A lim de permitir uma melhor comprecnsão de cada uma das métricas, são apresentados exemplos da utilização de cada uma delas: 
- Utilidade das Prediçoes (Usefulness of Predictions): A razão entre o número de páginas buscadas $\mathrm{cm}$ antccipação $\mathrm{c}$ de fato requisitadas pelo usuário (ou seja, as páginas que o usuário requisitou e já estavam no cache por causa da pré-busca), c o númcro total de páginas requisitadas. Valor obtido com essa métrica, significa o real benefício percebido pelo usuário com o emprego da pré-busca. Suponha que o usuário tenha lançado 10 requisições e essas tenham gerado 6 pré-buscas. Dessas 6 pré-buscas, 4 foram de fato solicitadas postcriormente pelo usuário. $\mathrm{O}$ valor seriat então $4 / 10$ ou $40 \%$.

- Precisáo das prediçoes (Accuracy of Predictions): A razão entre o número de páginas buscalas em antecipaçào e de fato requisitadas pelo usuário, e o número total de páginas buscadas em antecipação. Valor obtido com cssa métrica, significa o quanto o mecanismo de pré-busca está condizente com o padrão real de acesso do usuário. Suponha que o usuário tenha lançado 10 requisições e essas tenham gerado 6 pré-buscas. Dessas 6 pré-buscas, 4 foram de fato solicitadas posteriormente pelo usuário. O valor seria então $4 / 6$ ou $66,66 \%$.

- Trafego da rede (Nenwork Traffic): A razão cntrc o volume de tráfego gerado na rede quando a pré-busca é empregada, c quando não é empregada. Suponha que a soma dos byles transferidos para o cache pelas requisições reais seja 300 byles, e que a soma dos bytes transferidos pelas requisições colocadas no cache pcla prébusca (independente de utilizadas ou não) seja 225 bytes. O valor seria então $225 / 300$ ou $75 \%$.

- Melhoria da tava de acerto do cache $(H R++)$ : Difcrença entre o incremento no número de acertos do cache quando a pré-busca é utilizada, e o número acertos no cache sem a pré-busca. Essa diferença é normalizada pelo número de acertos do cache sem a pré-busca, para medir qualitativamente o número real de acertos do mecanismo de pré-busca $\mathrm{cm}$ relação a taxa de acerto do cache. Suponha que o total de acertos do cache com a pré-busca seja 15, e o total de acertos no cache sem a pré-busca seja 10 . O valor seria então (15-10)/10 ou $50 \%$.

- Melhoria da laxa de acerto do cache por byte $(B H R++)$ : Diferença cntre o incremento no númcro de accrtos do cache por bytes quando a pré-busca é utilizada. e o número acertos no cache por bytes sem a pré-busca. Essa diferença é nomalizada pelo número de acertos do cache por bytes sem a pré-busca, para medir qualitativamente o número real de accrtos do mecanismo de pré-busca em 
relação a taxa de acerto por bytes do cache. Suponha que o total de acertos do cache por byte com a pré-busca seja 500 bytes, e o total de acertos no cache sem a pré-busca seja 300 byles. O valor seria então (500-300)/300 ou 66,66\%.

\subsection{Correções e Modificações no Simulador}

As seções anteriores apresentaram uma visão geral do simulador utilizado como base para o desenvolvimento deste trabalho de mestrado. Para tornar sua utilização viável e apropriada, foram necessárias algumas correções e modificações nesse simulador.

Como alertado pelo próprio autor do simulador utilizado neste trabalho, a implementação cedida continha problemas. Durante o rastrcamento para solução desses problemas, observou-se que haviam parâmetros de cntrada da simulação que constavam em seu trabalho, mas não estavam implementados nesta versũo, além de outros problemas na estrutura da implementação e erros de código (ex.: alocaçào de memória indevida).

Assim, um processo que, inicialmente, parccia consistir em simples análise da implementação e subseçüente alterações, mostrou-sc demorado por haver diversas inconsistências, tanto na cngenharia, quanto na codificação propriamente dita. Portanto, as alterações foram não só para incluir parâmetros e mćtricas inerentes a este trabalho, mas também para correções de diversos problemas já existentes.

\subsubsection{Correções}

De posse do código lonte, o primciro passo foi tentar compilá-lo. De imediato pode-se identificar algumas das falhas na implementação, como variáveis não declaradas, funções sem seus devidos retornos, chamadas a funções com parâmetros incorretos, etc. que impossibilitavam a compilação do mesmo. leez-se então uma análise no programa para sanar esses problemas. A maior dificuldade nessa fase foi definir o valor apropriado das variáveis. Foi necessário fazer uma análise mais detalhada do programa para garantir que os valores definidos para essas variáveis não interferissem na coerência do programa com as demais partes dele e nem com a 
lógica da técnica de pré-busca. Ao linal dessas correçôes, conseguiu-se executar o programa ainda com uma carga de trabalho ficticia.

Continuando na tentativa de executar o programa, o próximo passo foi submetê-lo a um log real. A execução desta ctapa foi mais longa e dificultosa que a anterior. Já no inicio dela, observou-se a ocorrência de vários crros de alocação de memória (crro comum em programas desenvolvidos através da linguagem $\mathrm{C} / \mathrm{C}++$ ) em pontos diferentes do programa. Utilizou-se então uma ferramenta de depuração de programa (gdb), percorrendo praticamente linha a linha, sendo possível assim observar o comportamento das variáveis (valor, tamanho e tipo), retorno de funções, condição de parada de laços e alocação e liberação de memória. À medida que os problemas cram identificados e solucionados, mais módulos do programa cram pcrcorridos e novos erros surgiam, principalmente de alocação e liberação de memória. Os problemas foram sanados e o código, enfim, executou por completo. Nesse ponto, tinha-se o código rodando, scm a garantia de que ele estava alcançando seu objetivo, de simular um ambiente com cache e pré-busca na Web.

Tornou-se a usal um arquivo de log fictício, elaborado à mão e com poucas entradas. Assim, foi possivel acompanhar o teste manualmente (sem computador) c identificar algum comportamento que não fosse adequado à técnica de cache ou pré-busca. Essa ctapa foi dividida $\mathrm{cm}$ duas partes, onde inicialmente testou-se só a funcionalidade do cache e depois a funcionalidade da pré-busca (trabalhando juntamentc com o cache).

A política de substituiçio implementada pelo criador do simulador foi a LRU (subseção 2.2.4). Porém, tal política nào funcionava corretamente. Havia uma lista dos objetos acessados que representava o cache, ordenada, em ordem crescentc, pcla data de acesso do objeto. Quando o cache cstava chcio, a substituição sempre ocorria no último elemento da lista que, devido a ordem dos objetos no cache, cra sempre o último objeto acessado. A solução adotada nesse caso foi refazer toda a operação de substituição em cache, mantendo a LRU como política adotada.

Com essa correção, a ferramenta passou a funcionar corretamentc quanto ao comportamento do cache, como loi constatado em vários testes. Porém, notou-se outro problema ao introduzir a pré-busca junto ao cache. Quando ocorrc a ação da pré-busca, os objetos colocados no cache nâo são mais somentc as requisições do usuário, mas também os objetos buscados $\mathrm{cm}$ antecipação. No simulador, a árvore de predição é construída armazcnando-se vários dados contidos em uma linha do log, inclusive a data de acesso da requisição. O problema 
é que, quando essa página vem para o cache através da pré-busca, a data de acesso tende a ser antiga em relação às demais requisições armazenadas, como é o caso de uma requisição colocada na árvore ainda na fase de treino da árvore de predição. Assim, como a política de substituição LRU baseia-sc na data do accsso do objeto, algumas decisõcs tomadas na hora de substituir um objeto no cache estavam incoercntes com o comportamento esperado. Esse problema também foi solucionado, com a inclusão de alģumas listas auxiliares, funções para manipular essas listas e instruções do tipo if then else.

Depois das correçôes expostas nesta seção, efetuou-se exaustivos testes, com arquivos de $\log$ fictícios e reais, e o simulador comportou-se como esperado. Outros proccdimentos foram tomados no sentido de tornar possivel a execução ou funcionalidade do software e são mencionados na próxima scção, por serem considerados modificações c não correções. Tais modificações, realizadas para a atualização e adaptação do simulador, são essenciais para o desenvolvimento deste trabalho.

\subsubsection{Modificações}

Com o passar dos anos, pode-se observar algumas mudanças que, naturalmente, ocorreram nas caractcrísticals dos arquivos de $\log$. Com isso, fizcram-se necessárias algumas atualizações no simulador para que o simulador funcionasse corretamente. Uma dclas é relacionada à filtragem de dados sobre as requisições vindas do arquivo de log. Com o passar do tempo novos objetos surgiram na Web e a filtragcm cxistente no simulador tornou-se obsoleta. Essa filtragem e scu objetivo são discutidos no capítulo 5. Outra atualização de mesmo caráter diz respeito à data das requisições, pois o simulador não era capaz de lidar com arquivos de logs que continham requisiçŏes postcriores ao ano de 1999. Para essas requisições, ele considerava o ano de 1970, mantendo corretos os demais dados: horário. dia e mês.

A atualização dá árvore do modelo de predição pode ser feita no decorrer das requisiçõcs feitas pelos clientes (metade do arquivo de log destinado à simulação), c não somente na fasc de iniciação da árvore de predição (metade do arquivo de $\log$ destinado ao treino). No entanto, o simulador não estava atualizando os dados na árvore na medida em que novas requisições eram feitas, ou seja, a predição se bascava na árvore como ela saía da fase de treino e, à medida que as requisições eram efetuadas na fase de teste, a árvore não se atualizava com essas novas 
requisições. Essa adaptaçào loi leita, c na medida em que os clientes encerram suas sessões, suas seqüências de acessos săo transferidas para a árvore de predição.

Os parâmetros de configuração considerados na avaliação da técnica de pré-busca são citados na seção 4.3. Dentre eles, dois foram implementados neste trabalho: confiança e contador. Fles foram encontrados em outros trabalhos corrclatos c considerados relevantes para cste estudo. Fles visam um maior ajuste no modelo de pré-busca, promovendo o cquilíbrio entre tráfego gerado na rede e utilização da pré-busca.

Outra modificação diz respcito às métricas utilizadas para avaliar o desempenho da prébusca, discutidas na seçio 4.5. Dessas, duas foram definidas e consideradas por este trabalho: melhoria da taxa de acerto do cache e melhoria da taxa de acerto do cache por byte. Preocupouse em observar mais diretamente o efeito que a pré-busca causa no cache. Essas métricas já são bastante utilizadas quando se avalia caches, e foram adaptadas aqui, considerando a técnica de pré-busca. Algumas modificaçoes foram feitas no simulador para que fosse possivel fazer tais avaliaçòes.

Como relatado na seçào 3.I. a pré-busca pode ser empregada em diferentes cenários, que são estabelecidos de acordo com a disposição do cache do cliente, que nesse caso é um cache de navegador. Palpanas [Pal 1999] estudou pré-busca quando ela ocorre entre o servidor Web e o cliente. Um novo cenário foi estudado neste trabalho: pré-busca entre proxy e cliente, onde o proxy age como servidor de páginas Web. A motivação para estudar um novo cenário de prébusca e as principais caracteristicas de cada um dos logs são discutidas no capítulo 5 desta dissertação, onde se fà um estudo das características das cargas de trabalho.

Para poder avaliar esses dois cenários por meio do mesmo simulador, sem que scja necessário realizar modifícações em sua arquitetura, converte-se um $l o g$ de proxy Wcb em um log de servidor Web, mantendo-se o mesmo padrão de acesso dos usuários e validade das requisições. Isso é possível pois para cada campo do log do scrvidor, existe um campo no arquivo de proxy corrcspondente. Os demais campos do arquivo de proxy que não tenham correspondência com o arquivo de log do servidor foram descartados. Para fazer essa conversão, implementou-sc um programa que transforma um log de proxy Web em um log de servidor Web considerando-se tais campos. Com isso, a utilização desse log resultante pode ser feita de forma automática pelo simulador, que já é capaz de manipular requisições do tipo de um servidor Web. 
Após as correçòcs c modificações feitas, o trabalho deteve-se $\mathrm{cm}$ avaliar os resultados obtidos através de experimentos com o simulador.

\subsection{Considerações Finais}

Como apresentado na seçio 3.7, há vários trabalhos que objetivam avaliar a pré-busca na Web. Partindo disso, iniciou-se a procura por um simulador que pudesse ser utilizado neste trabalho. Os trabalhos mais relevantes nesse sentido, dos quais tentou-se obter o simulador, foram apresentados na seçio 7.1 , assim como o simulador adotado neste trabalho.

A segunda seçào expôs a arquitetura geral do simulador. Nessa seção, a arquitetura foi discutida considerando-se a funcionalidade de cada um dos módulos que compõcm o simulador, assim como a interaçào entre cles. Mostrou-se, em detalhes, qual a função dos módulos $\log$, cliente e unidade de predição, e como o módulo direcionador faz a mediação na comunicação entre eles.

Continuando a descrição dos aspectos do simulador, na seção 4.3 discutiram-se os parâmetros de configuraçào do simulador. Tais parâmetros são exemplificados no contexto de pré-busca na Web. buscando assim um bom entendimento de cada um deles. Fsses parâmetros são de suma importância para o desempenho de uma pré-busca, como será visto no capítulo 5 , onde são apresentados os experimentos feitos com o simulador.

Após a apresentação dos aspectos do simulador, feita nas três primeiras seções deste capítulo, foi discutido na seção seguinte a metodologia e algumas contribuições deste trabalho quanto a análise, correção e modificação do simulador de Palpanas [Pal 1999].

A discussão feita sobre as correções do simulador, mostram a razão pela qual concluiu-se que, a idéia inicial, que era a de partir de uma ferramenta existente, facilmcnte analisá-la e subseqüentemente adicionar novas funcionalidades a ela, não foi uma tarefa trivial. Muitos problemas foram identificados e resolvidos nessa etapa do trabalho.

Ainda na seçio 4.4. foram discutidas as adaptações e modificações feitas no software, para adaptá-lo às necessidades deste trabalho. Entre as modificações feitas, destacam-se: a inclusão de parâmetros vistos na literatura, mas que não estavam implementados no simulador 
Confiança e Contudor); o estudo da pré-busca, quando aplicada cm outro cenário: (entre o cliente e proxy Web).

Encerrando o capítulo, apresentaram-se todas as métricas utilizadas para avaliar os resultados obtidos nos experimentos sobre a técnica de pré-busca. Tais métricas são definidas e exemplificadas, onde duas delas, Melhoria da taxa de acerto do cache e Melhoria da taxa de acerto do cache por hỵte, não foram vistas em trabalhos correlatos, sendo consideradas, por terem como objctivo principal avaliar, com mais propriedade, o feito da pré-busca sobre o cache, que é um dos objetivos a que se destina este trabalho de mestrado. 


\section{CAPÍTULO 5}

\section{Avaliação de Resultados da Pré-Busca}

Após analisar, no capítulo anterior, o mecanismo utilizado neste trabalho para simular pré-busca na Web, este capítulo, inicialmente (seção 5.I) descreve o processo da geração das cargas de trabalho usadas nas simulações, que foram originadas a partir de arquivos de acessos reais $\mathrm{em}$ dois scrvidores distintos, pontuando suas principais características.

$\mathrm{Na}$ seção 5.2, apresentam-se os resultados obtidos com as simulações realizadas $\mathrm{cm}$ cada uma das cargas de trabalho, demonstrando os efeitos de cada um dos parâmetros que afetam o funcionamento do modelo de predição. A seção 5.3 cnccrra o capítulo discutindo-sc as várias conclusões alcançadas sobre o desempenho da pré-busca na Web.

\subsection{Cargas de Trabalho}

A simulações realizadas neste trabalho foram feitas sobre duas cargas de trabalho distintas, as quais diferem tanto $\mathrm{cm}$ termos do tipo de servidor em que os logs foram coletados como na natureza da organização onde se encontram esses servidores. O primeiro log pertence ao servidor Web do CISC - Centro de Informática de São Carlos, do campus da Universidade de São Paulo -, que registra todos os acessos às páginas do site do CISC. O segundo log pertence ao servidor proxy de uma empresa privada, a W3 - Indústria Metalúrgica L.tda., que registra todos os pedidos de acessos do usuário dessa organização. Vale ressaltar que, inicialmente, outros arquivos de $\log$ com origem e características diferentes foram experimentados e analisados no 
simulador, e escolheu-se adotar esses dois arquivos por serem representativos dos diferentes cenários para a pré-busca, que este trabalho tem como objetivo analisar: entre cliente e servidor Web (representado pelo log CISC), e entre cliente e proxy (representado pelo log W3).

As particularidades dos arquivos de $\log$ são apresentadas na tabela 5.1. Ncla, vê-se que os arquivos são relativamente recentes, sendo que o tempo decorrido desde então não é suficiente para mudanças representativas no cenário da Web. Os tamanhos e os períodos dos logs são hábeis para o processo de análise desejado, já que fornecem quantidades suficientes de requisições para alimentar de forma eficaz o modelo de predição.

A tabela 5.1 apresenta os arquivos de logs em seus estados originais, sem que haja nenhum tratamento ou filtragem de seus dados. As cargas de trabalho originadas desses arquivos através da filtragem realizada são analisadas na próxima seção.

Tabela 5.1-Características dos arquivos de log originários das cargas de trabalho

\begin{tabular}{|l|r|r|}
\hline \multicolumn{1}{|c|}{ Características } & \multicolumn{1}{c|}{ CISC } & \multicolumn{1}{c|}{ W3 } \\
\hline Duração & 182 dias & 28 dias \\
\hline Início & $08 / 10 / 2002$ & $26 / 02 / 2003$ \\
\hline Término & $07 / 04 / 2003$ & $25 / 03 / 2003$ \\
\hline Total de requisições & 760.679 & 287.161 \\
\hline Bytes Transferidos (GB) & 3,41 & 1.07 \\
\hline
\end{tabular}

\subsubsection{Filtragem dos dados}

Os logs de servidores, que originam as cargas de trabalho aplicadas à análise de prébusca, precisam passar por um processo de filtragem dos dados. Essa filtragem se dá por diversos motivos e em diferentes níveis, e os trabalhos científicos que estudam a pré-busca costumam adotar os mesmos procedimentos aqui expostos [Pal 1999; Che 2002; Dav 2002; Sen 2002]. A filtragem mais elementar é a eliminação de inconsistências no log, já que as linhas das requisições podem conter caracteres estranhos, campos ausentes, dentre outros problemas, e também o próprio arquivo pode ter sido corrompido durante sua geração. 
Tratada essa inconsistência inicial do $\log$, deve-sc analisar quais objetos requisitados, mesmo sendo válidos, devem ser considerados, já que muitos deles já são computados quando se analisa outros objetos com os quais eles possuem ligação. Essa ligação cntre objetos é chamada de referência cmbutida [Kri 2001], e um exemplo de sua utilização pode scr visto no caso de imagens em uma página Web. Por exemplo, quando um cliente requisita uma página Web, esta página provavelmente pode referenciar, internamente, imagens que não devem scr contadas e acrescentadas no modelo de predição, bastando que o objeto original (a página propriamente dita) seja computado, já que as imagens serão pré-buscadas por conseqüência. De maneira geral, as imagens não correspondem a um acesso direto do usuário, mas, sim, parte do conteúdo que cle requisitou. A fim de analisar o modelo de predição bascando-sc em acessos diretos do usuário, muitos autores [Pal 1999; Dav 2002, Che 2003] descartam os objetos embutidos, por considerálos como um conteúdo da página, e não representar uma requisição direta do usuário. Como neste trabalho o objetivo enfoca avaliar a precisão da pré-busca estatística, as imagens são descartadas do arquivo de log. Nenhum dos dois servidores em questão scrvem conteúdos voltados para imagens, e isso não ocasiona impactos na análise da pré-busca no ambiente tratado no trabalho.

Outra filtragem necessária diz respeito às requisições com conteúdo dinâmico. Como já discutido, a pré-busca só considera documentos/objetos estáticos. A tabela 5.2 apresenta uma classificação de objetos comuns no ambiente Web. A porcentagem de cada um desses objetos nos logs estudados é mostrada na tabela 5.3, que demonstra as características dos logs originais e dos logs após a filtragem dos conteúdos que não devem ser considerados no processo de análise de pré-busca. Na experimentação, a filtragem desconsiderou imagens e o conteúdo dinâmico entre as requisições realizadas. Assim, como se vê na tabela 5.3, a porcentagem de objetos HTML do servidor CISC passou de $17,23 \%$ das requisições, para $68,56 \%$ das requisições, aumentando também a porcentagem do tamanho dessa classe de objetos perante o tamanho de todos os objetos do log.

Tabela 5.2 - Classes de objetos

\begin{tabular}{|l|l|}
\hline \multicolumn{1}{|c|}{ Classes de Objetos } & \multicolumn{1}{|c|}{ Extensões de arquivos } \\
\hline HTML/XML/Texto & $\begin{array}{l}\text { html, shtml, htm, htx, htw, map, xml, xsl, dtd, } \\
\text { smi, css, txt, dat, bib, readme, desc, faq }\end{array}$ \\
\hline Imagens & vhm inm iner rif rifeo tif tiff hmn isf \\
\hline
\end{tabular}




\begin{tabular}{|l|l|}
\hline \multicolumn{1}{|c|}{ Classes de Objetos } & \multicolumn{1}{c|}{ Extensões de arquivos } \\
\hline & $\begin{array}{l}\text { jpe, ras, pnm, pgm, ppm, rgb, xpm, xwd, pbm, } \\
\text { pic, xwd, pcx, png, crd }\end{array}$ \\
\hline Áudios & $\begin{array}{l}\text { au, wav, snd, lha, mid, aif, aiff, aifc, mp3, } \\
\text { ram, asf, ra rmi, wma, vqf, asx, rip, dsf }\end{array}$ \\
\hline Vídcos & $\begin{array}{l}\text { mov, ql, avi, mpe, movic, mpeg, mpg, mp2, } \\
\text { viv, wmv }\end{array}$ \\
\hline Dinâmicos & $\begin{array}{l}\text { cgi, pl, perl, php, php3, php4, phps, asp, jsp, } \\
\text { cfm, cgi-bin, HTTPs }\end{array}$ \\
\hline $\begin{array}{l}\text { Outros } \\
\text { (Binários/Compactados, } \\
\text { Script cliente/Animação, } \\
\text { Documentos) }\end{array}$ & $\begin{array}{l}\text { exe, bin, hqx, class, dll, ocx, rpm, cab, lib, Z, } \\
\text { gz, zip zoo, tgz, taz, tar, jar, js, vs, vbs, swf, } \\
\text { dcr, class, ps, pdf, dvi, ppt, tex, rtf, src wsrc, } \\
\text { xls, ppz }\end{array}$ \\
\hline
\end{tabular}

Tabela 5.3 - Caracterização dos logs antes e depois da filtragem de conteúdo

\begin{tabular}{|l|l|r|r|r|r|}
\hline \multirow{3}{*}{ Carga } & \multirow{2}{*}{ Tipo de Arquivo } & \multicolumn{2}{|c|}{ Log Original (\%) } & \multicolumn{2}{c|}{ Log Transformado (\%) } \\
\cline { 2 - 6 } & Requisições & \multicolumn{1}{c|}{ Bytes } & Requisições & \multicolumn{1}{c|}{ Bytes } \\
\hline \multirow{5}{*}{ CISC } & HTML & 17,23 & 24,77 & 68,56 & 44,72 \\
\cline { 2 - 6 } & Imagens & 63,77 & 43,91 & 0,00 & 0,00 \\
\cline { 2 - 6 } & Áudio & 0,00 & 0,00 & 0,00 & 0,00 \\
\cline { 2 - 6 } & Vídeo & 0,00 & 0,00 & 0,00 & 0,00 \\
\cline { 2 - 6 } & Dinâmico & 11,10 & 0,71 & 0,00 & 0,00 \\
\cline { 2 - 6 } & Outros & 7,90 & 30,61 & 31,44 & 55,28 \\
\hline \multirow{5}{*}{ W3 } & HTML & 8,32 & 13,74 & 45,32 & 37,68 \\
\cline { 2 - 6 } & Imagens & 56,35 & 35,66 & 0,00 & 0,00 \\
\cline { 2 - 6 } & Áudio & 0,06 & 0,17 & 0,26 & 0,46 \\
\cline { 2 - 6 } & Vídeo & 0,00 & 0,20 & 0,01 & 0,58 \\
\cline { 2 - 6 } & Dinâmico & 24,57 & 24,43 & 0,00 & 0,00 \\
\cline { 2 - 6 } & Outros & 10,70 & 25,79 & 54,41 & 61,28 \\
\hline
\end{tabular}

Até esse ponto, a filtragem foi feita baseada apenas no campo URL de cada uma das entradas dos logs. São necessárias também filtragens sobre outros campos do arquivo de $\log$, como é o caso do campo referente aos métodos que os clientes podem invocar (seção 2.1.2), os 
quais funcionam como comandos enviados ao servidor. Vários estudos apontam que, na prática, um pequeno número desses métodos é responsável pela quase totalidade dos pedidos HTTP [Kri 2001; Pin 2001]. Mais cspecificamente, a grande maioria desses pedidos são para o método GET, já que cle ć o método que realmente solicita objetos Wcb aos scrvidores [Arl 1999; Pad 2000]. Para os dois arquivos de log considerados neste trabalho, pode-se observar tais características, como mostra a tabela 5.4. Somente as requisições com o método GET foram considerados como requisições efetivadas para testar a pré-busca, pois clas efetivamente representam uma requisição (ou seja, um clique do usuário) e representam a grande maioria das requisições encontradas no $\log$.

Tabela 5.4-Percentual de métodos nos logs

\begin{tabular}{|l|r|r|}
\hline \multicolumn{1}{|c|}{ Métodos } & \multicolumn{1}{c|}{ CISC } & W3 \\
\hline GET & $99,67 \%$ & $98,08 \%$ \\
\hline POST & $0,13 \%$ & $1,80 \%$ \\
\hline HEAD & $0,10 \%$ & $0,10 \%$ \\
\hline Outros & $0,10 \%$ & $0,03 \%$ \\
\hline
\end{tabular}

Uma etapa final de filtragem é necessária, dado que somente as requisições atendidas com sucesso devem ser consideradas na análise, porém os logs registram todas as ocorrências de requisições, mesmo que não tenham sido atendidas. Como visto na seção 2.1.2, os servidores podem retornar diferentes códigos de status, dependendo de como as requisições foram tratadas. A tabela 5.5 apresenta o percentual de cada um dos códigos de status registrados nos logs, em resposta às requisições. Somente os códigos 200 e 304 foram considerados como requisições efetivadas, já que de fato significam requisições válidas. A diferença entre esses dois códigos de status está na execução. Enquanto no código 200 a requisição é plenamente completada sem restrições, no código 304 o cliente exccutou uma solicitação condicional, a um recurso já armazcnado em seu cache e o acesso foi permitido, mas o objcto solicitado não foi modificado desde a data e hora especificados no campo if-modified-since (se modificado desde) e, por isso, o objeto não é enviado. 
Tabela 5.5 - Percentual de status retornados pelos servidores, em resposta às requisições

\begin{tabular}{|l|r|r|}
\hline \multicolumn{1}{|c|}{ Código } & \multicolumn{1}{c|}{ CISC } & \multicolumn{1}{c|}{ W3 } \\
\hline 200 & $58,31 \%$ & $46,93 \%$ \\
\hline 304 & $38,40 \%$ & $35,49 \%$ \\
\hline Outros & $3,29 \%$ & $17,58 \%$ \\
\hline
\end{tabular}

Por fim, após todas as eliminações e correções resultantes da filtragem, os logs encontram-se prontos para a análise da pré-busca. A tabela 5.6 apresenta o estado original dos arquivos e o resultado final após a filtragem, caracterizando as cargas de trabalho utilizadas nos experimentos.

Tabela 5.6 - Caracterização dos logs resultantes da filtragem

\begin{tabular}{|c|l|r|r|}
\hline Carga & \multicolumn{1}{|c|}{ Características } & \multicolumn{1}{c|}{ Log Original } & \multicolumn{1}{c|}{ Log Transformado } \\
\hline \multirow{2}{*}{ CISC } & Total de requisições & 760.679 & 110.680 \\
\cline { 2 - 4 } & Bytes Transferidos (GB) & 3,41 & 1,83 \\
\hline \multirow{2}{*}{ W3 } & Total de requisições & 287.161 & 27.763 \\
\cline { 2 - 4 } & Bytes Transferidos (GB) & 1,07 & 0,31 \\
\hline
\end{tabular}

\subsubsection{Divisão da Carga de Trabalho}

Com as cargas de trabalho prontas para serem submetidas a um simulador, foi necessário mais um passo antes de executar os cxpcrimentos propriamente ditos, devido a uma particularidade do simulador usado neste trabalho, que trabalha com dois arquivos gerados a partir de uma mesma carga de trabalho, denominados "treino" e "teste".

O arquivo de treino destina-se exclusivamente a inicializar a árvore de predição, fazendo com que o modelo de predição passe de um estado transiente a um estado estável de operação, evitando que ele gerc pré-buscas não baseadas em padrões de acessos de usuários, ou não as gere 
por não encontrar as sequiências de acessos na árvore. Essa técnica é usada $\mathrm{cm}$ trabalhos correlatos e chama-sc "pcríodo de aquecimento do modelo" (warm-up) [Pin 2001].

Para os dados contidos no arquivo de treino, năo se considcra a cxistência de clientes e seus caches, e portanto não se realiza nenhuma pré-busca, apenas prepara-se a árvore do modelo de predição para a simulação. Já o outro conjunto de dados resultante dessa divisão, chamado de arquivo de teste, reserva-se a testar o ambiente de pré-busca na Wcb.

Para decidir como seria feita essa divisão das cargas de trabalho para aplicá-las nos experimentos, realizaram-se vários testes quanto à influência da porcentagem do arquivo de treino $\mathrm{c}$ a porcentagem do arquivo de teste no mecanismo de pré-busca. Analisaram-se os tamanhos, para o arquivo de treino e de teste, de $30 \%$ e $70 \%, 50 \%$ e $50 \%$ e $70 \%$ c $30 \%$, respectivamente.

Nesses experimentos, observou-se que, com o aumento do arquivo de treino (de $30 \%$ até $70 \%$ ), a atividade de pré-busca apresentou melhoras em seu desempenho, porém pouco significativas. Depois de constatado que, para as cargas de trabalho utilizadas neste trabalho, o tamanho dos arquivos de treino $\mathfrak{c}$ teste não teriam influência significativa nos resultados alcançados pela pré-busca (para os tamanhos analisados), optou-sc por usar o mesmo tamanho para eles $(50 \%$ da carga original). Isso facilita a visualização das características de cada um desses segmentos, que são ilustrados na tabela 5.7, c essa divisão é a mesma adotada em outros trabalhos [Yan 2001; Zha 2001a].

Tabela 5.7 - Caracterização das cargas em relação a suas subdivisões

\begin{tabular}{|l|r|r|r|}
\hline Carga/Segmento & Requisições & \multicolumn{1}{c|}{ URIs } & \multicolumn{1}{c|}{ Hosts } \\
\hline CISC Total & $\mathbf{1 1 0 . 6 8 0}$ & $\mathbf{1 . 0 7 4}$ & $\mathbf{2 0 . 1 7 5}$ \\
\hline CISC Trcino & 55.340 & 887 & 10.879 \\
\hline CISC Teste & 55.340 & 960 & 11.094 \\
\hline & & & \\
\hline W3 Total & $\mathbf{2 7 . 7 6 3}$ & $\mathbf{7 . 6 1 8}$ & $\mathbf{2 5}$ \\
\hline W3 Treino & 13.882 & 4.013 & 25 \\
\hline W3 Teste & 13.882 & 4.399 & 16 \\
\hline
\end{tabular}


É importante conhecer não só a característica do arquivo de log usado nos cxperimentos ("carga total"), mas também as peculiaridades de cada uma de suas partes, que desempenham papéis diferentes na simulação.

Durante o treino, não se considera o cliente que faz a requisição, apenas considera-se o objeto que foi requisitado, o qual é utilizado para gerar a árvore de predição. Portanto, a quantidade total de clientes considerados na atividade de pré-busca propriamente dita é definido pelo número de clientes que fizcram requisições durante a fase de teste. Por exemplo, para o servidor CISC, o número de clientes considerados é de 11.094 (existentes no arquivo de teste), e não de 20.175 (existentes no arquivo total).

Por outro lado, o número total de objetos que influenciam a pré-busca deve ser contabilizado considerando os objetos utilizados no treino e no teste. Por exemplo, para o scrvidor W3, o número de objetos contidos no modelo de predição $\mathrm{c}$, portanto, candidatos a irem para o cache de um cliente, é de 7.618 (existentes no arquivo total, tabela 5.7).

Além de endereçar questões sobre o número de hosts que acessam o scrvidor, número de objetos servidos e o número de requisições, é intcressante analisar a distribuição dos tamanhos dos objetos em cada uma das cargas, bem como de seus segmentos (treino e teste), a fim de identificar a existência de um comportamento discrepante que possa influenciar os resultados obtidos. O tamanho dos objetos pode influenciar, por exemplo, nos resultados das métricas, Tráfego c BHR++, que são envolvidas diretamente com o campo "tamanho" (bytes) do objeto transferido.

A tabela 5.8 sintetiza o padrão de acesso das requisições, definidas por classes de tamanho. Para cada uma das cargas e suas partes, tem-se a porcentagem de requisições e a porcentagem dos bytes transferidos por classe de tamanho.

Nota-se uma diferença no padrão de acesso de um servidor web e de um proxy. No caso do servidor CISC, a maioria das requisições, $83,23 \%$, é para objetos de 1 a $15 \mathrm{~KB}$ que compreende $34,9 \%$ dos bytes transferidos. E no servidor W3, a maioria das requisições é para objetos de 0 a $5 \mathrm{~KB}: 71,23 \%$, que compreende somente $5,94 \%$ dos bytes transferidos. Ou seja, em ambos servidores transfere-se uma grande quantidade de arquivos pequenos, porém no servidor W3 esses arquivos tem menor peso na quantidade total de bytes transferidos. 
No que diz respeito à porcentagem dos bytes transferidos por classe de tamanho, a maioria dos acessos em ambas as cargas de trabalho é pra objetos acima de 40KB: 50,87\% no caso do CISC e $60,42 \%$ no caso do W3, que compreendem somente $3,56 \%$ e $3,86 \%$ das requisições, respectivamente.

Concluindo-se, observa-se que não há nenhuma discrepância entre os arquivos de treino e testc, para ambos servidorcs. Esse fato é muito importante na medida em que garante maior confiabilidade à avaliação feita neste trabalho, pois cvita-sc uma possível influência nos resultados decorrente da diferença entre os dois segmentos de um log.

Tabela 5.8 - Classificaçöes das subdivisóes das cargas en relação aos tamanhos dos objetos requeridos

\begin{tabular}{|c|c|c|c|c|c|c|c|}
\hline \multirow{2}{*}{ Cargas } & \multirow{2}{*}{ Tamanho } & \multicolumn{2}{|c|}{ Total } & \multicolumn{2}{|c|}{ Treino } & \multicolumn{2}{|c|}{ Teste } \\
\hline & & $\begin{array}{c}\% \text { das } \\
\text { Referências }\end{array}$ & $\begin{array}{l}\% \text { dos } \\
\text { Bytes }\end{array}$ & $\begin{array}{c}\% \text { das } \\
\text { Referências }\end{array}$ & $\begin{array}{l}\text { \%dos } \\
\text { Bytes }\end{array}$ & $\begin{array}{c}\text { \% das } \\
\text { Referências }\end{array}$ & $\begin{array}{l}\% \text { dos } \\
\text { Bytes }\end{array}$ \\
\hline \multirow{9}{*}{ CISC } & 0 a 250 Bytes & 0,15 & 0,00 & 0,16 & 0,00 & 0,14 & 0,00 \\
\hline & $250 \mathrm{~B}-1 \mathrm{~KB}$ & 2,55 & 0,07 & 2,28 & 0,07 & 2,83 & 0,07 \\
\hline & $1 \mathrm{~KB}-5 \mathrm{~KB}$ & 30,35 & 4,60 & 29,72 & 5,06 & 30,98 & 4,32 \\
\hline & $5 \mathrm{~KB}-10 \mathrm{~KB}$ & 28,58 & 12,53 & 28,75 & 13,80 & 28,41 & 11,47 \\
\hline & $10 \mathrm{~KB}-15 \mathrm{~KB}$ & 24,30 & 17.71 & 25,88 & 20,62 & 22,72 & 15,27 \\
\hline & $15 \mathrm{~KB}-30 \mathrm{~KB}$ & 7,87 & 9,03 & 7,51 & 9,52 & 8,23 & 8,62 \\
\hline & $30 \mathrm{~KB}-40 \mathrm{~KB}$ & 2,64 & 5,14 & 2,70 & 5,76 & 2,58 & 4,62 \\
\hline & $40 \mathrm{~KB}-1 \mathrm{MB}$ & 3,50 & 27,43 & 2,96 & 22,90 & 4,05 & 31,23 \\
\hline & $>1 \mathrm{MB}$ & 0,06 & 23,44 & 0,04 & 22,28 & 0,07 & 24,41 \\
\hline \multirow{9}{*}{$\mathbf{W 3}$} & O a 250 Bytes & 37,54 & 0,65 & 34,33 & 0.66 & 40,74 & 0,64 \\
\hline & $250 \mathrm{~B}-1 \mathrm{~KB}$ & 11,04 & 0,53 & 12,44 & 0,65 & 9,65 & 0,42 \\
\hline & $1 \mathrm{~KB}-5 \mathrm{~KB}$ & 22,65 & 4,76 & 24,19 & 5,70 & 21,11 & 3,99 \\
\hline & $5 \mathrm{~KB}-10 \mathrm{~KB}$ & 10,35 & 6,40 & 10,55 & 7,26 & 10,15 & 5.69 \\
\hline & $10 \mathrm{~KB}-15 \mathrm{~KB}$ & 4,68 & 4,73 & 4,89 & 5,37 & 4,47 & 4,20 \\
\hline & $15 \mathrm{~KB}-30 \mathrm{~KB}$ & 5,69 & 10,10 & 5,61 & 10,86 & 5,78 & 9,47 \\
\hline & $30 \mathrm{~KB}-40 \mathrm{~KB}$ & 4,19 & 12,62 & 4,36 & 14,59 & 4,01 & 10,99 \\
\hline & $40 \mathrm{~KB}-1 \mathrm{MB}$ & 3,70 & 27.63 & 3,52 & 27,93 & 3,88 & 27,39 \\
\hline & $>1 \mathrm{MB}$ & 0,16 & 32,57 & 0,12 & 26,99 & 0,21 & 37,21 \\
\hline
\end{tabular}


$\Lambda$ análise do $\log$ usado nos experimentos, assim como a análise de cada uma de suas partes, é de grande valia para a visualização e compreensão de certos comportamentos vistos nos resultados da pré-busca. Isso fica cvidente quando se discute a natureza distinta de cada uma das cargas de trabalho (servidor Web e proxy Wcb).

\subsubsection{Comparação de Cenários: Servidor Web e Proxy Web}

Os diferentes cenários presentes na Web influenciam diretamente nos métodos, processos e tecnologia cmpregados no seu desenvolvimento e manutenção. Por consequiencia, quando prébusca é aplicada em diferentes cenários, as técnicas, parâmetros c resultados sofrem reflexos desses ambientes, especialmente quando uma mesma técnica é empregada em meios diferentes. Como abordado anteriormente, Palpanas [Pal 1999] estudou pré-busca entre o servidor Web e o cliente, e este trabalho de mestrado se concentrou, além desse cenário, no estudo de pré-busca entre proxy e cliente, em que o proxy assume o papel de servidor do conteúdo Web.

A principal molivação $\mathrm{cm}$ realizar os expcrimentos sobre esses dois cenários, está na natureza distinta do padrão de acesso de cada um deles. No cenário entre o cliente c o servidor Web, tem-se como principais características um número ilimitado de usuários - os conectados à Web, e um número limitado de páginas a serem servidas - as contidas nesse servidor Web. No caso do outro cenário aqui também considerado, tem-se como principais características um número limitado de usuários - os conectados a um proxy Web, que atende a uma comunidade de usuários específica, e um número ilimitado de páginas a serem scrvidas - na teoria, todas as que estão disponíveis na Web. A tabela 5.7 ilustra essa razão inversa entre número de páginas (URIs) e número de usuários (Hosts), uma característica própria da difcrença entre servidores Web e servidores proxy. Com isso, mesmo atendendo uma comunidade de usuários ao invés de todos os usuário da Web, a análise de um servidor proxy deverá lidar com padrões de acessos bastante diferenciados, já que um servidor Web limita o conteúdo a ser acessado.

Outra característica relcvante que diferencia esses cenários é o excesso de tráfego na rede. Dependendo de onde é empregada a pré-busca, o excesso de tráfego - uma das limitações de pré-busca - não é tão impactante, já que uma rede local (que liga os clientes ao scrvidor 
proxy) costuma apresentar largura de banda mais ociosa que a estrutura de uma rede externa (que liga os clientes a um scrvidor web). Além disso, o tempo de resposta é consideravelmente diferente entre os dois cenários (o proxy localiza-se mais perto do usuário), tendo consequiências dirctas na latência percebida pelo usuário.

Os padrões de acessos conseqüentes dos dois cenários distintos são decisivos na aplicação de pré-busca, principalmente no que diz respeito aos ajustes de parâmetros que o modelo de predição deve sofrer para atender as características de cada cenário. Dessa forma, este trabalho se concentrou no estudo de pré-busca entre proxy Web e cliente e de pré-busca cntre servidor Web e cliente.

Na próxima seção, são apresentados os resultados dos experimentos feitos considerando essas duas cargas de trabalho e o simulador descrito no capítulo 4.

\subsection{Resultados Experimentais}

Os resultados obtidos, apresentados nas próximas subseções, baseiam-se nas cargas de trabalho (seção 5.1) e simulador (seções 4.2 e 4.4) expostos. As métricas (seção 4.5) obtidas das simulações são analisadas a partir do comportamento da pré-busca diante da variação dos parâmetros Ordem, Confiança, Contador, Número de requisições prévias, Tamanho de cache e Tempo ocioso de sessão (seçāo 4.3).

Duas métricas estão ligadas diretamente à análise de custo/bencfício em pré-busca na Web: a Utilidade c o Tráfego. Enquanto a primeira cstá ligada à cficiência da pré-busca. mensurando a relação entre páginas sugeridas c se elas foram rcalmente utilizadas, a segunda está ligada aos efeitos indesejados que a pré-busca na Web pode causar. Obter una relação de equilíbrio entre esses dois fatores configura uma chave para o uso de pré-busca na Web. Através desse balanccamento é que a latência percebida pelo usuário pode ser reduzida, sem que isso traga novos problemas para as redes de dados.

Os valores padrão dos parâmetros do ambiente de simulação foram definidos, $\mathrm{cm}$ sua maioria, empiricamente através da análise dos resultados obtidos pelas execuções dos experimentos, e também do estudo de trabalhos correlatos [Che 2001; Che 2002]. O ambiente de 
simulação, exceto quando mencionado, assume a seguinte configuração padrão para seus parâmetros:

- Ordem: para esse parâmetro, o valor padrão definido para os experimentos foi igual a 3:

- Confiança: para esse parâmetro, o padrão definido para os expcrimentos foi igual a 0,3 . Esse valor serve como um ajuste para o modelo de predição, cvitando que objetos com pouca probabilidade de acesso (que tenham esse valor menor que 0,3 ) scjam sugeridos pela prébuscà. Não é interessante para a avaliação aqui apresentada que todos os parâmetros scjam ajustados com valores que não imponham nenhuma restrição à pré-busca, pois haveria uma distorção dos resultados finais para todos os gráficos. Por exemplo, o tráfego gcrado sempre ficaria extremamente alto. O parâmetro confiança foi escolhido para desempenhar a função de restringir a pré-busca pois foi o que permitiu uma melhor avaliação dos demais parâmetros em ambos cenários;

- Contador: para esse parâmetro, o valor padrão definido para os experimentos foi igual a 1. Ao contrário do parâmetro Confiança, que também é utilizado para exigir que o modelo gere pré-buscas mais precisas, adotou-se um valor que não restringisse a pré-busca. Qualquer página na árvore de predição tem, no mínimo, o valor igual a 1 para o número de acessos, e portanto é candidata à pré-busca em relação a esse parâmetro;

- Número de requisições prévias: para esse parâmetro, o valor padrão definido para os experimentos foi igual a 0. É o mesmo caso do parâmetro anterior, onde adotou-sc uma configuração agressiva;

- Tamanho de cache: para esse parâmetro, o valor padrão definido para os expcrimentos foi igual a 30 . Durante todos os experimentos conduzidos, tal valor mostrou-se adcquado no caso geral, pois valores baixos (por excmplo 5), favoreccm as métricas $H R++\mathrm{e}$ $B H R++$ em detrimento das métricas utilidade, prccisão e tráfego, assim como valores altos (por cxcmplo 50) favorecem estas últimas em detrimento das métricas $H R++$ e BHR++.

- Tempo ocioso de sessão: para esse parâmetro, o valor padrão definido para os experimentos foi igual a 1800 segundos (30 minutos). Isso significa que dado um acesso do mesmo usuário, ele vai ser considerado seguinte ao seu antccessor (e portanto representado assim na árvore de predição) se o intervalo entrc eles for de até 30 minutos.

Como a análise se deu cm dois cenários distintos, servidor Web e proxy (represcntados pelas duas cargas de trabalho), há grálicos específicos de apresentação de resultados para cada 
um desses cenários. São apresentadas considerações pertinentes a cada um dos parâmetros, analisando pontos em comum nas análises dos dois cenários $\mathrm{c}$, quando as características dos cenários são suficientemente distintas, faz-se uma análise dos efeitos do parâmetro sobre a prébusca na Web em cada cenário individualmente. Além disso, a fim de facilitar a observação, cada cenário possui dois gráficos, cada um deles com métricas relacionadas. O primeiro gráfico de cada cenário reúne as métricas Utilidade, Precisāo e Tráfego, e o scgundo gráfico reúne as métricas $H R++$ e $B H R++$.

Dá-se ênfase na discussão das métricas Utilidade, Precisāo e Tráfego porque elas realmente denotam e mensuram o custo/bencfício do uso de pré-busca na Web em relação à latência percebida pelo usuário. As duas últimas métricas complementam a análise, scrvindo como base de observação dos cfeitos da pré-busca sobre o uso de cache.

A fim de facilitar a discussão que se segue, evitando repetições constantes, quando for utilizado o termo "servidor", estará se referindo a "servidor Wcb", e quando o termo "proxy" for utilizado, estará se referindo a "servidor proxy".

\subsubsection{Parâmetro Ordem}

Conforme descrito no Capítulo 4, o parâmetro ordem define o tamanho do contex to que o algoritmo de predição utiliza para encontrar uma seqüência na árvore e sugerir a previsão. Quando utiliza-se valores mais altos, pode-se identificar com maior precisão o accsso seguinte de uma seqüência mais longa de acesso, caso ela exista. Nos experimentos, optou-se por variar os valores desse parâmetro desde o valor de 2 até um valor que o comportamento das métricas se mantivesse constante (escolheu-se o valor 8). Conforme esperado, o gráfico mantcve-se constante na medida em que se aumentou o valor do parâmetro, o que já era esperado, pois as seqüências de acesso mais longas (as quais seriam beneficiadas por ordens maiores) não foram encontradas nos logs consultados e portanto, na prática, apenas os valores de ordem menores são útcis.

Os resultados obtidos com a simulação mostram que esse parâmetro não tem muita influência no desempenho da pré-busca, pois para a maioria dos valores assumidos do parâmetro, exceto na passagem do valor de 2 para 3. onde pode-se notar uma leve alteração no desempenho, 
os valores das métricas mantiveram-se quase inalterados, conforme ilustrado nas figuras 5.1 e 5.2. Portanto, pode-se concluir que os melhores valores para o parâmctro ordem são iguais a 2 ou 3 , por dois motivos principais. O primeiro motivo é desempenho verificado com esses valores através da simulação, que é igual aos demais valores experimentados. O segundo motivo é a observação de que valores menores do parâmetro ordem exigem menos recursos computacionais para executar a pré-busca, principalmente no que tange a utilização de memória para a criação da árvore de pré-busca e tempo de processamento para percorrer a árvore. Como o mecanismo de predição serve a vários usuários concomitantemente, valores inadequados desse parâmetro refletem dirctamente no desempenho à medida que o número de usuários aumenta [Mof 1990; Che 2003]. 


\section{- Servidor Web}

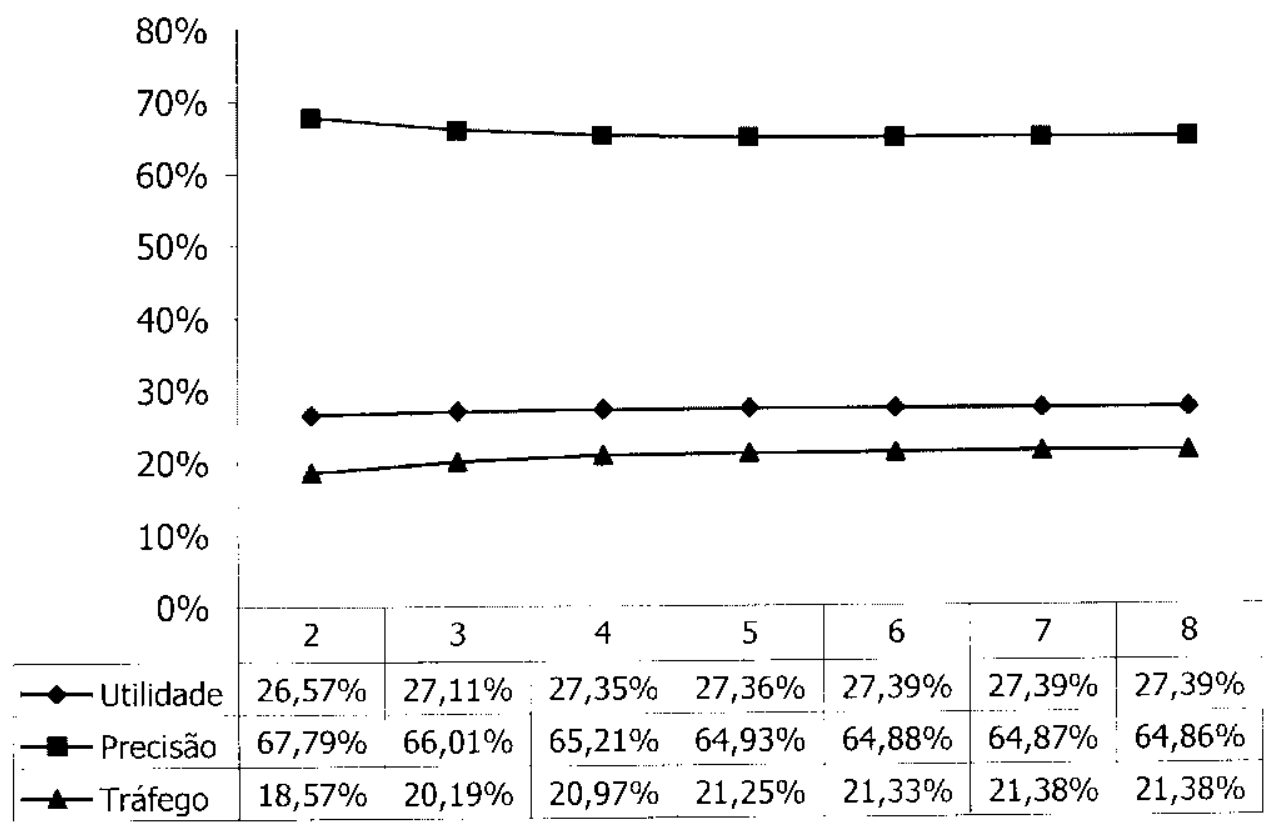

(a)

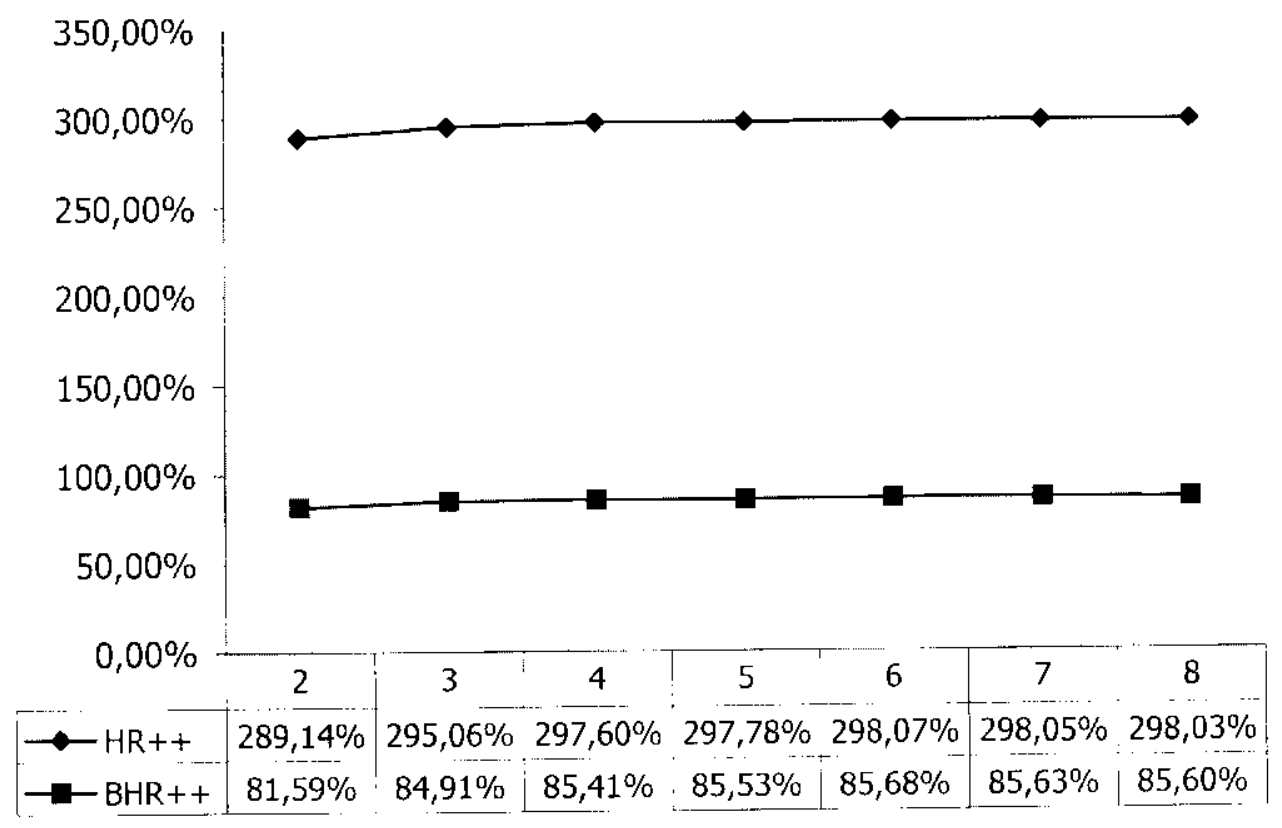

(b)

Figura 5.1 - Avaliação do parâmetro ordem para o servidor Web 


\section{- Proxy Web}

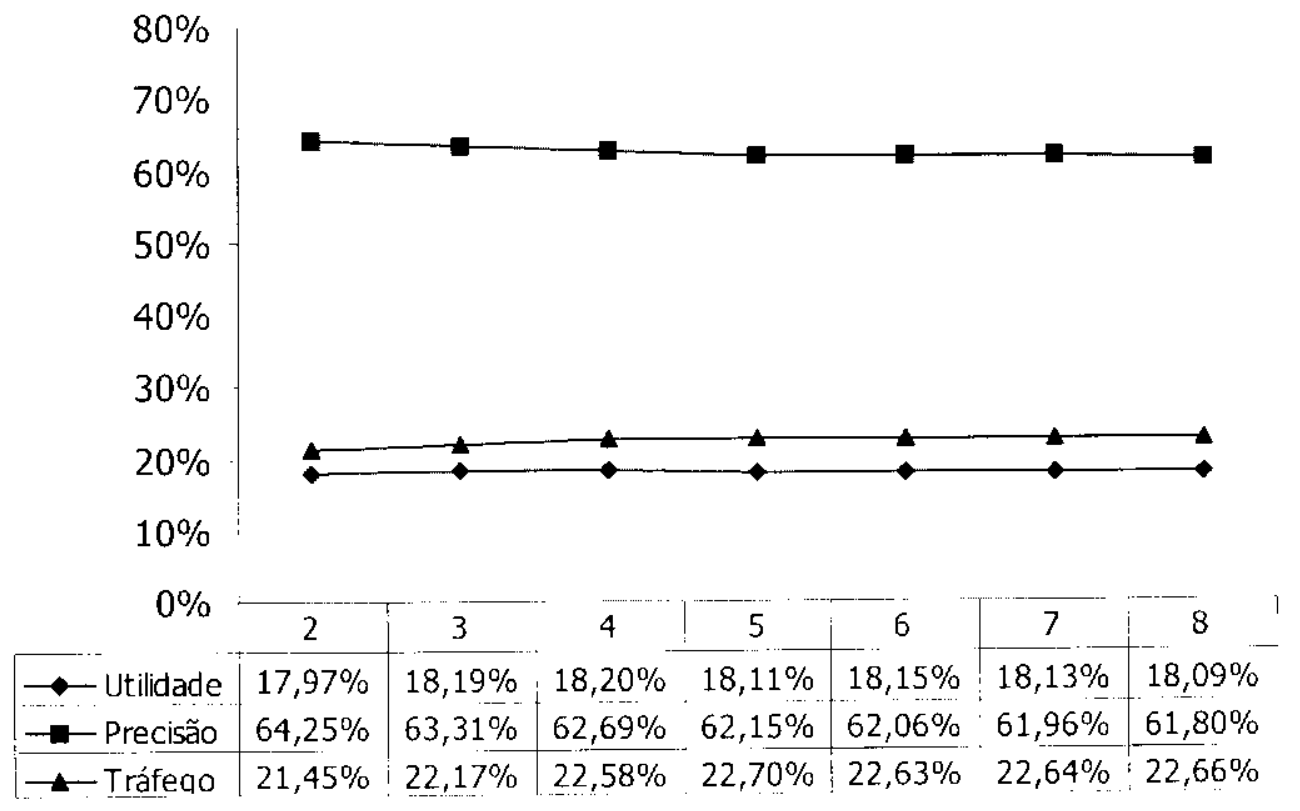

(a)

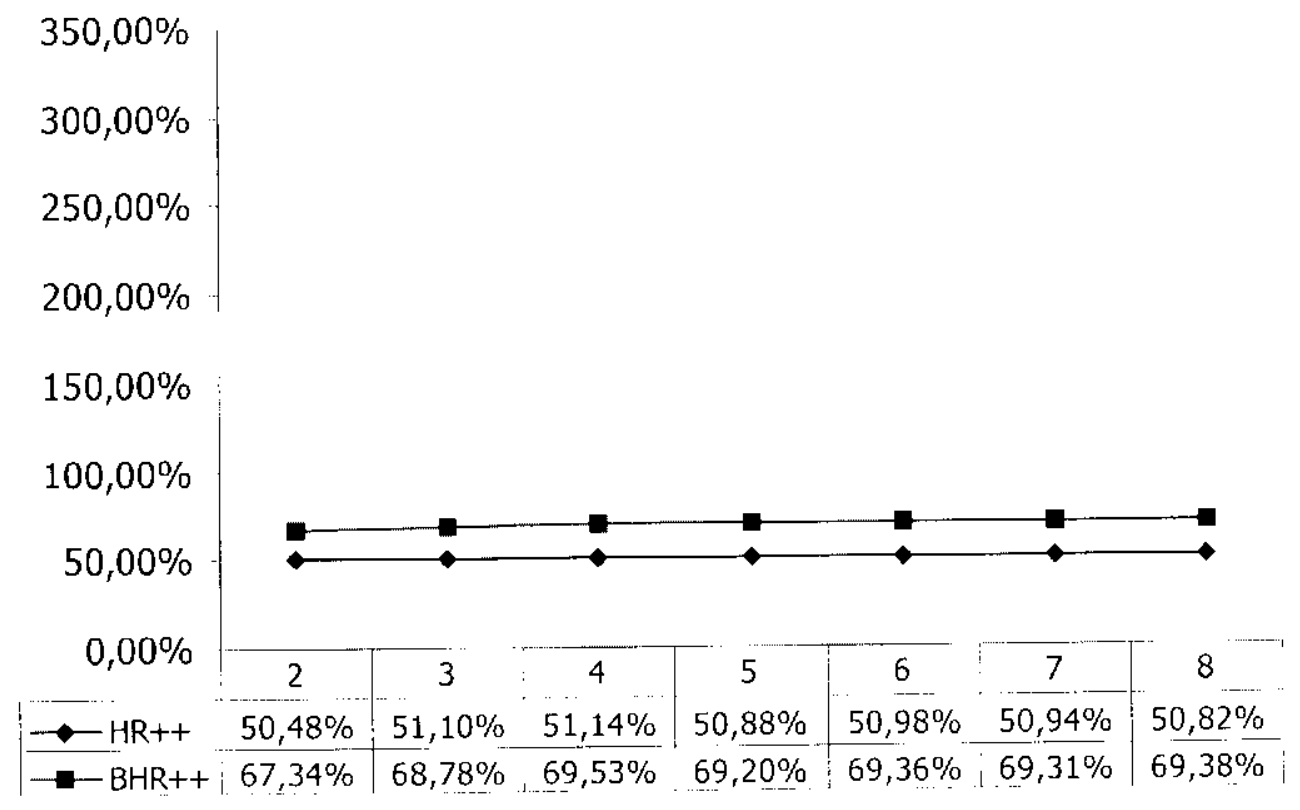

(b)

Figura 5.2 - Avaliação do parâmetro ordem para o proxy 


\subsubsection{Parâmetro Contador}

Conforme descrito no capítulo 4, o parâmctro Contador define o número mínimo de acessos necessários a um objeto, para que ele possa ser sugerido pelo mecanismo de predição. Esse parâmetro serve para exigir do modelo de predição sugestões mais precisas. Nos experimentos, optou-sc por variar os valores desse parâmetro desde o valor de 1 , que é o valor inicial do parâmetro, até um valor em que o comportamento das métricas se mantivesse estável. O valor final escolhido é 10. A estabilidade, ora alcançada para os valores iniciais ora para os valores finais do parâmetro, que pode scr conferida nos gráficos das figuras 5.3 e 5.4, é esperada. Isso ocorrc, pois apenas uma pequena fração entre os inúmeros objetos scrvidos (tanto pelo scrvidor Web, quanto pelo servidor proxy) refere-se aos "objetos populares" (objetos acessados muitas vezes), e só esses continuam obedecendo aos critérios para poderem ser sugeridos pelo mecanismo de predição à medida que o parâmetro atinge valores mais altos.

Os resultados obtidos com a simulação (fïguras 5.3 e 5.4) mostram que a manipulação desse parâmetro tem influência significativa no ajuste do modelo de predição. Com ele, conscguc-se melhorar a precisão das páginas sugeridas em pré-busca à medida que se aumenta o valor do parâmetro, como pode-sc conferir nos valores da métrica Precisāo. Também, nota-se a redução no tráfego gerado na rede com a atividade de pré-busca, como mostram os valores da métrica Tráfego. O aumento do valor do parâmetro torna o modelo de precisão mais exigente. Com essa cxigência de pré-buscar objetos mais prováveis, diminui-se o tráfego evitando prébuscar páginas que não têm grande probabilidade de ocorrer. Como consequêencia de se gerar menos pré-buscas, naturalmente, o cliente irá precisar de algumas páginas pré-buscadas que cstavam anteriormente disponíveis no cache, o que não ocorre neste caso, devido ao aumento do valor do parâmetro Contador. Reflexo disso é a diminuição dos valores da métrica Utilidade. Contudo, a utilidade da pré-busca cai aproximadamente pela metade, em relação à queda do tráfego, o que sugere a eficiência do parâmetro Contador. Ou seja, o parâmetro garante uma grande economia de largura de banda da rede sem depreciar, na mesma proporção, a cficiência da pré-busca.

O comportamento do modelo de predição, quanto à variação do parâmetro Contador, é o mesmo para ambos os logs, do servidor e do proxy, como pode-se também observar nos gráficos das figuras 5.3 e 5.4. Porém, pelos resultados, é possível notar que a variação do parâmetro causa 
mais cfeito no proxy do que no servidor. Isso ć mais aparente para as métricas Utilidade, Precisão e Tráfego.

Nota-se uma cxpressiva alteração das métricas do proxy quando o valor do parâmetro Contador passa de 1 para 2 (quando comparado com os demais valores do parâmetro), sendo que no servidor essa alteração é bem mais discreta. Essa significativa alteração quando o valor do parâmetro é 1 ocorre por ter várias páginas com um único accsso sendo sugeridas pelo modelo de predição no caso do proxy. O motivo para tal comportamento, é que o número de páginas com baixa freqüência de acesso no proxy é maior do que no servidor, dado que o universo de páginas servidas pelo proxy (toda a Internet) é muito maior do que o universo de páginas servidas pelo servidor (apenas as páginas disponíveis no scrvidor). Em relação ao proxy, é valido salientar, que dentre todas as avaliações dos parâmetros, foi com esse que parâmctro que o modelo de predição alcançou o melhor valor para a métrica Precisăo: 78,01\%. Isso confirma a influência desse parâmetro na pré-busca.

Os resultados apresentados, mostram que o valor desse parâmetro pode ser configurado de acordo com os recursos disponíveis. Se o intuito for de melhorar a navegação do usuário e a largura de banda da rede suportar esse acréscimo no tráfego sem maiores consequiências, o valor do parâmetro deve scr baixo. Por outro lado, se pretende-sc fazer uma pré-busca conscrvadora, esse valor deve ser tão elevado quanto se deseja, uma vez que quanto mais alto, maior será a restrição à pré-busca. Contudo, tanto para o servidor quanto para o proxy, o valor 2 mostrou-se particularmente interessante. Restringindo páginas que tenham somente um acesso, a taxa de largura de banda da rede salva é compensatória em relação a diminuição da utilidade da prébusca. Portanto, pode-se sugerir o valor 2 como adequado, tanto para o servidor quanto para o proxy. 
- Servidor Web

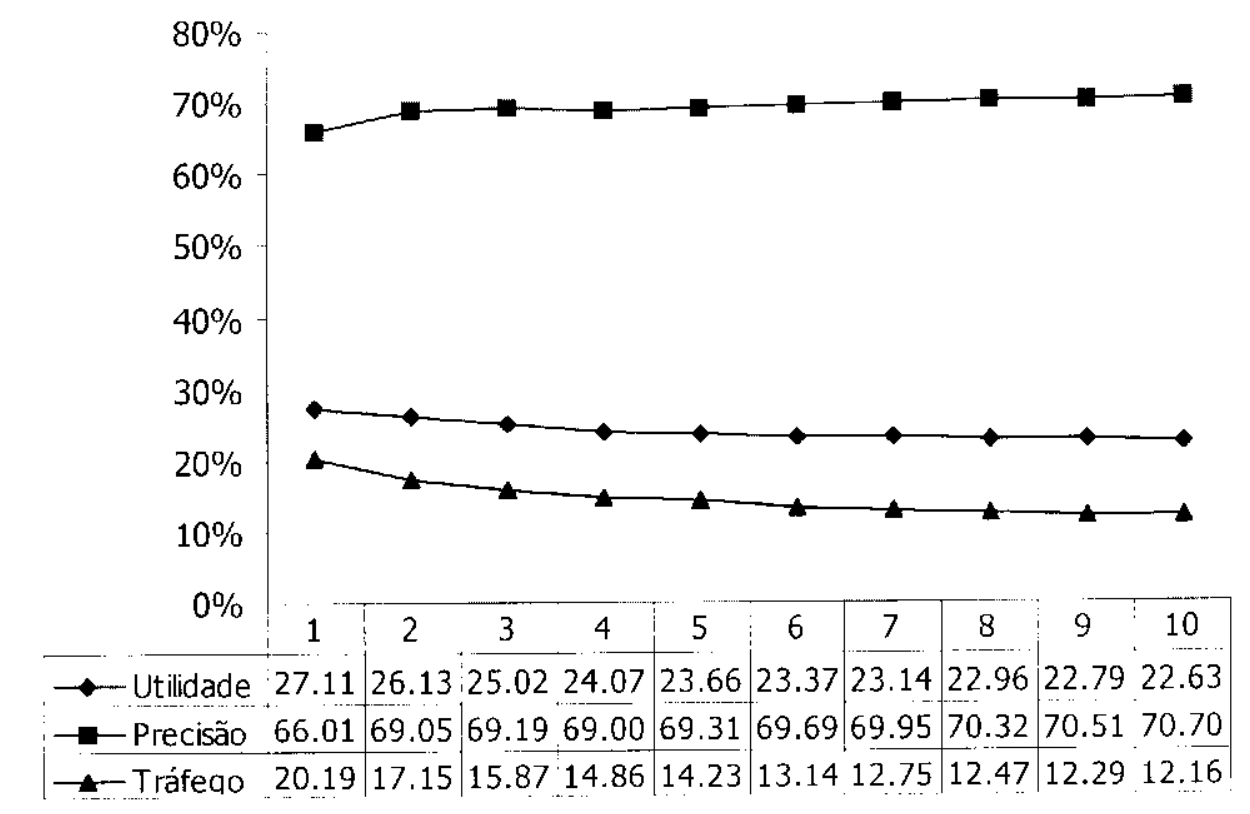

(a)

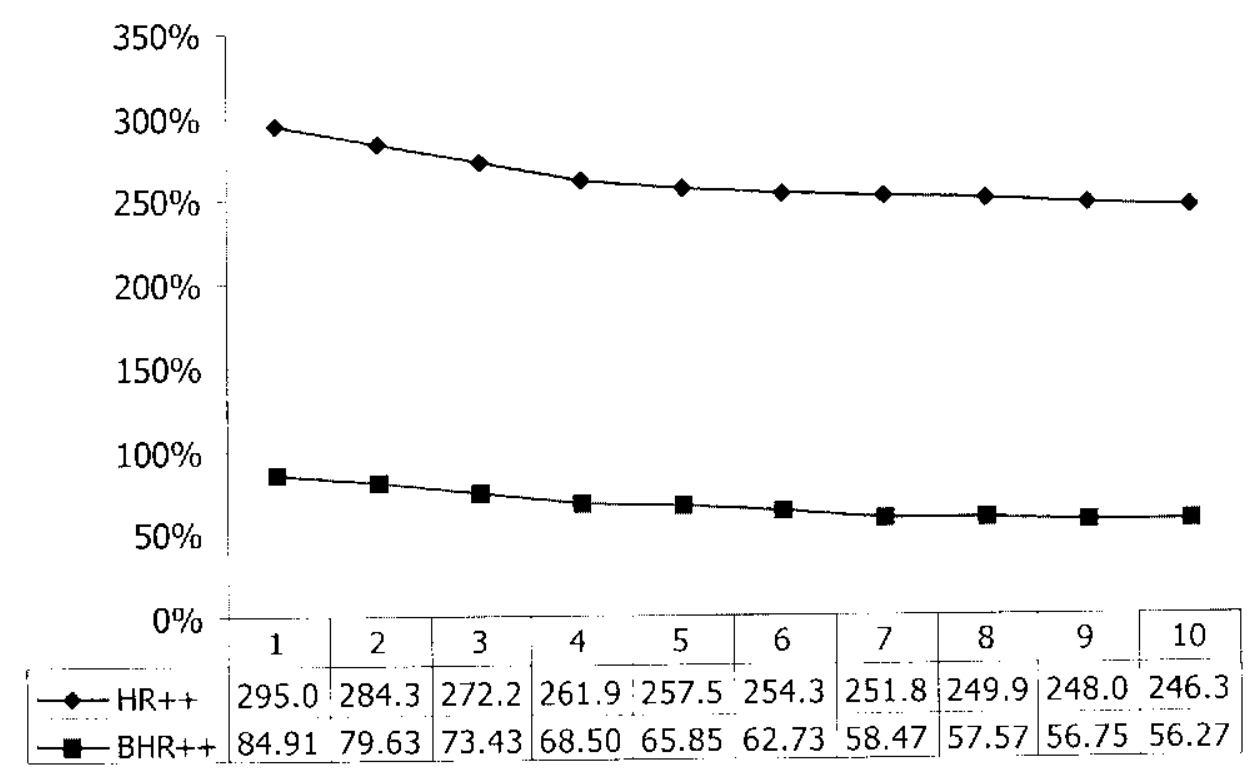

(b)

Figura 5.3-Avaliação do parâmetro Contador para o servidor Web 


\section{- Proxy Web}

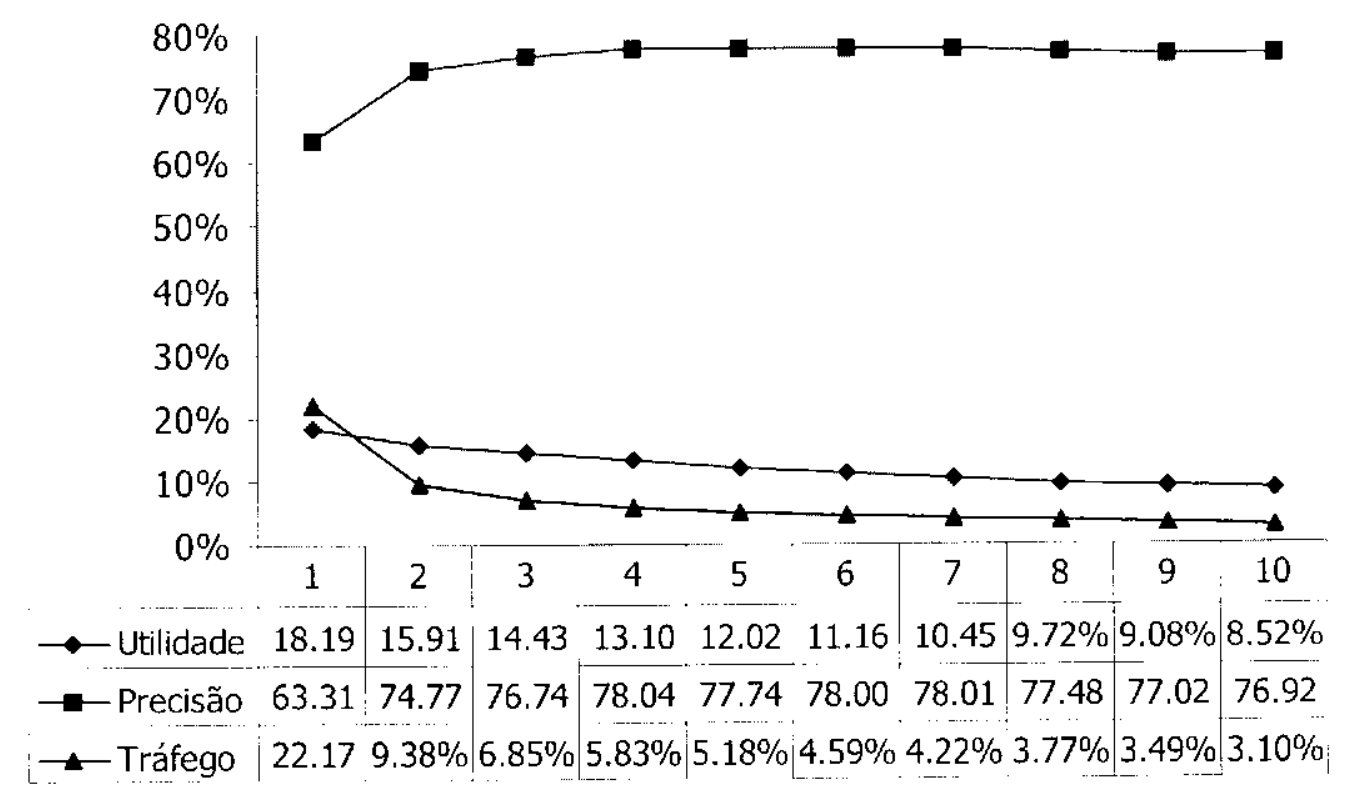

(a)

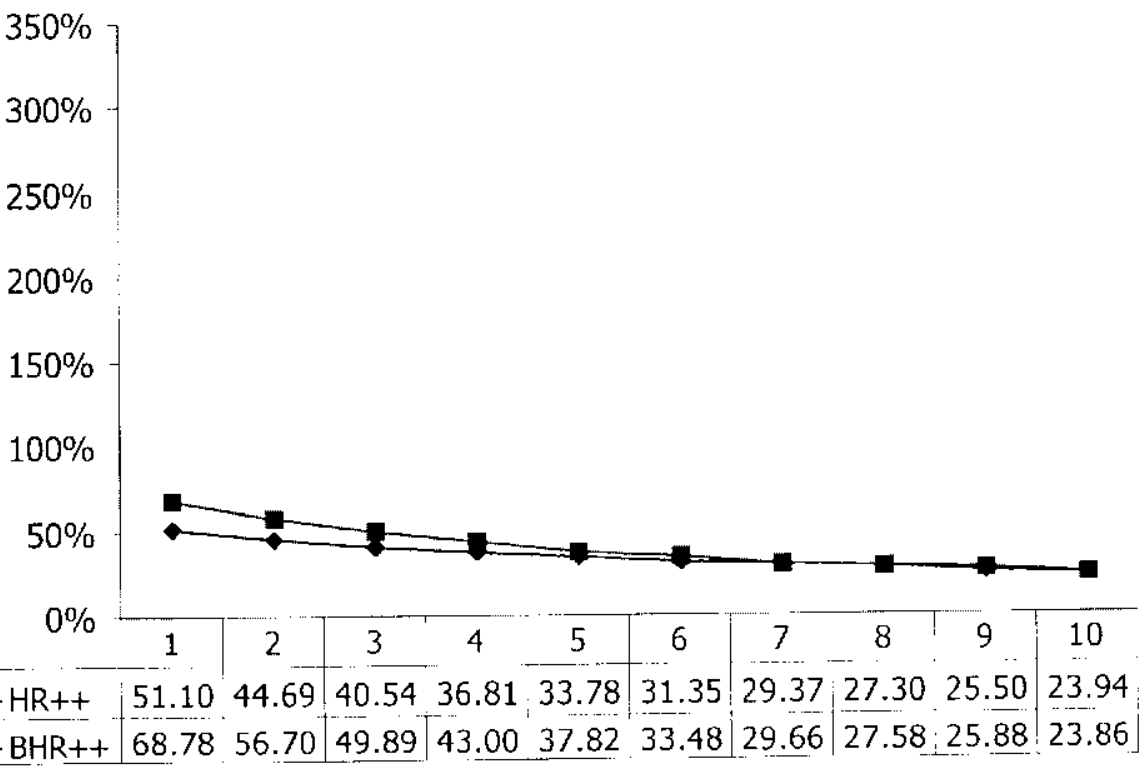

(b)

Figura 5.4 - Avaliação do parânetro Contador para o proxy 


\subsubsection{Parâmetro Confiança}

Conforme descrito no capitulo 4, o parâmetro Confiança define a porcentagem mínima que uma sequiência de acessos deve ter sido feita, em relação às demais, para que se gere uma pré-busca. Essc parâmetro, assim como o parâmetro visto antcriormente, serve para ajustar o modelo de predição para que ele faça sugestões mais precisas. Nos cxperimentos, optou-sc por variar os valores desse parâmetro desde o valor de 0,0 , que é o valor mínimo para o parâmetro, até o valor máximo que ele pode assumir: 0,9 .

Os resultados obtidos na simulação confirmam a relevância desse parâmetro sobre o ajuste da precisão do modelo de predição. Na medida que o scu valor é acrescido, a precisão da pré-busca aumenta e, como conseqüência, o tráfego gerado na rede diminui. Porém, quando esse valor vai se aproximando do máximo, apenas uma pequena fração das páginas satisfazem a restrição de ser sugerida pela pré-busca. Por isso, espera-se que o tráfego e a utilidade da prébusca, diminuam consideravelmente quando o parâmetro atingir o seu valor máximo.

Isso pode ser notado tanto para o servidor como para o proxy. Para o servidor, o valor da métrica Tráfego variou de $60,62 \%$ para $5,33 \%$, oscilando em $55,29 \%$, que é a maior diferença observada durante a avaliação dos parâmetros. A métrica Precisão por sua vez também foi bastante influenciada ao longo da simulação, oscilando em $34,50 \%$, atingindo a maior variação de valor para essa métrica nos experimentos aqui realizados.

No proxy, como no caso do scrvidor, as métricas Tráfego e Precisão (figura 5.6a) apresentaram as maiores oscilações obscrvadas, cujos valores são: $36,70 \%$ e 16,05\%. Porém, não foi através da variação desse parâmetro que se alcançou a melhor precisão do modelo de predição, como foi no caso do servidor.

A variação do parâmetro Confiança causou algumas semelhanças no comportamento do scrvidor e do proxy. Os resultados de ambos sugerem como opção adcquada o valor 0,3 para esse parâmetro, ponderando entre o tráfego gerado na rede e a utilidade da pré-busca. Nos gráficos das figuras 5.5 e 5.6, pode-se notar que o valor da métrica Tráfego diminui em um grau bem mais acentuado do que para o valor da métrica Utilidade. Outra característica comum aos dois cenários são os valores alcançados pelas métricas Precisăo e Tráfego quando o valor desse parâmetro é 0,0 . Para o valor 0,0 , o modelo gcrou uma quantidade de tráfego relativamente alta, 
assim como a diminuição da precisão para sugerir pré-buscas, indicando que deve-se evitar esse valor para o parâmetro.

\section{- Servidor Web}

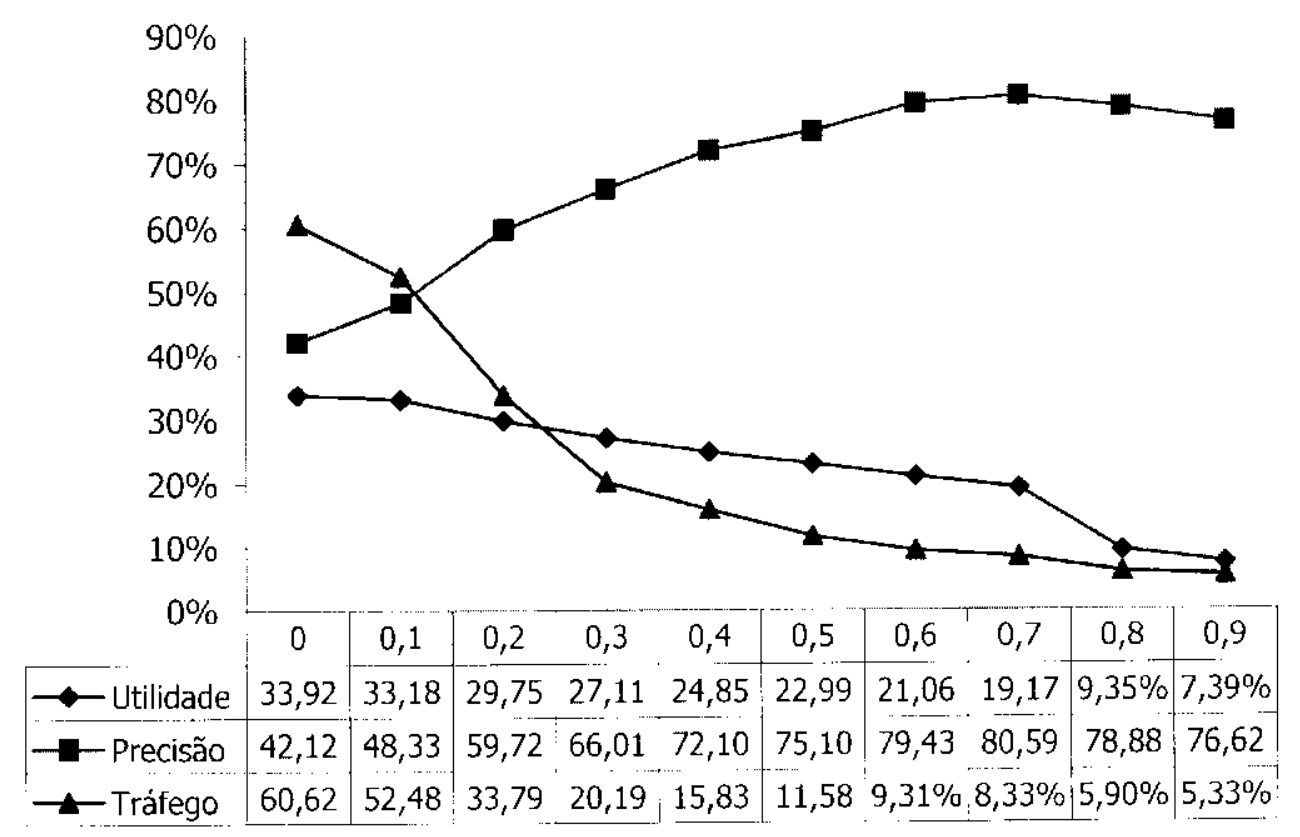

(a)

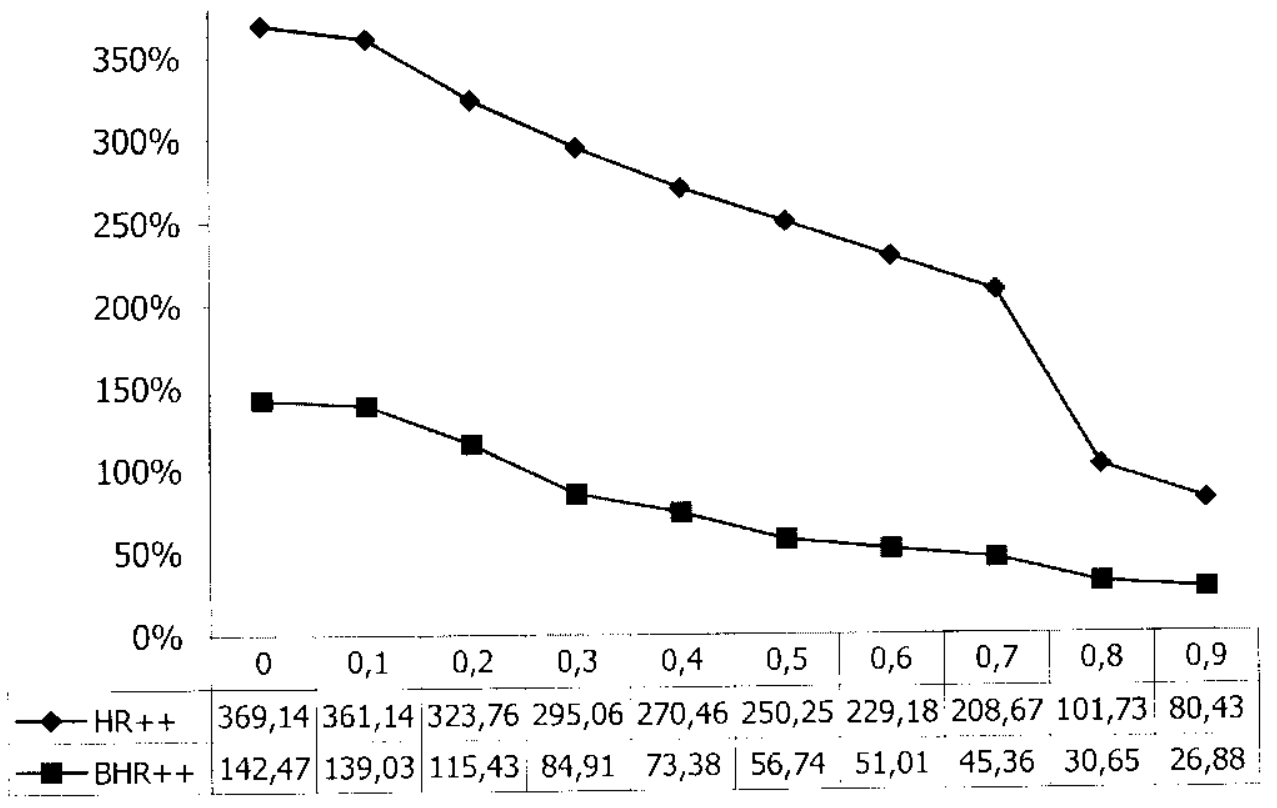

(b)

Figura 5.5 - Avaliação do parâmetro Confiança para o servidor Web 
- Proxy Web

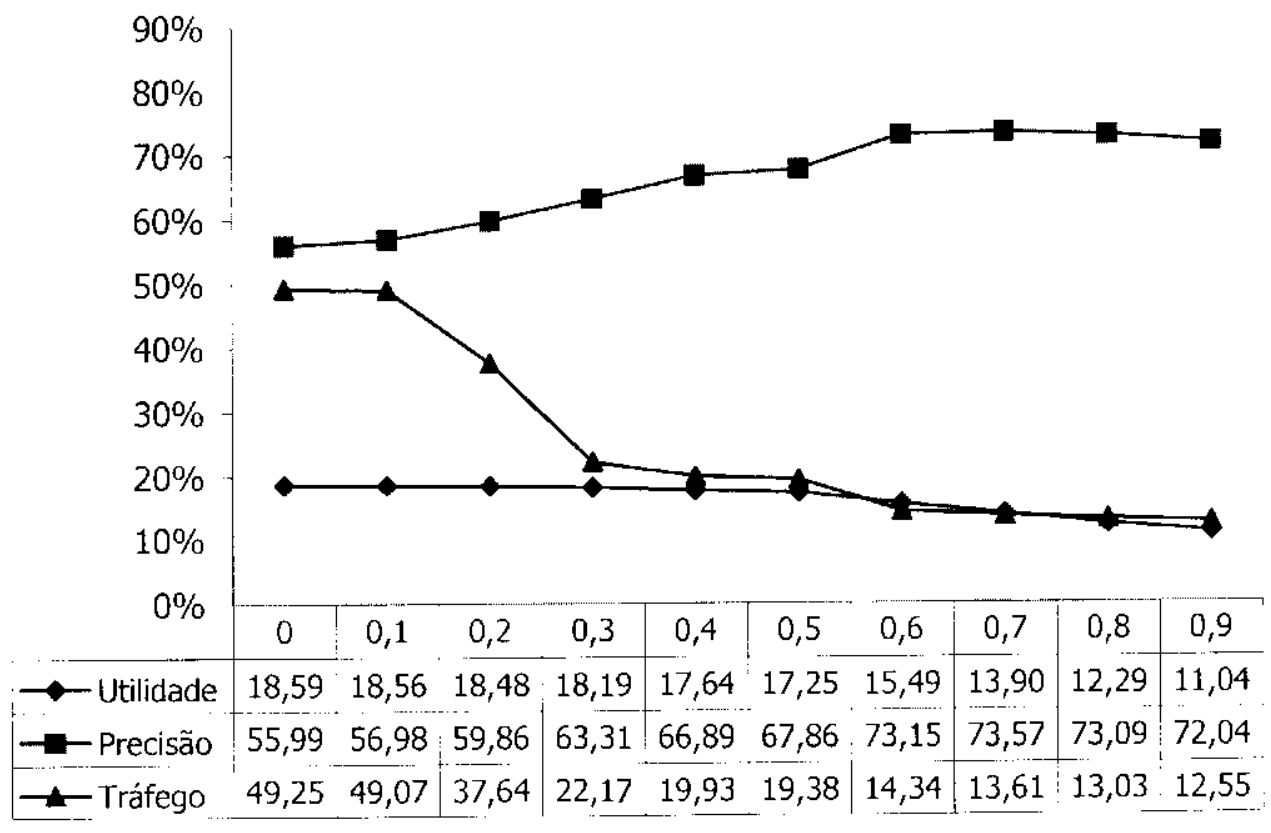

(a)

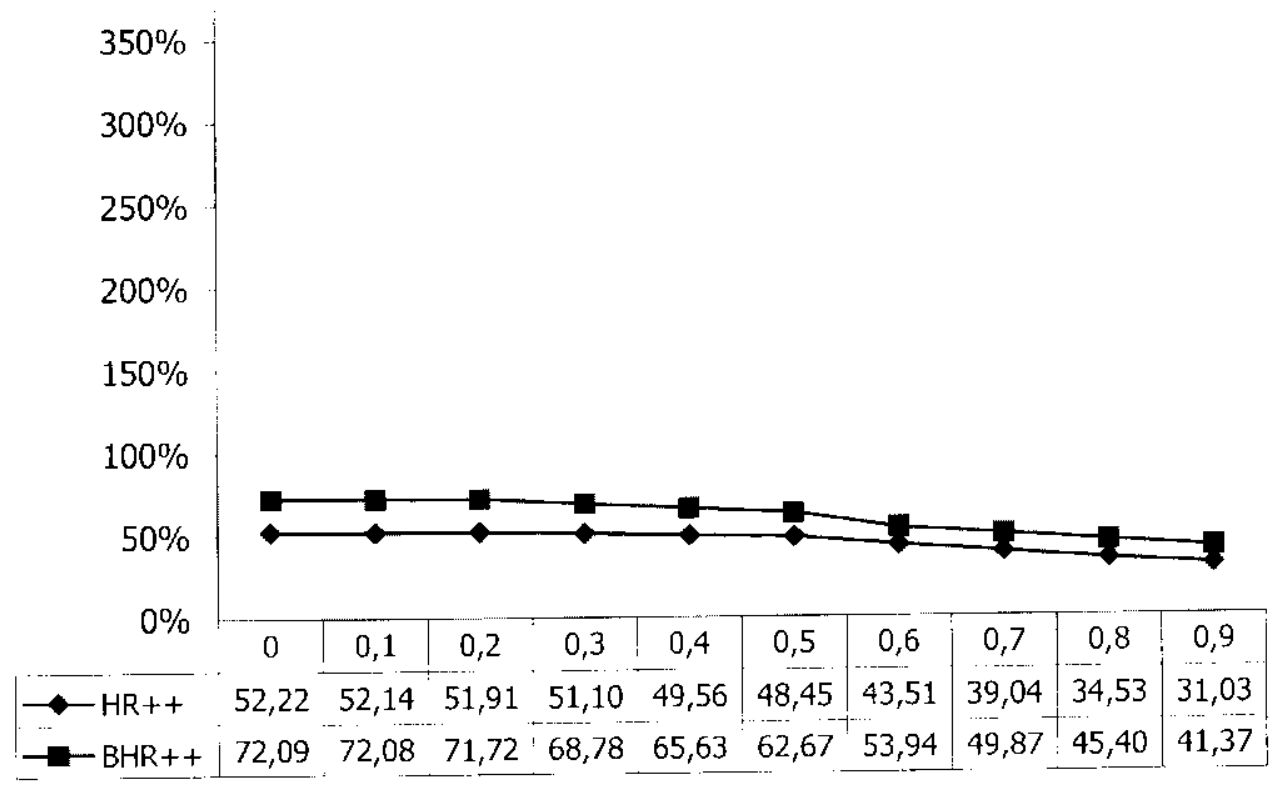

(b)

Figura 5.6 - Avaliação do parâmetro Confiança para o proxy 


\subsubsection{Parâmetro Número de Requisições Prévias}

O parâmetro Número de requisiçōes prévias, como visto no capítulo 4, diz respeito ao número necessário de requisições que um determinado cliente deve fazer para que possam ocorrer pré-buscas para suas requisições. Esse parâmetro visa restringir que usuários com passagens rápidas pclo servidor ou em seus acessos iniciais recebam páginas $\mathrm{cm}$ seus caches por ação da pré-busca. Nos experimentos, optou-se por variar os valores desse parâmetro desdc o valor de 0, que é o valor mínimo para o parâmetro, até um valor que fosse considerado adequado para o número mínimo de acessos que um determinado usuário deve fazer para que sc beneficie com a técnica de pré-busca. O valor escolhido no caso foi 7.

A variação do parâmetro Número de requisições prévias, teve maior influência no cenário referente ao servidor do que no cenário referente ao proxy. O comportamento das métricas não chegam a ser distintos, mas alternaram-se $\mathrm{cm}$ graus bem diferentes, como ilustram as figuras 5.7 c 5.8. Nos dois casos, o valor 0 mostrou-se apropriado para utilização. Porém, especificamente para o servidor, csse valor é mais vantajoso e preferível que os demais, diferente do proxy, que por apresentar qucda gradativa e análoga das métricas Utilidade e Tráfego, poderia ter outros valores. Valores adequados para o parâmetro Número de requisiçōes prévias, serão discutidos separadamente mais adiante, quando for feita uma análise individual dos resultados para cada cenário.

A explicação do valor 0 no parâmetro Número de requisições prévias apresentar maior influência no servidor, deve-se ao fato que, no servidor, existe uma quantidade limitada de páginas servidas cm relação a um proxy (tabela 5.7), c cssa limitação leva um servidor usual a ter um conjunto bastante restrito de objetos entre os que ele serve. Esses objetos são ditos "objetos populares". Exemplo de um objeto que tem tal característica é a página inicial do site. Esses objetos populares formam um conjunto bastante rcstritos, que são marcados por serem bastante acessados por scus clientes. Assim, colocá-los no cache do cliente de imediato (sem que ele tenha feito requisições prévias), pode ser vantajoso, pois a probabilidade de um usuário requisitar um desses objetos no decorrer de suas próximas solicitaçõcs ao servidor tende a ser grande. Já no caso de um proxy, as páginas servidas são aleatórias, diversificadas (várias origens) e em quantidade ilimitada (ao longo do tempo), não sendo possível estabelecer $\mathrm{cm}$ um pequeno conjunto de objetos, os ditos objetos populares. 
Outra observação comum para os dois cenários, refere-se a queda do tráfego gerado na rede no decorrer da simulação. Com o emprego do parâmetro Número de requisições prévias, espera-se atacar diretamente o tráfego adicional conseqüente do uso de pré-busca na Web, restringindo esta a usuários que permancçam por mais tempo lançando requisições ao servidor. Essa restrição quanto ao tráfego ocorreu para os dois cenários, porém, novamente, em maior grau no caso do servidor.

\section{- Servidor Web}

A análise individual desse parâmetro, para o caso do servidor Web, como é disculido adiante, é importantc para elucidar o comportamento das métricas $H R++$ e $B H R++$ (figura $5.7 b)$, quando se avalia os demais parâmetros apresentados neste capítulo. Antes de debater sobre isso, faz-se observações sobre o comportamento das métricas da figura 5.7a.

De acordo com os resultados dessas métricas, o parâmetro cumpre seu objetivo de reduzir o tráfego gerado na rede, que cai em $15,81 \%$ no decorrer da simulação, chegando ao valor de 4,38\%. Mas, por outro lado, a declínio da utilidade da pré-busca superou o declínio do tráfcgo, oscilando em $21,95 \%$, apresentando a maior queda vista nos experimentos do cenário do servidor. Esse comportamento, onde a utilidade ultrapassa a queda do tráfego, só acontece com esse parâmetro, comparando-o com os demais parâmetros que, como ele, coíbem o trálego na rede $\mathrm{cm}$ detrimento da utilidade da pré-busca. Os outros parâmetros são, Contador e Confiança. A partir dessa constatação, conclui-se que é melhor ajustar o tráfego extra para uma pré-busca modificando os valores dos parâmetros Contador e Confiança, e utilizando-se valores baixos para Número de requisiçōes prévias, que não restrinjam a pré-busca.

A obscrvação relevante quanto as métricas da figura $5.7 \mathrm{~b}$, refere-se particularmente ao comportamento da métrica $H R++$ para o valor 0 do parâmetro Número de requisições prévias. Pode-se notar na figura, uma acentuada queda no valor dessa métrica, quando o parâmetro Número de requisições prévias passa de 0 para 1. Essa queda é de $157,99 \%$, bem superior a qualquer outro declive obscrvado em qualquer uma das várias avaliações com os outros parâmetros, para a métrica $\mathrm{HR}++$. É válido rclembrar que o valor 0 para o parâmetro Número de requisiçōes prévias, foi utilizado como valor padrão para as demais simulações, c portanto, por causa desse parâmetro, todos os demais experimentos possuíram grande diferença entre os 
valores de $H R++$ e BHR++. Portanto, o comportamento distante dessas duas métricas no decorrer dos experimentos explica-se também pela utilização de um valor 0 como padrão para o parâmetro Número de requisiçôes prévias.

\section{- Proxy Web}

O parâmetro não teve muita influência no cenário cujo proxy desempenha o papel de servidor. Como já mencionado, um determinado usuário tende a ter muitos mais acessos ao servidor nesse cenário do que no outro. Com isso, não se restringe tanto a geração de pré-busca, na medida que se aumenta o valor de Número de requisições prévias em uma unidade. Ainda assim, ele cumpre com o seu objetivo, que é de diminuir o tráfego gerado na rede. Porém, como no caso do servidor, ele apresentou resultados aquém daqueles vistos pelos outros dois parâmetros que visam também conter o tráfego na rede: Confiança c Contador.

Portanto, a discussão e os resultados do parâmetro Número de requisiçōes prévias mostram que a contenção do tráfego feila por ele, tem maiores efeitos colaterais no servidor. Contudo, em ambos os casos, servidor e proxy, tem-se outras opções mais vantajosas que podem ser empregadas alternativamente antes da utilização de valores diferentes de 0 para o parâmetro. Essas opções consistem da utilização dos parâmetros Confiança e Contador. 


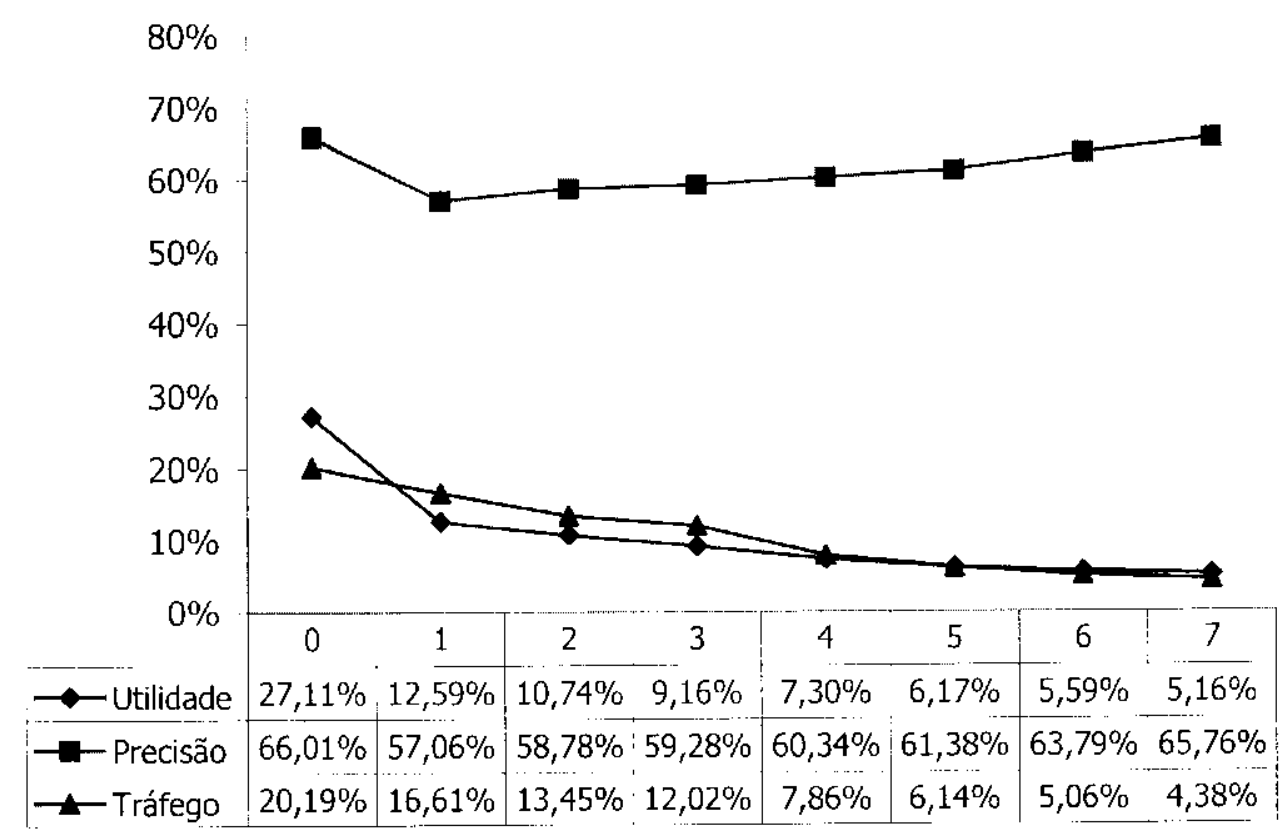

(a)

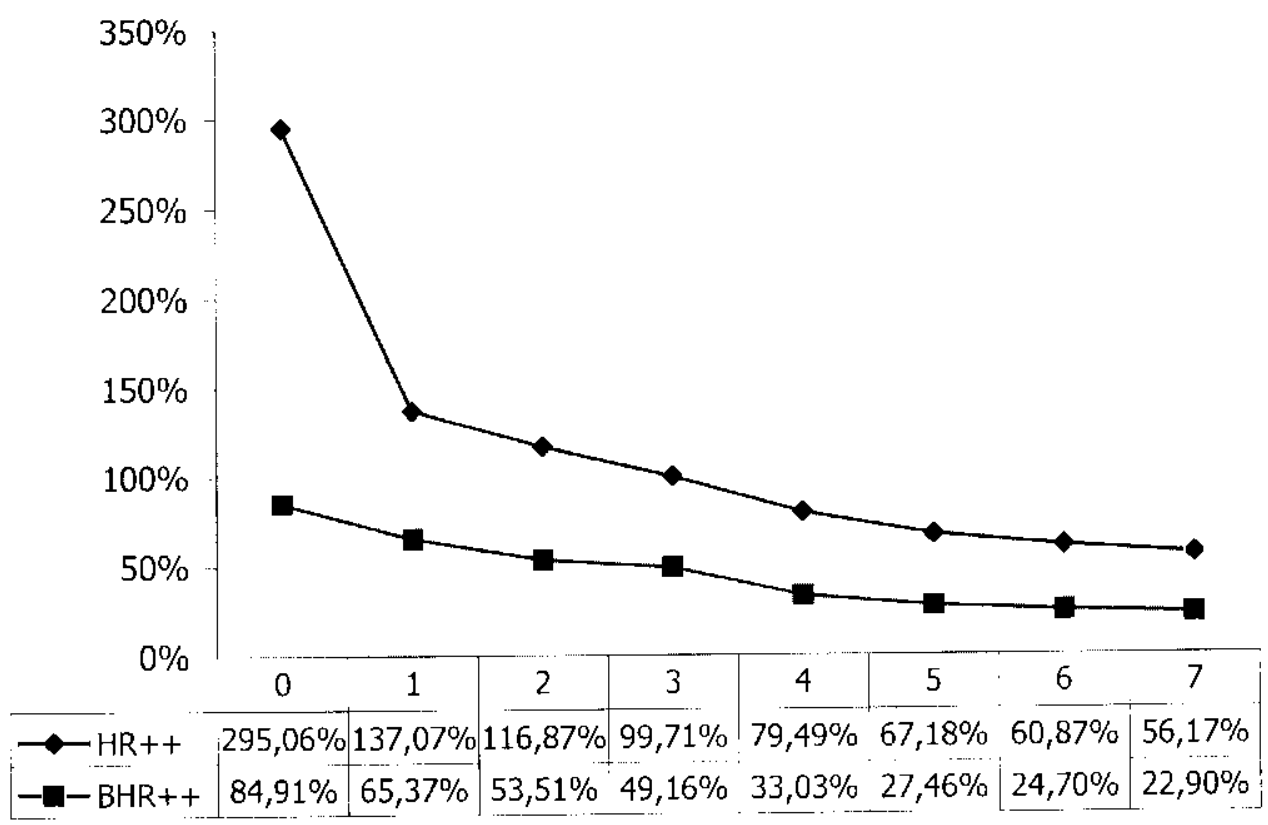

(b)

Figura 5.7 - Avaliaçăo do parâmetro Número de requisições prévias para o servidor Wets 


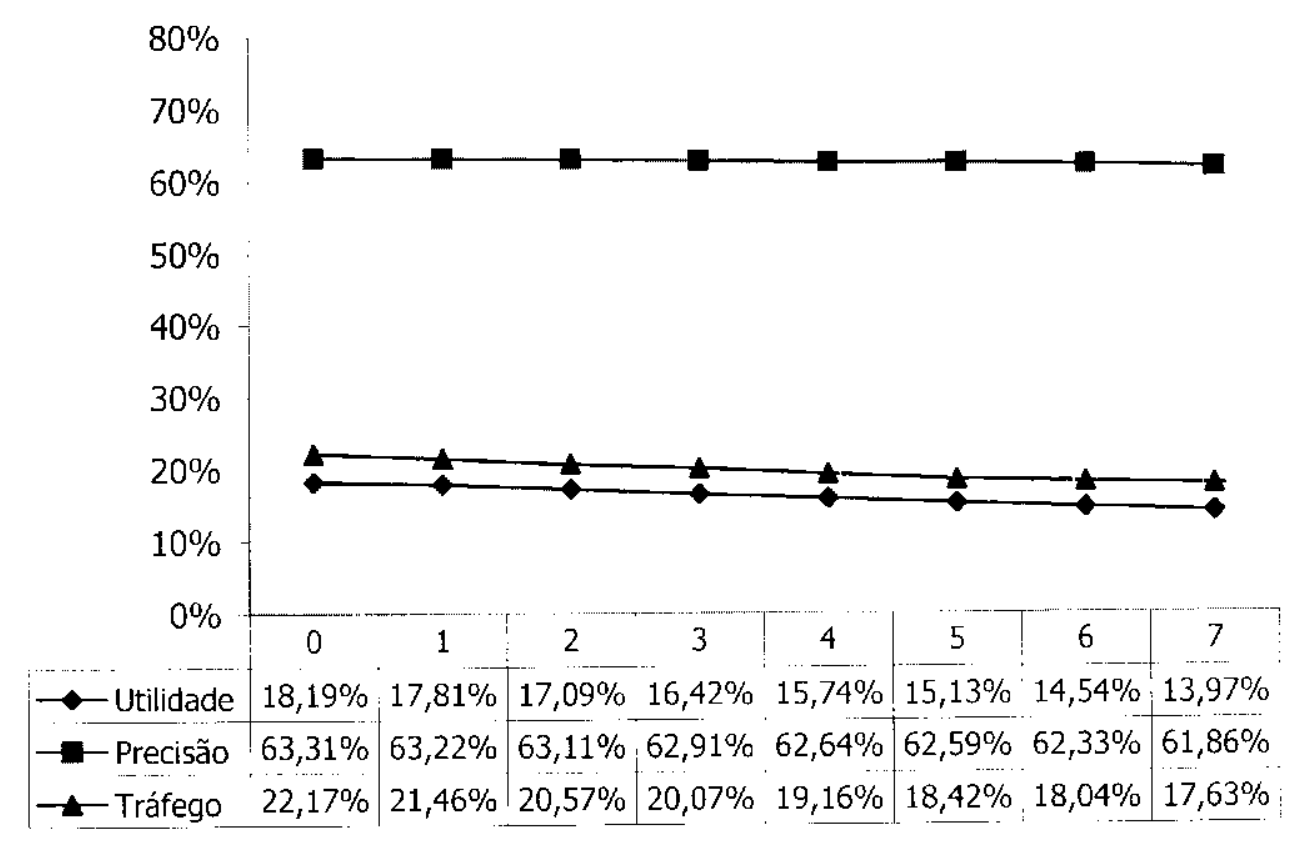

(a)

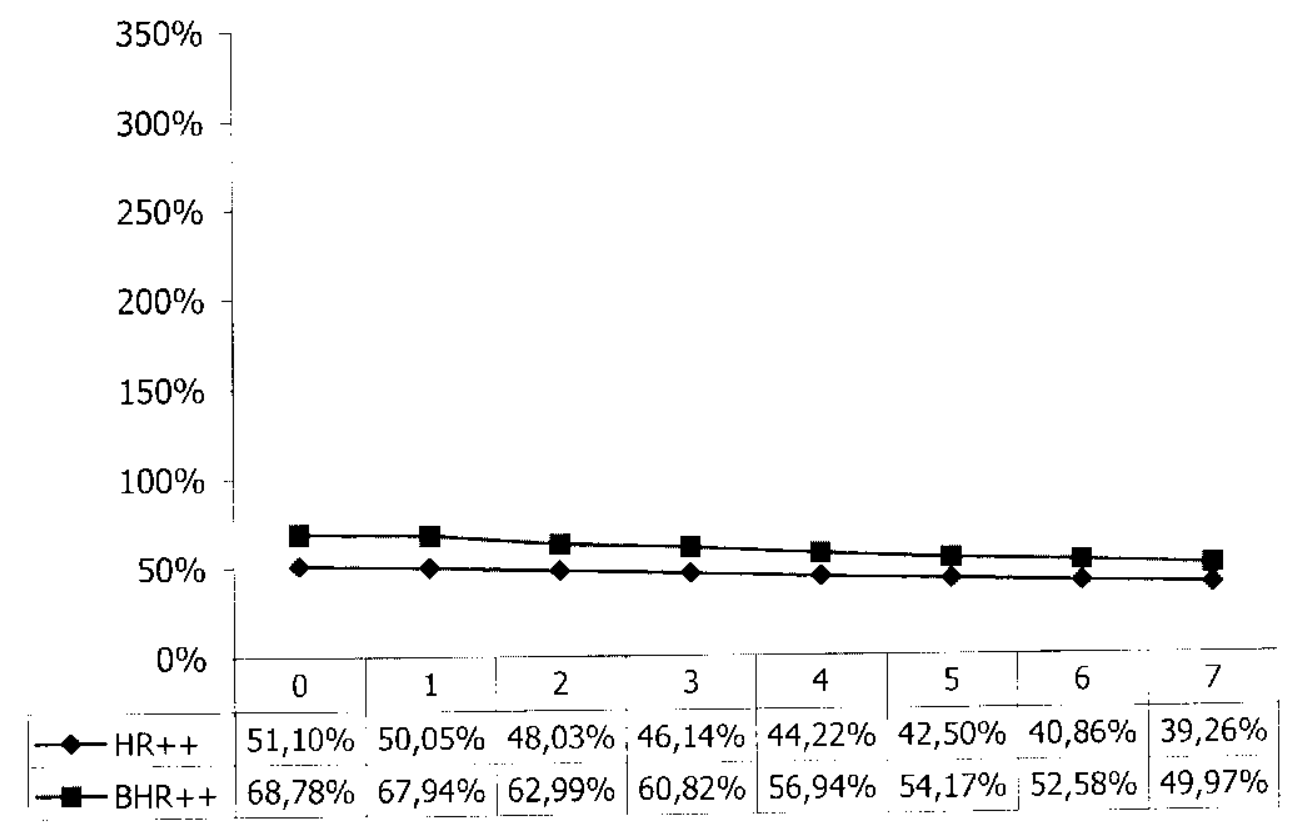

(b)

Figura 5.8 - Avaliação do parâmetro Nümero de requisiçóes prévias para o proxy 


\subsubsection{Tamanho de Cache}

O parâmetro Tamanho de cache define o número de objetos que podem ser armazenados no cache do cliente, como discutido no capítulo 4. Nos experimentos, optou-se por variar os valores desse parâmetro desde o valor de 5 , que foi considerado adequado para scr dito como mínimo, em tcrmos de páginas armazenadas por um cache de um browser, até o valor de 115 , onde observou-se que o comportamento das métricas se manteve estável. Nota-se, no caso do proxy, obscrvando o comportamento das cinco métricas, que essa estabilidade ocorre para os valores finais da simulação. Já no caso do servidor, ela ocorre nos valores iniciais. Isso acontece pois o servidor serve um universo de páginas menor que o proxy. Então, para os clientes do scrvidor, um cache relativamente pequeno tende a ser suficiente para compreender as páginas requisitadas sem a necessidade de fazer as substituições. Por isso, no caso do proxy, o parâmetro tem maior influência.

Obscrvando-se as métricas das figuras 5.9 a e $5.10 \mathrm{a}$, percebc-se que em ambos os casos (servidor e proxy), a precisão do modelo melhora com o aumento do tamanho do cache. Deve-se a isso o fato de serem considerados caches coopcrativos neste trabalho, ou scja, uma página que já está armazenada $\mathrm{cm}$ cache não é sugerida pela pré-busca. Portanto, quando aumenta-se a capacidade de armazenamento do cache, tende-se a diminuir o número de pré-buscas, garantindo maior precisão.

No caso do servidor os valores das métricas se estabilizam para valores de cache pequenos, e praticamente não há variação do tráfego e da utilidade. No caso do proxy, por outro lado, experimenta-se uma diminuição do tráfego e da utilidade, explicados pela diminuição da atividade de pré-busca.

As figuras $5.9 b$ e $5.10 b$ mostram a influência que a pré-busca causa na utilização do cache. Nota-se uma caracteristica comum dos dois cenários para o tamanho do cache igual a 5 . 0 que ocorre nesse caso é que o cache não é grande o suficiente para lidar com o número de páginas que o usuário requisita constantemente. Com o auxílio da pré-busca, as páginas que provavelmente serão acessadas scgundo o padrão de acesso, mantêm-se por mais tempo no cache, fazendo com que a pré-busca desempenhe uma função decisiva com relação aos acertos no cache, tanto por número de requisições quanto por bytes $(\mathrm{HR}++\mathrm{e} \mathrm{BH}++)$. Porém, à medida 
que o cache consegue lidar com um maior número de páginas, a pré-busca passa a desempenhar um papel sccundário no desempenho do cache. Como já mencionado, isso ocorre mais rapidamente no caso do servidor do que no caso do proxv. Pode-se concluir que clientes que possuem menor quantidade de cache são bastante bencficiados pela pré-busca, pois quanto menor for o tamanho do cache, mais a pré-busca pode auxiliá-lo no desempenho experimentado pelo cliente na Web.

Para o parâmetro cache não é sugerido um valor adequado de configuração. Ele é um parâmetro externo, que não diz respeito a pré-busca em si, e sim, à configuração definida pelo clicntc. Sua avaliação é interessante, pois pode-se observar a influência da pré-busca para diferentes tamanhos de cache. 
- Servidor Web

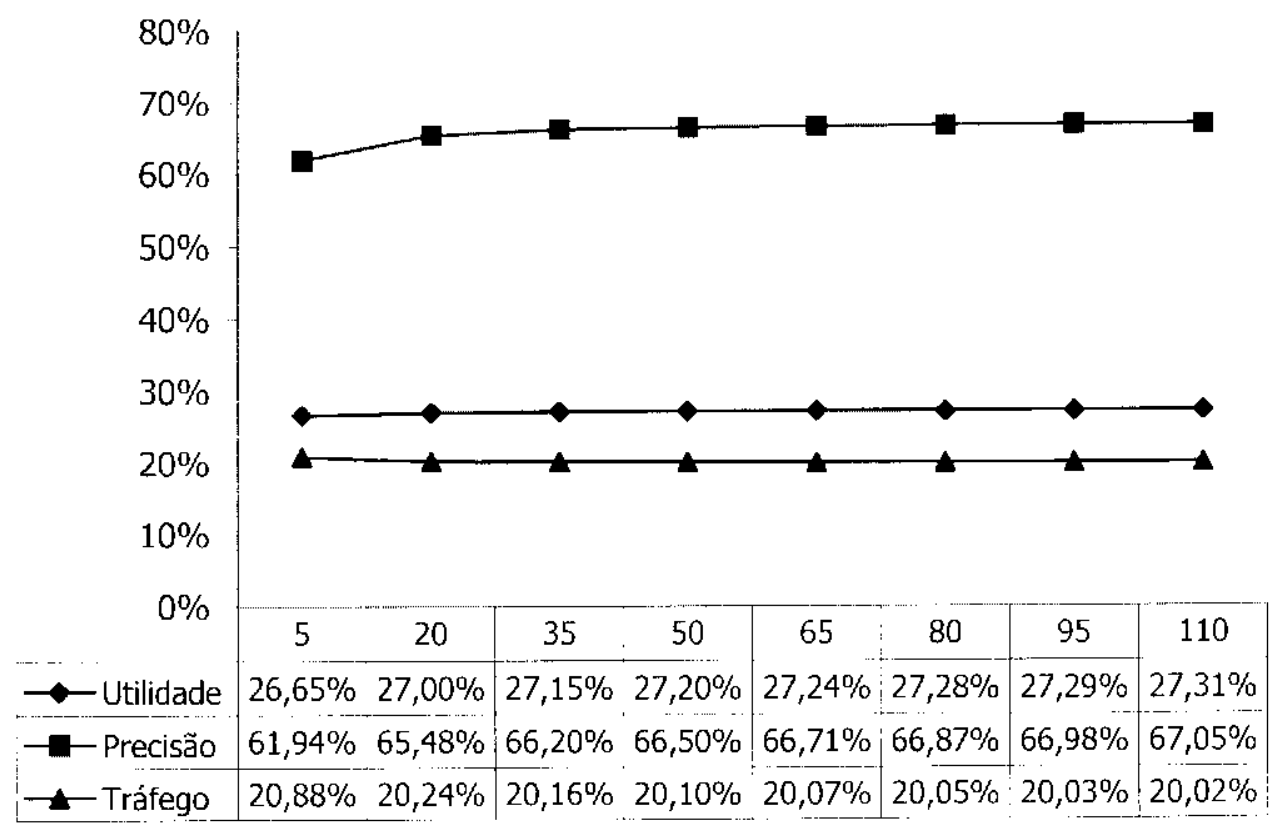

(a)

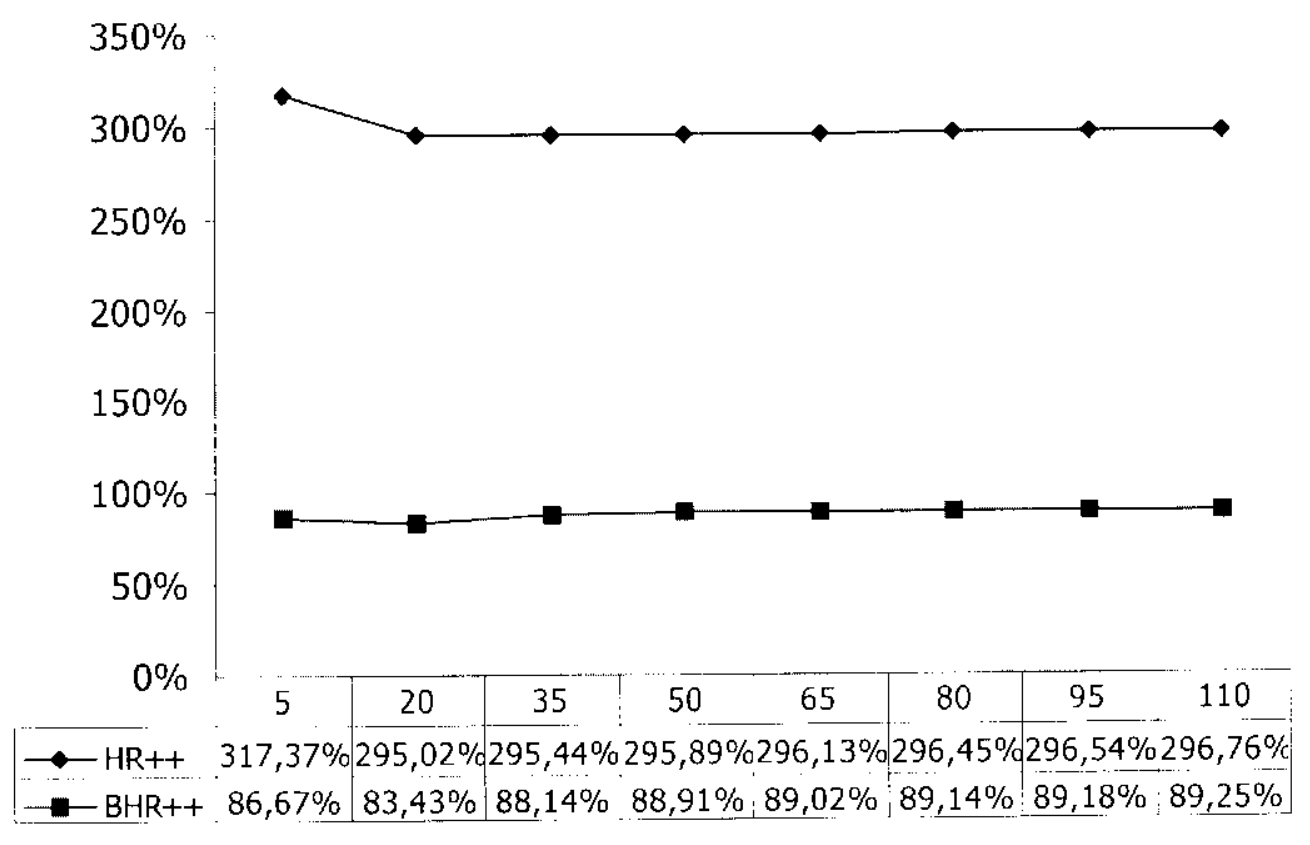

(b)

Figura 5.9 - Avaliação do parâmetro Tamanho de cache para o servidor Web 


\section{- Proxy Web}

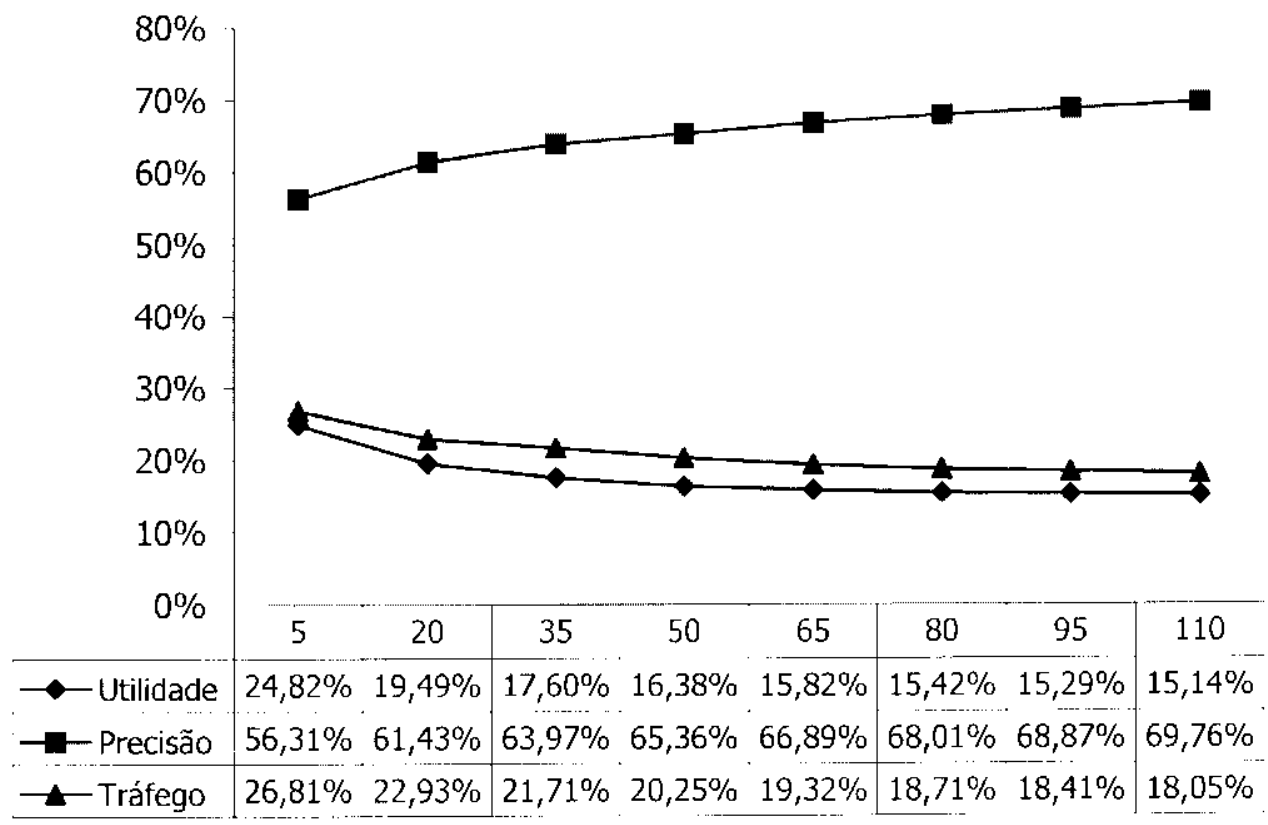

(a)

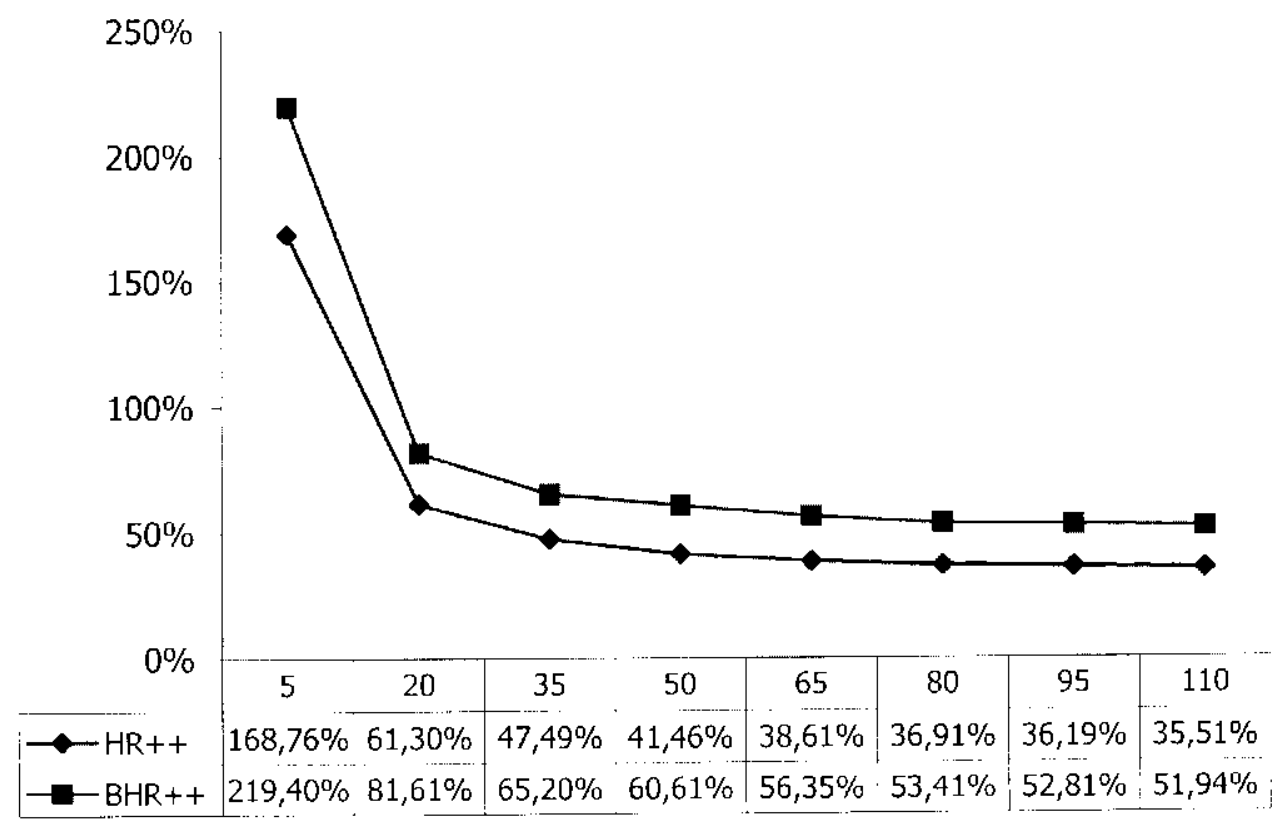

(b)

Figura 5.10 - Avaliaçāo do parâmetro Tamanho de cache para o proxy 


\subsubsection{Tempo Ocioso de Sessão}

Conforme descrito no capítulo 4, o parâmetro Tempo ocioso de sessão define o tamanho do intervalo de tempo ocioso que determina a quebra de uma sessão. Nos experimentos, procurou-se determinar o intervalo da simulação, usando um valor consideravelmente curto e um valor consideravelmente longo que estejam de acordo com um ambiente real de acessos de usuários, que nesse caso, é a Web. Assim, os valores desse parâmetro variaram desde o valor dc 500 , até o valor de 4000 (segundos). Além disso, a fim de certificar-se que esse intervalo de valores é suficiente para avaliação desse parâmetro, obscrvou-se o comportamento das métricas quando submetidos a um valor de intervalo cujos extremos são 100 (mínimo) e 10000 (máximo), e observou-se que as alterações no comportamento das métricas não foram relevantes.

Os resultados são apresentados nas figuras 5.11 e 5.12. Pode-se notar, pelas curvas dos gráficos, quc o parâmetro Tempo ocioso de sessão não tem muita influência no desempenho da pré-busca, pois para a maioria dos valores assumidos desse parâmetro, os valores das métricas mantiveram-sc quase inalterados. Porém, obscrvando-se o desempenho da pré-busca em cada um dos cenários, nota-se comportamentos distintos. Ao longo da simulação, no caso do servidor os valores das métricas alteraram-se positivamente, enquanto que no caso do proxy, ncgativamente. A explicação para esses comportamentos está na natureza distinta dos cenários, mais especificamente, no universo de páginas servidas em cada um deles.

O servidor se beneficia do menor número de páginas que ele scrve. A medida que se considera sessões de duração maior, um maior número de acessos são considerados consccutivos, de maneira que mais contextos são cncontrados na árvore de predição e mais precisa fica a pré-busca. Conseqüentemente, o tráfego gerado na rede e a utilidade da pré-busca aumentam, ambos por se fazer maior quantidade de pré-buscas.

Por outro lado, dado o volumoso e disperso universo de objetos servidos pelo proxy, o aumento do valor do parâmetro deteriora o descmpenho da pré-busca. Acessos que não tem correlação são considerados consccutivos com csse aumento, quando na prática não são (como mostram os gráficos da figura 5.12). Isso causa distorção no modelo de predição e declínio no número de páginas corretamente sugeridas pela pré-busca. 
Discutida essa distinção quanto ao efeito do parâmetro para cada um dos cenários, servidor e proxy, sugere-se a utilização de valores mais altos para o servidor (por exemplo, 3500 ), e de valores mais baixos para o proxy (por exemplo, 1000). Porém, uma cscolha diferente dessas sugeridas, mas dentro do intervalo avaliado, não interfere muito no desempenho do modelo de predição, como mostram os resultados.

Por outro lado, decidir pela eliminação desse parâmetro não seria adequado, pois a avaliação feita não abrange situações irreais de intervalo entre acessos. Por exemplo, sem a existência do parâmetro, o primeiro acesso realizado no dia seguinte ao último acesso realizado no dia anterior, seria identificado como conseguinte a este. Esse mesmo raciocínio pode ser estendido de dias para semanas, e assim por diante. Nos experimentos constatou-se que até um intervalo de 10000 segundos o parâmetro não tem muita influência. Esse é um valor considerado razoável na prática. Porém, isso não permite, adequadamente, estender essas conclusões para parâmetros cujos valores sejam muito maiores do que 10000 , por excmplo. 
- Servidor Web

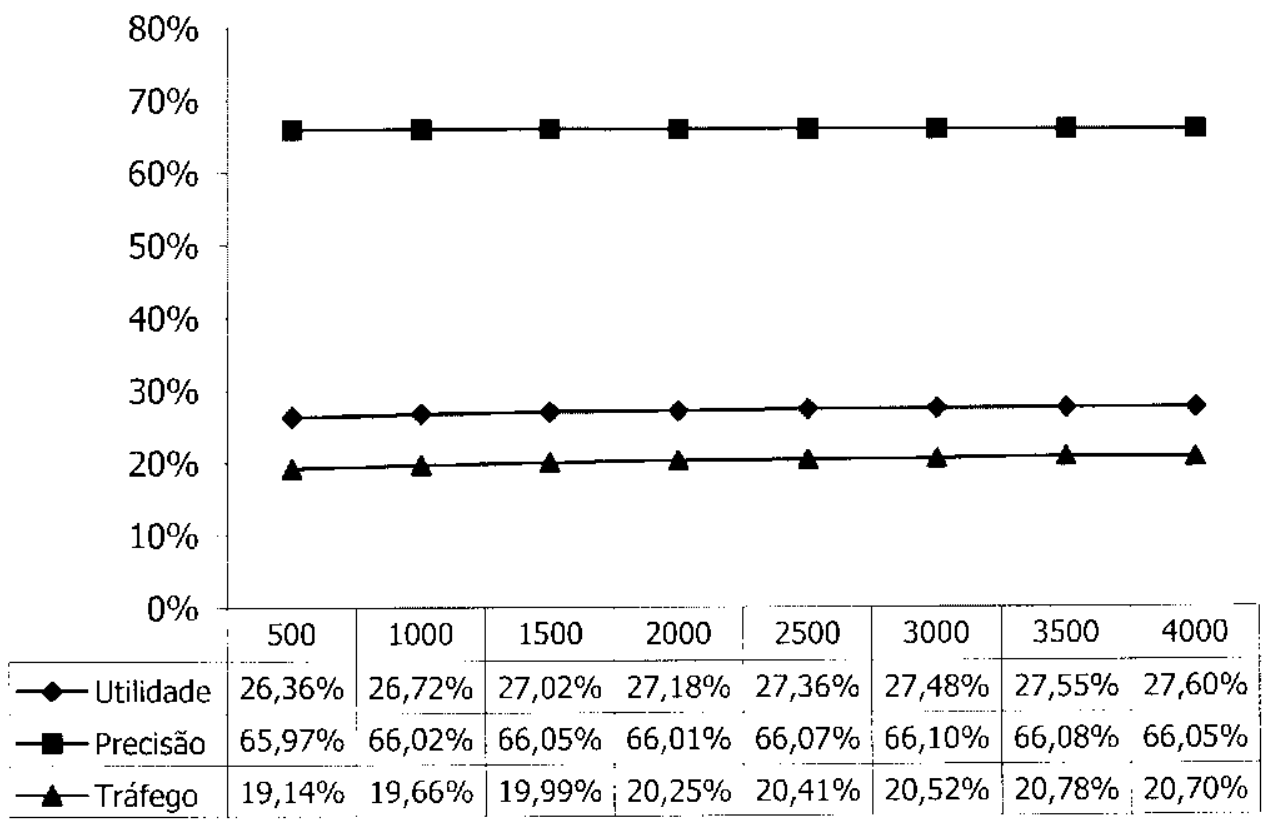

(a)

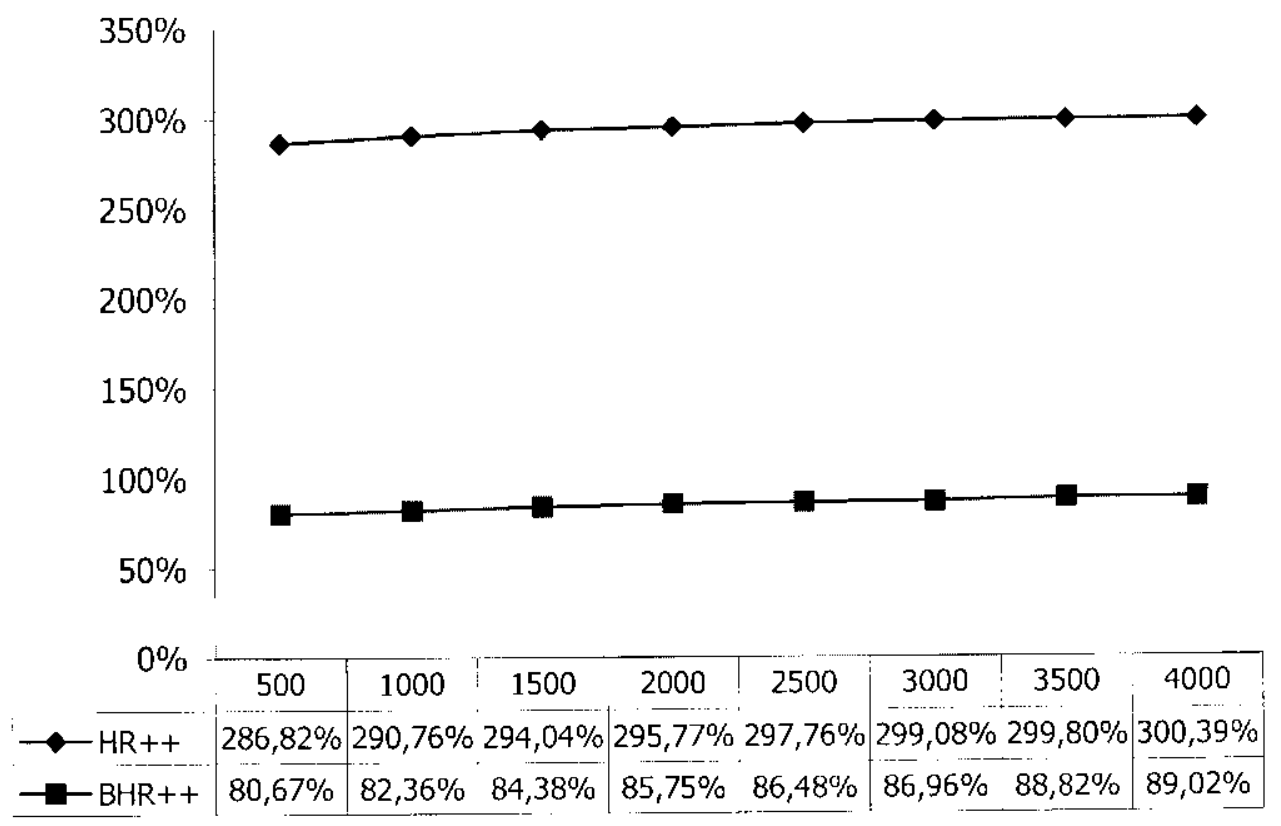

(b)

Figura 5.11-Avaliação do parâmetro Tempo ocioso de sessão para o servidor Web 


\section{- Proxy Web}

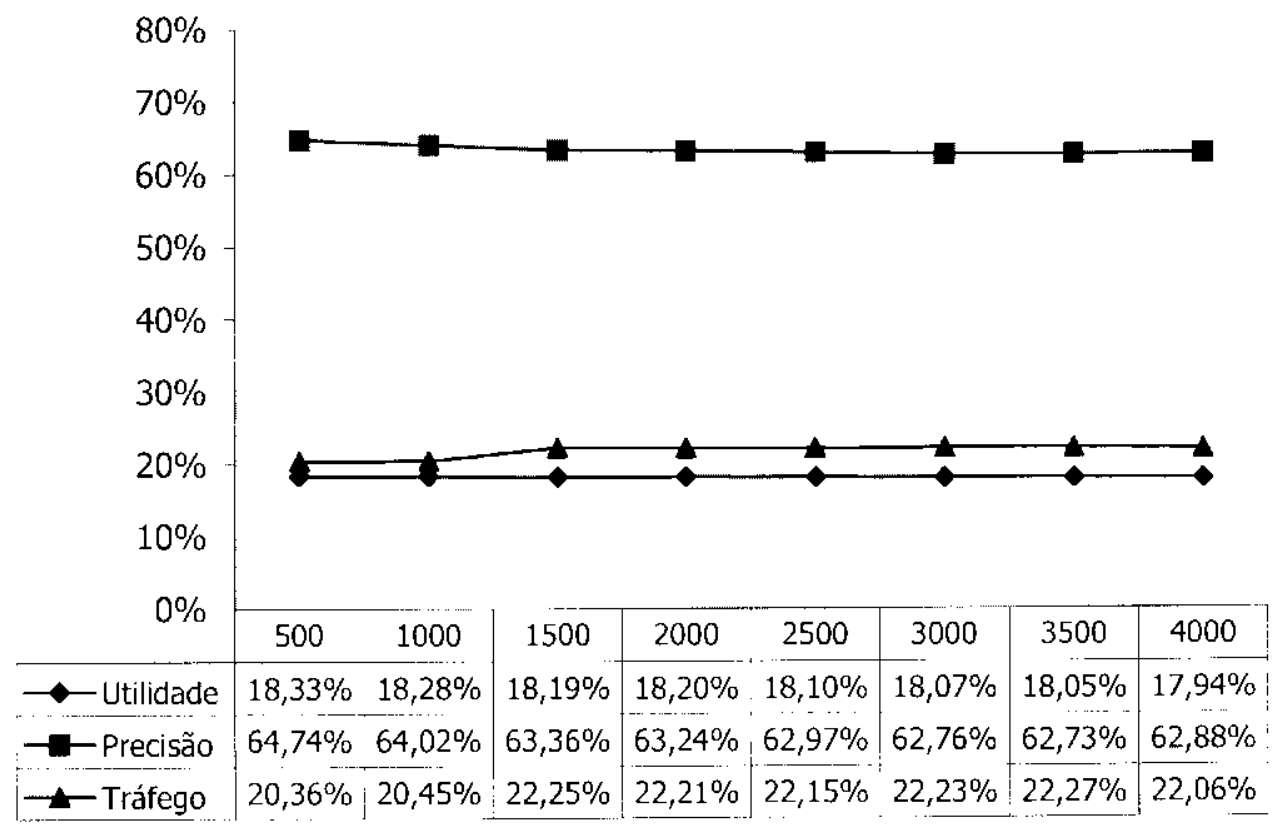

(a)

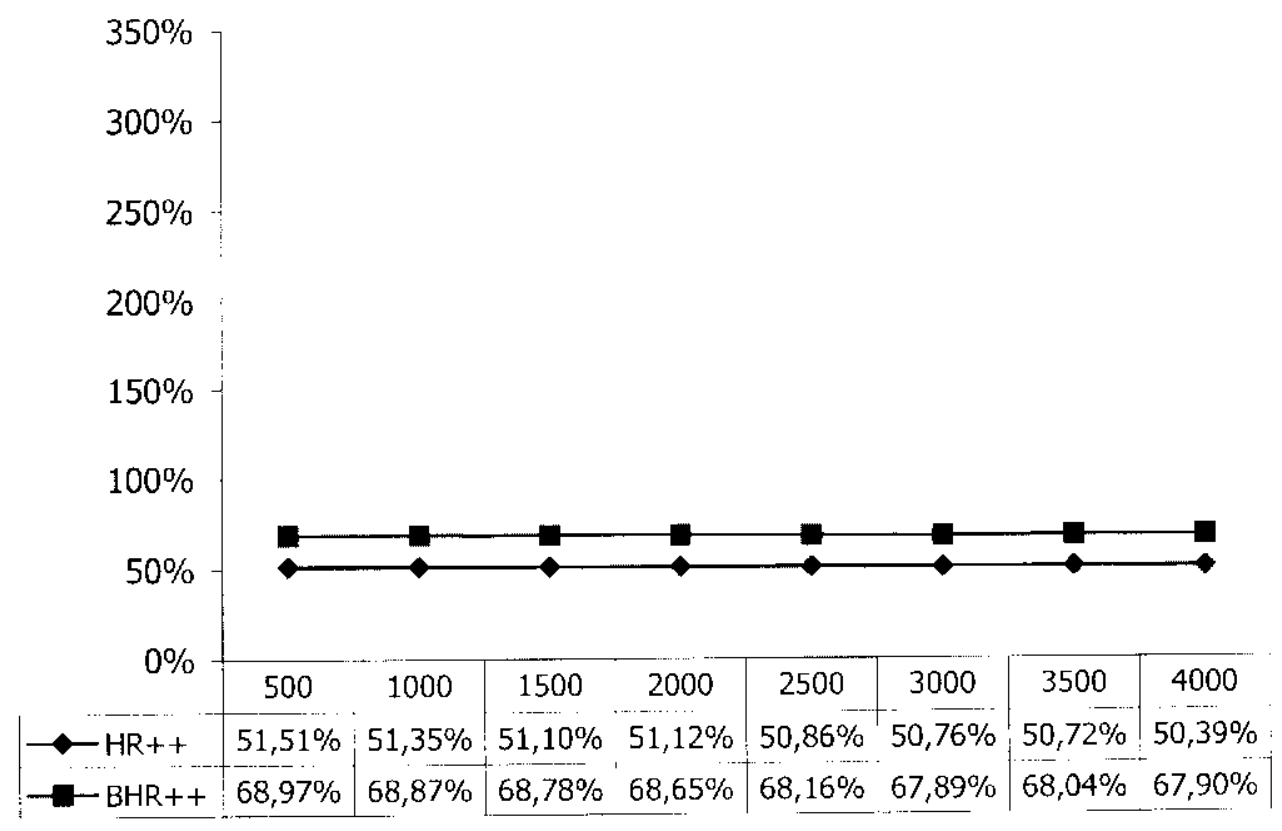

(b)

Figura 5.12 - Avaliação do parâmetro Tempo ocioso de sessão para o proxy 


\subsection{Considerações Finais}

Para cada um dos cenários analisados neste trabalho têm-se algumas peculiaridades (seção 5.1.3). Essas podem favorecer ou debilitar o desempenho da técnica pré-busca. Durante a cxecução dos experimentos e avaliação dos resultados, observou que quando a pré-busca ć empregada no cenário entre o cliente e o servidor cla é mais eficiente. Notou-se que a pré-busca é mais útil a um custo menor, ou seja, gera menos tráfego extra na rede, conforme constatado nos valores das métricas Utilidade e Tráfego ao longo dos experimentos.

Os efeitos diretos que a pré-busca causa no cache são conferidos nas métricas $H R++\mathrm{e}$ $B H R++$. Novamente, para o cenário referente ao servidor, observa-se maior usufruto da técnica de pré-busca.

Além disso, percebe-se que o modelo de predição foi capaz de identificar com maior precisão o padrão de acesso, quando tcm-se um grande número de usuários e acessando uma quantidade limitada de objetos (servidor), do que quando tem-se um número reduzido de clientes acessando um ilimitado universo de objetos (proxy).

É importante ressaltar que o critério para considerar a oscilação de uma determinada métrica relevante se dá, principalmente, através da observação visual de seu comportamento no gráfico ao longo da simulação. Essa abordagem ć adotada, pois as métricas estão em escalas muito distintas. Então, uma oscilação de $8 \%$ representa uma oscilação significativa pra uma métrica, por exemplo, Utilidade, e não é significativo para outra, como por excmplo $I I R++$.

A seguir, são destacadas, sucintamente, as principais conclusôes obtidas da avaliação feita por este trabalho, as quais já foram discutidas no decorrer deste capítulo:

- A pré-busca apresentou melhores resultados, quando empregada no cenário cliente e scrvidor Web do que aqueles alcançados quando empregada entre o cliente e proxy Web, como mostram os resultados das figuras 5.1 a 5.12;

- Os parâmetros Contador, Confiança, Número de Requisições Prévias e Tamanho de Cache são os que causam maior influência no desempenho da pré-busca. Essa influência é observada separadamente nos itens a seguir;

- O parâmetro Ordem foi avaliado e os resultados indicam que cle não influenciou no desempenho da pré-busca; 
- O Tempo Ocioso de Sessāo foi avaliado e os resultados indicam que ele não influenciou no desempenho da pré-busca:

- Os parâmetros Contador, Confiança e Número de Requisições Prévias cumprem bem seus ofícios no ambiente de pré-busca na Web, ponderando efetivamente o custo/benefício para se obter vantagem com a utilização da pré-busca, prcocupando-se com o tráfego adicional gerado na rede. Viu-se o tráfego extra diminuir substancialmente. Para esses parâmetros, os valores do Trágefo foram $12,16 \%, 5,33 \%$ e $4,38 \%$, respectivamente, no caso do servidor. Para o proxy, os valores foram: $3,10 \%, 12,55 \%, 17,63$, respectivamente.

- Os parâmetros Contador e Confiança restringem de forma cficiente o tráfego adicional gerado na rede, pois a redução dos valores da métrica Utilidade é inferior à redução dos valores da métrica Tráfego, proporcionalmente;

- O parâmetro Número de Requisiçōes Prévias restringe o tráfego extra a um alto custo da utilidade da pré-busca, comparando-o com os demais parâmetros que se destinam a fazer csse equilíbrio;

- Os parâmetros Tamanho de Cache e Contador geram maior influência no contexto do proxy $\mathrm{cm}$ relação ao servidor. Isso ocorre, dado o universo de páginas diversificado $\mathrm{e}$ numeroso servidas pelo proxy em relação ao servidor;

- O parâmetro Número de Requisições Prévias teve maior influência o contexto do servidor em relação ao proxy. Por exemplo, enquanto a utilidade oscila em 21,95\% no scrvidor, ela oscila somente $4,22 \%$ no proxy;

- O parâmetro Confiança teve maior influência em ambos cenários, proxy e servidor. Os valores mais altos para as métricas Utilidade, Tráfego, $H R++$ e $B H R++$ foram obscrvados quando o valor desse parâmetro foi igual a 0 , para os dois cenários. E na mesma circunstância do valor de Confiança, viu-se os valores mais baixos para a Precisão, nos dois cenários;

- A pré-busca ć ainda mais valiosa quando são servidos clientes cujos caches são pequenos. Nesses casos, por exemplo, a oscilação causada na passagem de um valor para o outro (de 5 para 20), foi de 107,46\%, para o proxy. Esse comportamento é ímpar em todas as simulações, considerando-se a métrica e cenário relacionados. Deveu-se a maior influência no cenário do proxy devido ao número de páginas que este serve.

A segunda etapa da análise dos resultados visa quantificá-los de acordo com uma configuração para cada um dos parâmetros, originada da avaliação individual dos parâmetros por ccnário. Assim, na tabela 5.9 são apresentados os valores sugeridos para cada um dos cenários 
cm questão. Alguns parâmetros têm seu valor sugerido acompanhado por um asterisco (*). Para eles, é fortemente aconselhável que esse valor seja adotado, pois notou-se uma significativa melhora no desempenho da pré-busca com sua utilização. Para o parâmetro Tamanho de Cache não é sugerido um valor para configuração, por ser um parâmetro externo ao modelo de predição (subseção 5.2.5).

Tabela 5.9 - Valores sugeridos para os parâmetros nos cenários proxy e servidor

\begin{tabular}{|l|r|r|}
\hline \multicolumn{1}{|c|}{ Parâmetro } & \multicolumn{1}{c|}{ Servidor } & \multicolumn{1}{c|}{ Proxy } \\
\hline Ordem & 2 & 2 \\
\hline Contador & 2 & $2^{*}$ \\
\hline Confiança & $0,3^{*}$ & $0,3^{*}$ \\
\hline Requisições Mínimas & $0^{*}$ & 0 \\
\hline Tempo ocioso de Sessão & 4000 & 500 \\
\hline
\end{tabular}

Na seção 3.4, debate-se sobre as estratégias de implementação de pré-busca na Web. Como dito, uma implementação pode ser ajustada, por meio de parâmetros, para ser agressiva ou conservadora. As tabelas 5.10 e 5.11 ilustram essas diferentes configuraçõos de pré-busca para os cenários, servidor e proxy, respectivamente. A configuração dita "Sugerida" é baseada na análise dos valores dos parâmetros, de acordo com a tabela 5.9. A exemplo dessa tabela, o parâmctro cache é tratado diferentemente dos demais. Assim, optou-se por um valor do parâmetro cache padrão igual a 30. Esse valor é o mesmo usado nas simulaçõcs apresentadas na seção 5.2, e foi utilizado para as três configurações: Sugerida, Agressiva c Conservadora, cm ambos os casos: scrvidor e proxy. Os demais valores das configurações - Agressiva e Conservadora, são escolhidos baseando-sc nos valores da métrica Tráfego. Para configurar a pré-busca Agressiva, percorreu-se todos os valores de cada parâmetro e aquele que apresentou o maior valor para essa métrica foi eleito para compor a configuração Agressiva. O mesmo foi feito para configurar a pré-busca Conservadora, porém, optando-se pelos menores valores vistos em cada parâmetro.

Analisando as tabelas 5.10, por exemplo, pode-se perceber como a configuração da prébusca pode ser direcionada de acordo com o seu objetivo. Se a escolha for por uma pré-busca 
agressiva, por exemplo, obteve-se uma utilidade de $32,92 \%$. Adiciona-se na rede, nesse caso, um tráfego extra de $56,46 \%$. Nota-se também, que o cache melhorou sua taxa de acerto em $358,31 \%$ com o emprego de pré-busca. Essa é uma configuração que favorece a ação da pré-busca. Por outro lado, a precisão, que apresentou o valor de 44,89\% (métrica Precisão) mostrou-se prejudicada. Isso ocorre pois nenhum parâmetro exige do modelo probabilidade ao fazer a predição.

Tabela 5.10 - Configurações de pré-buscas do servidor Web

\begin{tabular}{|c|r|r|r|r|r|}
\cline { 2 - 6 } \multicolumn{1}{c|}{} & \multicolumn{1}{c|}{ Utilidade } & Precisão & \multicolumn{1}{c|}{ Tráfego } & \multicolumn{1}{c|}{ HR++ } & \multicolumn{1}{c|}{ BHR++ } \\
\hline Sugerida & $26,00 \%$ & $69,38 \%$ & $17,37 \%$ & $282,99 \%$ & $79,61 \%$ \\
\hline Agressiva & $32,92 \%$ & $44,89 \%$ & $56,46 \%$ & $358,31 \%$ & $138,39 \%$ \\
\hline Conservadora & $0,65 \%$ & $92,07 \%$ & $0,26 \%$ & $7,08 \%$ & $1,85 \%$ \\
\hline
\end{tabular}

Tomando como exemplo a tabela 5.11, referente ao proxy, e adotando-se uma pré-busca conservadora, tem-se que a atividade da pré-busca diminui consideravelmente. Nesse caso, quando explicitamente a preocupação é quanto o tráfego extra gerado na rede, o valor da métrica atinge somente $0,55 \%$. Dessa forma, a pré-busca é feita somente para página que atende a critérios exigentes de precisão, como se pode observar na mćtrica Precisão: 92,07.

Tabela 5.11 - Configurações de pré-buscas do proxy

\begin{tabular}{|c|r|r|r|r|r|}
\cline { 2 - 6 } \multicolumn{1}{c|}{} & \multicolumn{1}{c|}{ Utilidade } & \multicolumn{1}{c|}{ Precisão } & \multicolumn{1}{c|}{ Tráfego } & \multicolumn{1}{c|}{ HR++ } & \multicolumn{1}{c|}{ BHR++ } \\
\hline Sugerida & $15,72 \%$ & $75,16 \%$ & $9,12 \%$ & $44,16 \%$ & $55,01 \%$ \\
\hline Agressiva & $18,20 \%$ & $54,89 \%$ & $26,55 \%$ & $51,12 \%$ & $71,93 \%$ \\
\hline Conservadora & $2,07 \%$ & $96,97 \%$ & $0,55 \%$ & $5,83 \%$ & $5,19 \%$ \\
\hline
\end{tabular}

A configuração Sugerida busca equilibrar a atividade da pré-busca, ponderando o seu custo custo/benefício. Tal configuração mostrou-se bastante eficiente em relação às demais. Nas tabelas 5.10 e 5.11 pode-se perceber que comparar a configuração Sugerida com a Agressiva é interessante. Já no caso da configuração Conservadora, pouco se tem para analisar, já que essa configuração praticamente anulou a atividade da pré-busca, que, é de fato o seu objetivo. 
No caso do scrvidor, adicionando-se $17,37 \%$ de tráfego na rede, o usuário experimenta uma utilidade de $26 \%$. Além disso, considerando-se os valores obtidos com a configuração agressiva, pode-se notar a relevância da configuração Sugerida. Os valores das métricas Utilidade e Tráfego naturalmente diminuem no caso da configuração Sugerida. Porém, enquanto o tráfego cai $39,09 \%$, a utilidade cai apenas $6,92 \%$. O cache, por sua vez, continua usufruindo de uma boa melhora com a atividade da pré-busca, o que é indicado pelo valor das métricas $H R++$ e $B H R++: 282,99$ e $79,61 \%$, respectivamente. A precisão do modelo, principalmente com a exigência dos parâmetros Confiança c Contador aumenta $24,49 \%$ em relação a configuração Agressiva, alcançando o valor de $69,38 \%$.

No outro cenário analisado, o proxy, percebe-se também grandes melhorias na ação da pré-busca, ao se utilizar a configuração Sugerida em vez da Agressiva. Considerando-se os valores obtidos com a configuração agressiva, a métrica Tráfego e Utilidade oscilam em 17,43\% c $2,48 \%$, respectivamentc. Mesmo com o baixo tráfego gerado na rede $(9,12 \%)$, o cache experimenta uma melhora na taxa de acerto de $44,16 \%$ e uma melhora na taxa de acerto em bytes de $55,01 \%$. O modelo de predição na configuração Sugerida passa a trabalhar com uma precisão de $75,16 \%$ contra os $54,89 \%$ observados na configuração Agressiva. Essa melhoria é garantida devido ao emprego adequado dos parâmetros Contador e Confiança. 


\section{CAPÍTULO 6}

\section{Conclusões}

A atividade de Pré-busca aplicada à Web tem se mostrado como uma das formas de melhorar o desempenho de cache, que é uma prática largamente utilizada nesse contexto, mas que vem apresentando limitações à medida que a natureza da Web diversifica-se com sua evolução.

Este trabalho apresentou uma análise e avaliação de desempenho da pré-busca em caches na Web utilizando predição estatística, considerando-se o custo/benefício de seu emprego. Faz-se necessário portanto, ponderar entre scu ganho e scu principal efeito colateral: o tráfego adicional gerado na rede, visto que a aplicação inadequada de pré-busca, considerando que os acessos não utilizados gerarão tráfego extra na rede, pode tornar-se prejudicial para o desempenho da Web como um todo.

Inicialmente, fez-se uma ampla revisão bibliográfica do assunto em questão (capítulos 2 e 3), que possibilitou a familiarização com o ambiente no qual este trabalho se insere - Caches na Web, e com os aspectos que caracterizam a prática de pré-busca no ambiente Web. Ao fazer esse estudo, naturalmente, deparou-se com vários trabalhos correlatos. Entre eles, alguns deixam claro a utilização ou desenvolvimento de ferramentas para simulação, que permitem a avaliação da pré-busca na Web. Dentre essas ferramentas, utilizou-se o simulador cedido por Palpanas [Pal 1999]. Depois de um estudo detalhado no código desse simulador, verificou-se a necessidade de adaptá-lo, para que ele atendesse adequadamente os objetivos propostos neste estudo, no que diz 
respeito à simulação do ambiente da Web. Os detalhes cnvolvendo essa adequação foram apresentados no capítulo 4.

Para realizar a simulação, além dos aspectos já tratados pelo simulador, modelo de predição e um cache para suportar a pré-busca, é necessário um log de acesso de clientes Web, para que se pudesse extrair a carga de trabalho para a simulação. Questões como cenário retratado por cada $\log$, período de registro de acessos e recentidade, foram decisivas para a escolha, dentre vários logs estudados. Dada as diretrizes para tal cscolha, dois logs foram tratados c caracterizados neste trabalho (capítulo .5).

De acordo com os resultados apresentados e discutidos no capítulo 5, notou-se relevantes ganhos quanto à utilidade da pré-busca, em ambos os cenários: quando empregada entre o cliente e o servidor, e quando empregada entre o cliente e o proxy. Isso se torna mais significante, quando se ressalta o fato de que o maior ganho obtido foi quando a pré-busca é aplicada no primeiro cenário - cliente servidor. Assim, pode-se aliar a essa vantagem expressá em números (diferença de desempenho entre os dois cenários), os benefícios que ela traz, tendo em vista o fato de que a latência externa (relativa ao scrvidor Web) é responsável pela grande maioria da latência percebida pelo usuário (seção 3.2).

A partir do exposto, este capítulo tem seqüência com a discussão sobre as principais contribuições geradas por este trabalho, sendo scguido por considerações sobre as dificuldades encontradas durante o período de desenvolvimento, juntamente às sugestões para a realização de trabalhos futuros.

\subsection{Contribuições}

As contribuições principais obtidas com a realização deste trabalho, são:

- A concepção de uma configuração adequada para a pré-busca, chamada "Sugerida", que tem como objetivo ponderar o custo/benefício do emprego de pré-busca na Web. Tal configuração foi definida considerando a análise individual de cada um dos parâmctros cstudados e o cenário ao qual a pré-busca cstá sendo utilizada; 
- A caracterização de duas cargas de trabalho atuais, que refletem o atual cenário da Web, quanto a seus objetos e comportamento dos usuários;

- Aprimoramento do simulador para pré-busca e caches na Web;

Com a análise e avaliação abrangente de técnicas de pré-busca em caches para a Web, derivou-se as seguintes conclusões:

- Os resultados dos experimentos realizados neste trabalho apontam que a pré-busca estatística é uma técnica efetiva e valiosa quanto à melhora do desempenho da Web e a taxa de acerto do cache. Constatou-se, por meio da análise dos valores assumidos por cinco métricas durante os experimentos, que para o atual padrão de acesso e o grande e diverso universo de objetos servidos na Web, a pré-busca pode ser utilizada de forma ponderada através da configuração dos parâmetros Contador, Confiança, Requisições Prévias. Essa configuração, se feita de forma adequada, garante a utilidade da pré-busca num custo relativamente baixo. Isso é conferido pelos valores apresentados pelas métricas Utilidade e Tráfego, que apresentaram, respectivamente, os valores $26 \%$ c $17,37 \%$ para o cenário referente servidor Wcb e $15,72 \%$ e $9,12 \%$ para o cenário referente ao proxy Web. Esses valores foram alcançados utilizando-se a configuração Sugerida;

- Os cenários referentes ao scrvidor Web e ao proxy Web foram analisados e avaliados nas mesmas circunstâncias. Concluiu-se que o emprego da pré-busca é mais interessante quando feito no servidor Web em relação ao scrvidor proxy. Além da diferença conferida pelos números, mencionada no item anterior, visto que a principal origem da latência percebida pelo usuário diz respeito a rede externa, ou seja, ao cenário ao qual o servidor Web está cnvolvido;

- O tratamento da problemática de tráfego extra adicionado à rede pode ser melhor resolvido com alguns parâmetros específicos e individualmente para cada cenário. É o caso, por exemplo, do parâmetro Contador, que foi mais efetivo no cenário cujo servidor de objetos é o proxy. Nesse caso, o tráfego extra gerado pela pré-busca variou de $22,17 \%$ para $3,10 \%$, cnquanto que no caso do servidor Web ele variou de $20,19 \%$ para $12,16 \%$ ao longo da simulação.

- Ambos os cenários, proxy Web e servidor Wcb, para o parâmetro Número de Requisiçōes Prévias, apresentaram resultados aquém daqueles vistos pelos outros dois parâmetros que destinam-se também a cquilibrar o tráfego gerado na rede com a utilidade da prébusca: Contador e Confiança. Esses parâmetros mostraram-se mais eficientes, uma fez que a queda do tráfego extra gerado na rede é superior a queda de utilidade da pré-busca. Por exemplo, 
no caso do servidor Web, com a avaliação do parâmetro Número de Requisições Prévias, a utilidade caiu em $24,95 \%$ e o tráfego somente em $15,81 \%$. Para os outros dois parâmetros citados, a queda do tráfego ć superior à queda da utilidade. Para o Contador, a queda foi de $4,48 \%$ e $8,03 \%$, respectivamente. No caso da Confiança, cssa diferença positiva é mais patente. A utilidade cai $26,53 \%$ e o tráfego $55,29 \%$.

- Através dos experimentos, pode-se verificar o impacto causado pela introdução da pré-busca sobre o cache, na ótica de duas métricas consideradas exclusivamente neste trabalho: $H R++$ e $B H R++$. Com seus resultados, pôde-se concluir que uma boa alternativa para contornar o problema de um cache relativamente pequeno, tendo em vista o univcrso de páginas que lhe é servido, é valer-se do usufruto que a pré-busca o proporciona. Para um cache pequeno, o incremento em sua taxa de acerto chega a $317,37 \%$ e $168,76 \%$ para o servidor e proxy Web, relativamente. Para a pré-busca utilizando a configuração Sugerida, esses valores são de $282,99 \%$ e $44,16 \%$, mostrando o quão proveitosa foi a pré-busca para o cache;

- Parâmetros comumente avaliados, como é o caso de Ordem e Tempo Ocioso de Sessão, podem em alguns casos não influenciar decisivamente no modelo de predição. Como pôde-se conferir por simples análise visual nos gráficos, esses parâmetros não apresentam nenhuma alteração significativa dos valores das métricas;

- O estudo possibilitou indicar o valor mais adequado dos parâmetros nos cenários servidor Web e proxy Web. Além disso, foram definidos valores de parâmetros que são considerados imprescindíveis para o bom desempenho da atividade de pré-busca.

\subsection{Trabalhos Futuros}

Este trabalho teve como foco principal avaliar o uso da pré-busca na Wcb objetivando, principalmente, procedimentos que tornam sua utilização adequada quanto a não utilização de páginas que não são de fato utilizadas. Por isso, os principais temas abordados foram o tráfego extra gerado na rede e a precisão do modelo de predição. Todavia, não considerou-se questões como quão custoso pode ser manter a árvore de predição em atividade, as medidas necessárias para tornar a pré-busca viável na Web, sua atual infra-estrutura e protocolos. A partir disso, pode-se dar seqüência a esta pesquisa, por mcio de alguns trabalhos futuros sugeridos: 
- Estudar técnicas que viabilizam inserir a pré-busca na Web, minimizando a demanda por recursos computacionais procedente de sua utilização. Esses recursos são, principalmente, memória e processamento. Outra forma de economizar recursos, dá-se através do descarte de dados que refletem antigos padrões de acesso (por cxcmplo, climinar da árvorc objetos muito antigos);

- Como mencionado, pretendeu-se verificar o impacto que a pré-busca com predição estatística provoca, em relação à melhora no desempenho da resposta ao cliente da Web, e a melhora na taxa de acerto do cache. Porém, dada a limitação da infra-estrutura atual da Web, que ainda não fornece subsídios para o emprego da pré-busca na prática, a avaliação da pré-busca é feita a partir de uma simulação do ambiente Web, como visto nos demais trabalhos correlatos. Uma ver comprovado o usufruto da pré-busca na Web, com este e vários outros trabalhos de mesmo cunho, deve-se concentrar esforços para viabilizar sua introdução na prática, como se fez com a técnica de cache;

- Viu-se neste estudo várias potencialidades e algumas reservas do emprego da prébusca na Web. Contudo, é necessário analisar como e quanto essas características são influenciadas quando o emprego da pré-busca ocorrer na prática. Deve-se tentar manter ou maximizar os benefícios da pré-busca e, por outro lado, não agravar ou minimizar suas desvantagens no que se refere ao seu emprego prático. Além disso, ainda $\mathrm{cm}$ relação ao uso prático, novas características seriam identificadas e scriam consideradas entre si e em conjunto com as já mencionadas;

- Pelo extenso período gasto para que esse simulador fosse intciramente modificado para ser utilizado neste trabalho, não pôde-se avaliar diferentes políticas de substituição de cachc. Comparar como as diferentes políticas de substituição (já estudadas em trabalhos anteriores no grupo) se comportam em conjunto com a pré-busca, seria relcvante. Um estudo ainda mais instigante consiste em analisar e propor novas políticas de substituição de cache, que considerem a existência de um elemento externo, a pré-busca, que tem influência direta e ativa no contcúdo do cache. 


\section{REFERÊNCIAS BIBLIOGRÁFICAS}

[Abr 1995] ABRAMS, M. ct al. Caching Proxies: Limitations and Potentials. In: Proc: of 4th International World Wide Web Conference. Boston, USA. 1995. p. $119-133$.

[Agg 1999] AGGARWAL, C. C.; WOLF, J. L.; YU, P. S. Caching on the World Wide Web. Knowledge and Data Engineering, v. 11, n. 1, p. 95-107, 1999.

[Alm 1996] ALMEIDA, V. ct al. Characterizing Reference Locality in the WWW. In: Proceedings Of The Fourth International Conference on Parallel and Distributed Information Systems. Washington, DC, USA: IEEE Computer Sociely, 1996. p. 92-107. ISBN 0-8186-7475-X.

[AIm 1996] ALMEIDA, V. et al. Characterizing Reference Locality in the WWW. In: Proceedings of the Fourth International Conference on Parallel and Distributed Information Systems. Washington, DC, USA: IEEE Computcr Society, 1996. p. 92-107. ISBN 0-8186-7475-X.

[Arl 1996] ARLITT, M. F.; WILIIAMSON, C. L. Web Server Workload Characterization: the Search For Invariants. In: Proceedings of the 1996 ACM SIGMETRICS International Conference On Measurement And Modeling Of Computer Systems. 1996. p. 126-137.

[Arl 1999] ARLITT, M.; JIN, T. Workload Characterization of the 1998 World Cup Web Site. HP Laboratorics Palo Alto. Relatório Técnico HPL-1999-35R I. Set. 1999.

[Bar 1999] BARFORD, P. et al. Changes in Web Clicnt Access Patterns: Characteristics and Caching Implications. World Wide Web, Kluwer Academic Publishers, Hingham, MA, USA, v. 2, n. 1-2, p. 15-28, 1999.

[Bar 2000] BARISH, G.; OBRACZKA, K. World Wide Web Caching: Trends and Tcchniques. IEEE Communications Magazine Internet Technology Series, v. 38 , p. 178-184, Mai. 2000 .

[Bes 1995] BESTAVROS, A. Using Speculation To Reduce Scrver Load And Service Time on the WWW. In: Proceedings of The Fourth International Conference On Information and Knowledge Management. 1995. p. 403410. ISBN 0-89791-812-6.

[Cao 1997] CAO, P.; IRANI, S. Cost-Aware WWW Proxy Caching Algorithms. In: Proceedings of the 1997 Usenix Symposium on Internet Technologies and Systems (USITS-97). Monterey, CA: USENIX Association, 1997. p. 193206. 
[Coh 2000] COHEN, E.; KAPLAN, H. Prefetching the Means for Document Transfer: A New Approach for Reducing Web Latency. In: IEEE COMPUTER SOCIETY. Proceedings of INFOCOM 2000. Nineteenth Annual Joint Conference of the IEEE Computer and Communications Societies. Piscataway, NJ: IEEE Computer Society Press, 2000. v. 2, p. 854-863.

[Com 2000] COMER, D. E. Internetworking with TCP/IP: Principles, Protocols, and Architecture. 4. ed. Upper Saddle River, N.J.: Prentice Hall, 2000. 640 p.

[Cun 1997] CUNHA, C. R.: JACCOUD, C. F. B. Determining WWW User's Next Access and its Application to Prefetching. In: IEEE COMPLTER SOCIETY. 2nd IEEE Symposium on Computers and Communications (ISCC '97). IEEE Computer Socicty Press, 1997. p. 6.

[Cur 1993] CUREWITZ, K. M.; KRISHNAN, P.; VITTER, J. S. Practical Prefetching Via Data Compression. In: Proceedings of the 1993 ACM SIGMOD International Conference on Management of Data. 1993. p. 257-266. ISBN 0-89791-592-5.

[Cha 1996] CHANKHUNTHOD, A. et al. A Hierarchical Internet Object Cache. In: USENIX Annual Technical Conference. San Diego, CA, USA: USENIX Association, 1996. p. 153-164.

[Che 2001] CHEN, X.; ZHANG, X. Coordinated Data Prefetching by Utilizing Reference Information at Both Proxy and Web Servers. SIGMETRICS Perform. Eval. Rev., v. 29, n. 2, p. 32-38, 2001. ISSN 0163-5999.

[Che 2002] CHEN, X.: ZHANG, X. Popularity-based PPM: An Efective Web Prefetching Technique for High Accuracy and Low Storage. Proceedings of 2002 International Conference on Parallel Processing (ICPP'02), IEEE Computer Society, Vancouver, B.C., Canada, p. 296-304, Ago. 2002.

[Che 2003] CHEN, X.; ZHANG, X. A Popularity-Based Prediction Model for Web Prefetching. Computer, v. 36, n. 3, p. 63-70, 2003. ISSN 0018-9162.

[Dav 2001] DAVISON, B. D. Assertion: Prefetching with get is not good. In: Proceedings of the Sixth International Workshop on Web Caching and Content Distribution (WCW'O1). Boston, MA: Elsevier, 2001.

[Dav 2001a] DAVISON, B. D. A Wcb Caching Primer. IEEE Internet Computing, v. 5, p. 38-45, Jul.-Ago. 2001.

[Dav 2002] DAVISON, B. D. The Design And Evaluation Of Web Prefetching And Caching Techniques. Tese (Doutorado) - New Brunswick, New Brunswick, New Jersey, Out. 2002. 
[Dod 1998] DODGE, R.; MENASCÉ, D. A. Prefetching Inlines To Improve Web Server Latency. Dez. 1998. Published in the Proc. of the 1998 Computer Measurement Group Conference, Anaheim, CA.

[Duc 1999] DUCHAMP, D. Prefetching Hyperlinks. In: Proc. 2nd Usenix Symp. Internet Technologies and Systems. Berkeley, Calif.: USENIX Association, 1999.

[El- 1998] EL-SADDIK, A.; GRIWODZ, C.; STEINMETZ, R. Exploiting User Behaviour in Prefetching WWW Documents. In: Proc: of International Workshop on Interactive Distributed Multimedia Systems and Telecommunication Services 98 (IDMS 98), Oslo, Norway. 1998. p. 302311.

[Fan-1999] FAN, L. el al. Web Prefetching Between Low-Bandwidth Clients and Proxies: Potential and Performance. In: Proceedings of the 1999 ACM SIGMETRICS International Conference on Measurement and Modeling of Computer Systems. New York, NY, USA: ACM Prcss, 1999. p. 178-187.

[Fic 1999] FIEIDING, R. et al. Iypertext Transfer Protocol-HTTP/1.1. Jun. 1999.

[Fon 1998] FONSECA, E. L. S.; ALMEIDA, V. A. F.; Meira Jr., W. Análise de Desempenho de Servidores Proxy Cache WWW. 1998. Universidade Federal de Minas Gerais. Disponível em:

<http://www.dcc.ufmg.br/pos/html/spg98/anais/crik/erik.html>. Acesso em 23 jan. 2004.

[Gwe 1996] GWERTZMAN, J.; SELTZER, M. I. World wide web cache consistency. In: Proceedings of the 1996 USENIX Annual Technical Conference. San Diego, CA: USENIX Association, 1996. p. 141-152.

[Hun 1997] HUNT, C. TCP/IP Network Administration. 2. cd. O'Reilly, 1997.

[Isc 2003] ISC - INTERNET SYSTEMS CONSORTIUM. 2003. Disponível em: $<$ http://www.isc.com>. Acesso em 23 jan. 2004.

[Jai 1991] JAIN, R. The Art of Computer Systems Performance Analysis: Techniques for experimental design, measurement, simulation and modeling. New York: John Wiley \& Sons, 1991. 685 p.

[Kha 2001] KHAN, J.; THAO, Q. Prefetch scheduling for composite hypermedia. IEEE International Conference on Communications - ICC 2001, Helsinki, Finland, Jun 2001.

[Kri 1994] KRISHNAN, P.; VITTER, J. S. Optimal Prediction for Prefetching in the Worst Case. In: Proceedings of the Fifth Annual ACM-SIAM Symposium on Discrete Algorithms. Philadelphia, PA, USA: Society for Industrial and Applied Mathematics, 1994. p. 392--401. 
[Kri 2001] KRISHNAMURTHY, B,; REXFORD, J. Redes para a web: HTTP/1.], Protocolos de rede, caching e medição de tráfego. Rio de Janeiro: Editora Campus, 2001. Tradução: Daniel Vieira.

[Kro 1997] KROEGER, T. M.; LONG, D. D. E.; MOGUL, J. C. Exploring the Bounds of Web Latency Reduction from Caching and Prefetching. In: Proceedings of the 1997 Usenix Symposium on Internet Technologies and System.s (USITS-97). Monterey, CA: USENIX Association, 1997. p. 193-206.

[Kro 1997] KROEGER, M.T.; Long, D.D.E. Exploring the Bounds of Web Latency Reduction from Caching and Prefetching. In Proc. USENIX Symp. on Internet Technologies and Systems, p.13-22, USENIX Dec 1997.

[Lee 1996] LEE, D.C. PreFetch Document Caching to Improve WorldWide Web User Response Time. Master's Thesis. Virginia Polytechnic Institute and State University. Mar 1996.

[Mar 1998] MARKATOS, E.P.; Chronaki, C.E. A Top-10 Approach to Prefetching on the Web. In Proc. INET 98. Jul 1998.

[Mof 1990] MOFFAT, A. Implementing the PPM Data Compression Scheme. IEEE Transations on Communications, v. 38, n. 11, p. 1917-1921, Nov. 1990.

[Mud 1996] MUDGE, T.; Chen, I. Coffey, J. Limits to Branch Prediction. CSE-TR-28296, Feb 1996.

[Mur 2000] MURTA, C. D.; Almeida, V. A. F. Modelo de Particionamento de Espaço para Caches da World Wide Web. Universidade Federal de Minas Gerais. 2000.

[Nan 2001] NANOPOULOS, A.; Katsaros, D.; Manolopoulos, Y. Effective prediction of web-user accesses: A data mining approach. In Proceeding of the Workshop WEBKDD 2001: Mining Log Data Across All Customer TouchPoints, San Francisco, CA, USA, Aug 2001.

[Orf 1999] ORFALI, R.; Harkey, D.; Edwards, J. Client/Server Survival Guide. 3. Ed. , Ed. John Wiley, 1999.

[Pad 1995] PADMANABHAN, V. Improving World Wide Web. Techinical Report $U C B / C S D-95-875$, Computer Science Division, University of California, Berkeley, CA, May 1995.

[Pad 1996] PADMANABHAN, V.; MOGUL, J. Using Predictive Prefetching to Improve World-Wide Web Latency. ACM SIGCOMM Computer Communocations Review, v.26, n.3, Jul 1996. 
[Pad 2000] PADMANABIIAN, V. N.; QIU, L. The Content and Access Dynamics of a Busy Web Site: Findings and Implications. In: Proceedings of the Conference on Applications, Technologies, Architectures, and Protocols for Computer Communication. New York, NY, USA: ACM Press, 2000. p. $111-123$.

[Pal 1998] PALPANAS, T. Web prefetching using partial match prediction - Master's thesis, Department of Computer Science, University of Toronto, Toronto, Ontario, CA, Mar. 1998. Available as Technical Report CSRG-376

[Pal 1999] PALPANAS, T.; MENDELZON, A. Web Prefetching Using Partial Match Prediction. Proceedings 4th Web Caching Workshop, Mar 1999.

[Pin 1997] PINTO, L. et al. Cache: Melhor Aproveitamento dos Recursos na Internet. In: Boletim Bimestral Sobre Tecnologia de Redes. RNP News Generation, 1997. v. 1, n. 2.

[Pin 2001] PINHEIRO. J. C. Avaliação de Políticas de Substituição de Objetos em Caches na Web. Dissertação (Mestrado), USP/ICMC, São Carlos, SP, 2001.

[Pod 2003] PODLIPNIG, S.; BÖSZÖRMENYI, L. A Survey of Web Cache Replacement Strategies. ACM Comput. Surv., ACM Press, New York, NY, USA, v. 35, n. 4, p. 374-398, 2003.

[Rab 2002] RABINOVICH, M.; SPATSCHECK, O. Web Caching and Replication. Addison-Wesley, 2002.

[Riz 1998] RIZZO, L.; VICISANO, L. Replacement Policies for Data Management Systems. In Research Note RN-98-13, Department of Computer Science. University College London, 1998.

[Rod 1999] RODRIGUEZ, P; SP $\Lambda$ NNER, C; BIERSACK, E, W. Web Caching Architectures: Hierarchical and distributed caching. In 4th. International Caching Workshop, Mar 1999.

[Sćg 2003] SÉGURA-DEVILLECHAISE, M. et al. Web Cache Prefetching as an Aspect: Towards a Dynamic-Weaving Based Solution. In: Proceedings of the 2nd International Conference on Aspect-oriented Sofiware

Development. New York, NY, USA: ACM Press, 2003. p. 110-119. ISBN $1-58113-660-9$.

[Sen 2002] SEND, R.; HANSEN, M. H. Predicting a Web User's Next Request Based on Log Data. 2002. To Appear in the Journal of Computational and Graphical Statistics. Disponível em: <http://cm.belllabs.com $/ \mathrm{cm} / \mathrm{ms} /$ who/cocteau/papers/pdif/asa.pd>. Acesso em 23 jan. 2004. 
[Squ 2003] SQUDD WEB PROXY CACHE. 2003. Disponível em: <http://www.squidcache.org>. Acesso em 23 jan. 2004.

[Sta 2003] STALLINGS, W. Arquitetura e Organização de Computadores: Projeto para o Desempenho. 5. ed. São Paulo: Prentice Hall, 2003. 786 p.

Tradução: Carlos Camarão de Figueiredo e Lucília Camarão de Figuciredo.

[Tan 1995] TANENBAUM, A. S. Sistemas Operacionais Modernos. Rio de Janeiro: LTC, 1995. 493 p. Tradução Nery Machado Filho.

[Tan 1997] TANENBAUM, A. S. Redes de Computadores. 3. ed. Rio de Janeiro: Campus, 1997.923 p. Tradução da terceira edição.

[Thi 2001] THIMBLEBY, H.; CAIRNS, P.; JONES, M. Usability analysis with markov models. ACM Trans. Comput.-Hum. Interact., ACM Press, New York, NY, USA, v. 8, n. 2, p. 99-132, 2001.

[Tua 2000] TUAH, N. J. Performance Modelling of Caching and Prefetching for Information Access in Distributed Systems. PhD's thesis, Curtin University of Technology, 2000.

[Ven 2001] VENKATARAMANI, A.; YALAGANDULA, P.; Kokku, R.; Sharif, S.: Dahlin, $M$. The potential costs and benefits of long term prefetching for content distribution Technical Report TR-01-13, UT, Austin, 2001.

[Vit 1991] VITTER, J. S.; KRISHNAN, P. - Optimal Prefetching via Data Compression - Journal of the ACM, v.43, n.5 Sep 1996, p.771-793. A shortened version appears in Proceedings of the 32nd Annual IEEE Symposium on Foundations of Computer Science (FOCS '91), San Juan, Puerto Rico, October 1991, 121-130.

[W3C 1999] W3C. HTML 4.01 Specification, 1999.

URL: http://www.w3.org/TR/html4

[Wan 1996] WANG, Z; CROWCROFT, J. Prefetching in World Wide Web. Proceeedings IEEE Global Internet 96, p.28-32. Nov. 1996.

[Wan 1999] WANG, J. A survey of web caching schemes for the Internet. $A C M$ Computer Communication Review, v.29, n.5, p.36-46, Out 1999.

[Wes 1997] WESSELS, D; CLAFFY, K. RFC 2187: Application of internet cache protocol (ICP). versão 2" Set 1997. Disponível em: http://www.squidcache.org/Doc/rfc2186.txt, Abr. 2002.

[Wes 2001] WESSELS, D. Web Caching. Sebastopol, CA: O’Reilly, 2001. (O'Reilly Internet Series). 
[Wil 1996] WILliamS, S.: Abrams, M. Standridge, C. R.; Abdulla, G.; Fox, E. A. Removal Policies in Caches for World-Wide Web Documents $I n$ Proceedings of the ACM SIGCOMM '96, Stanford University, 1996.

[Woo 1997] WOOSTER, R. P.; Abrams, M. Proxy caching that estimates Page Load Delays. Proceedings of the 6th International WWW Conference, Abr. 1997

[Yan 2001] YANG, Q.; Zhang, H.H.; Li, I.T.Y.; Lu, Y. Mining Web Logs to Improve Web Caching and Prefetching. Web Intelligence, p.483-492, 2001.

[Yu 2000] YU, S. A New Prefetch Cache Scheme. In Proceedings of the IEEE 2000 Global Telecommunications Internet Symposium, San Francisco, CA, Nov 2000.

[Zha 2001] ZHANG, H. Improving Performance On WWW Using Path-Based Predictive Caching And Prefetching. Master of Science, Simon Fraser University. Feb 2001

[Zha 2001a] ZHANG M. Z.; YANG, Q. Model-based Predictive Prefetching. In: Proceedings of the 2 nd International Workshop on Management of Information on the Web - Web Data and Text Mining (MIW'01). Munich, Germany: 2001. 